\title{
WestVirginiaUniversity
}

THE RESEARCH REPOSITORY @ WVU

Graduate Theses, Dissertations, and Problem Reports

2017

\section{The American Hunting Story and the Formation of Environmental Literature.}

Jericho Williams

Follow this and additional works at: https://researchrepository.wvu.edu/etd

\section{Recommended Citation}

Williams, Jericho, "The American Hunting Story and the Formation of Environmental Literature." (2017). Graduate Theses, Dissertations, and Problem Reports. 8180.

https://researchrepository.wvu.edu/etd/8180

This Dissertation is protected by copyright and/or related rights. It has been brought to you by the The Research Repository @ WVU with permission from the rights-holder(s). You are free to use this Dissertation in any way that is permitted by the copyright and related rights legislation that applies to your use. For other uses you must obtain permission from the rights-holder(s) directly, unless additional rights are indicated by a Creative Commons license in the record and/ or on the work itself. This Dissertation has been accepted for inclusion in WVU Graduate Theses, Dissertations, and Problem Reports collection by an authorized administrator of The Research Repository @ WVU.

For more information, please contact researchrepository@mail.wvu.edu. 
The American Hunting Story and the Formation of Environmental Literature

Jericho Williams

Dissertation submitted to the Eberly College of Arts and Sciences at West Virginia University in partial fulfillment of the requirements for the degree of

Doctor of Philosophy in

English

Timothy Sweet, Ph.D., Chair.

Kathleen Ryan, Ph.D.

Lowell Duckert, Ph.D.

Brian Ballentine, Ph.D.

Thomas Kinnahan, Ph.D.

Department of English

Morgantown, West Virginia

2017

Keywords: American literature environmental literature, hunting, animal studies, posthumanism

Copyright 2017 Jericho Williams 


\section{Abstract \\ The American Hunting Story and the Formation of Environmental Literature}

\section{Jericho Williams}

This dissertation addresses the almost complete absence of American hunting stories in the subfield of environmental literature within American literature. Since environmental literature's inception in the early 1990s with The Norton Book of Nature Writing (1990) and American Earth: Environmental Writing Since Thoreau (2008), environmental literary scholars have failed to take into account the roles of hunters in advancing conservationist measures to protect and preserve wildlife and lands throughout America from the early nineteenth century through the present day. This project seeks to build a bridge between environmental literary scholars and environmentalists far removed from hunting traditions and those whose involvement in hunting furthers both their commitment to improving their local surroundings and their support for conservationist measures.

The study begins with a reflection about preservationist icon Henry David Thoreau's complicated relationship with hunting. Because Thoreau's Walden (1854) remains so largely influential and because Thoreau expresses disapproval of hunting in that work, readers fail to realize that Thoreau's later writings reveal a more ambivalent response about the benefits and drawbacks of hunting. In addition to analysis of Thoreau's writings, this dissertation begins by briefly focusing on the writings of well-known American preservationist John Muir and conservationist Aldo Leopold. Then, it provides more extensive analyses of the works of nineteenth-century American writers Washington Irving and James Fenimore Cooper; nineteenth-century traveller Francis Parkman; nineteenth-century whale hunters Owen Chase and Thomas Nickerson; nineteenth-century Appalachian subsistence hunters Meshach Browning and Philip Tome; nineteenth-century African-American slaves John Thompson, Frederick Douglass, and Solomon Northup; twentieth-century authors William Faulkner, Fred Gipson, and Wilson Rawls; twenty-first-century writers Lily Raff McCaulou and Georgia Pellegrini.

More broadly, I argue that hunting stories comprise part of American environmentalism's beginnings and that they depict the evolving ways that humans have approached hunting in America since the country's founding. In a different manner than environmental literature that stresses sublime or pastoral appreciations of the outdoors, hunting stories interrogate humananimal boundaries by forcing readers to consider the complex relationships among humans, companion animals, and prey animals throughout the course of American hunting history. In presenting direct engagements with nonhuman life and in revealing the dangers of overhunting, of ignoring of the lives of animals and of not developing discernible, geographic-specific ethics and legislation, hunting stories ask readers to consider what humans demand from the natural world and what they should be prepared to do if hunting is to continue to remain sustainable. For these reasons, hunting stories should become a larger part of American environmental literature as the canon seeks to elucidate and grapple with human-animal and posthumanist relationships within the natural world. 


\section{Acknowledgements}

"It took a long line of dedicated maniacs / just to get this birdy off of the ground A crackerjack team of enlightened masters / just to help me see the ground"

-David Nelson-

First and foremost, thanks to my Heavenly Father above for strength and resilience through early mornings, long and dark nights, and snowy times.

Thanks to the unfailing support of dissertation director Tim Sweet, whose patience, close reading and guidance were limitless.

Thanks to Katy Ryan for careful reading and thoughtful suggestions, to Brian Ballentine for continually pointing me in new directions that I had not considered, to Lowell Duckert for pushing me to consider many of my deeper assumptions and for future direction, and to Thomas Kinnahan for helping me think about further dimensions of my project.

This project also would not have come to fruition without a spirit nourished by the late Derick Burleson of University of Alaska Fairbanks in a pair of Environmental Literature classes during June 2006 and June 2007. I am deeply indebted to Derick for his encouragement to pursue my interests and for his insistence that some of the best research, in addition to writing, emerges from the self.

The following people left a strong impression on me throughout graduate school. Rich Carr at the University of Alaska Fairbanks has proven to be an endearing humorist, my closest academic friend, and a living example of the power of literary study to transform people. John Ernest at the University of Delaware is one of the few people I have met who has the capability to make anyone believe that he or she can accomplish great things with time and dedicated study, regardless of their background. Terry Reilly at the University of Alaska Fairbanks provided great conversation, generosity, mentoring, and encouragement. William Naufftus at Winthrop University embodied a joy of learning each and every day. Cessilye Williams at Clark Middle School in Anchorage became the most capable and inspiring leader I have known.

I approached my graduate study and dissertation first and foremost as a student of art with little more ambition than to read and discuss works of literature and to grapple with some of the world's most gifted creators. Nearly a decade later, I still believe that the most heralded scholars among us are no greater than the James Boswells to the Samuel Johnsons of the world. The following artists inspired me the most along the way and kept me energized throughout doctoral study: Charles Dickens, Thomas Hardy, Elizabeth Bowen, Willa Cather, William Faulkner, Zora Neale Hurston, and Thomas Pynchon.

Finally, thanks to the most important folks, my immediate family members: Dad, Mom, Justin, and Jared plus Bean in South Carolina for their unwavering support and encouragement. 
My greatest amount of thanks goes to Alice, my companion, best friend, editor, and relentless supporter. If I could magically make "etc." a more honorable construction for just one moment in my life, now would be the time, as those four descriptors serve only as foundational corners of an immense house of love and generosity. You have been there throughout every stage of this process.

Back in 2012, we walked a marathon's worth of miles in the wee hours of a few humid summer nights in College Station talking about books, beliefs, and the unfolding of our lives, surrounded by droves of grasshoppers and frogs. After years of separation and letters travelling from Florida to West Virginia, New York to San Antonio, Michigan to Alaska, San Francisco to San Antonio, and San Francisco to Alaska, with South Carolina sprinkled here and there in between, we have made it. $\mathbf{J}$ 


\section{Table of Contents}

Introduction

1

Chapter One:

Washington Irving and the Literary Formation of Hunting in America

\section{Chapter Two:}

'Longing for Motion and Chase': Human-Canine Relationships in James Fenimore Cooper's The Leather-stocking Series

\section{Chapter Three:}

The Self and Survival in Nineteenth-Century Frontier and Subsistence Nonfiction

104

\section{Chapter Four:}

Traversing the Land Together: Companion Animals and Family in Twentieth-Century Comingof-Age Hunting Stories

\section{Chapter Five}

Trailblazers and Travellers: Women's Hunting Narratives in the $20^{\text {th }}$ and $21^{\text {st }}$ Centuries 


\section{Introduction}

Playing a foundational part within American history and literature, hunting merits greater discussion than it currently receives within environmental literature studies. In particular, the recreational, outdoor sport continues to exist at the center of continuing preservationist or conservationist controversies and studies of human relationships with animals. Beginning with the national debates surrounding a dam in Hetch Hetchy Valley between 1908-1913, the American twentieth century has featured some major clashes between citizens interested in improving the environment through the opposing notions of preservationism, which emphasizes impacting the natural world as little as possible from its current state, and conservationism, which stresses carefully orchestrating or reshaping the environment for human use that does not detract from nature as it is found. Within these discussions and environmental studies in general, hunting has largely been on the backburner since with the exception of isolated cases regarding overhunting or potential extinction of species, it does not garner as much attention as global warming and climate change. As a result, its adherents and its literature remain a more understudied part of the history of the environmental movement beyond hunting's major abuses during the nineteenth century.

Yet, hunting literature deserves more consideration among the evolution of environmental studies because outside of academic study and policy, the conflict among conservationist-oriented hunters and non-hunters still remains, and it speaks to cultural gaps that split groups of people who all have an interest in improving the environment. The literal and theoretical separations between hunters and non-hunters results largely from post-World War II affluence and the emptying of rural America, the home bases of the dominant news media 
companies in metropolitan areas near their major audiences, an increase in communication via screens over the past quarter-century, and the resulting divide between what qualifies as news and spectacle, or what we see and how it conveys meaning, in the digital and photographic compressions of urban and rural America. To offer a hypothetical example, how is a suburban college student from Detroit who spends ninety percent of his or her time indoors, and much of it in tune with digital devices, supposed to react to a one-minute news clip of older, burly, camouflaged men drinking canned, non-craft beer while ice fishing in Upper Peninsula of Michigan (Sterba xxiv)? And how might he or she react to the cameraperson documenting one of the men catching, killing, and processing a fish?

The underlying problem - the deliberate killing of an animal within the public's viewmight have been less of an issue prior to World War II, after which the distance between the majority of the population and domesticated farm animals expanded. Describing this shift, Michael Pollan writes, “At the same time as much of America's human population found itself leaving the city for the suburbs, our food animals found themselves traveling in the opposite direction, leaving widely dispersed farms in places like Iowa to live in densely populated new animal cities" (66-7). Two predominant changes occurred that rerouted domesticated farm animals further and further away. First, when suburban housing projects expanded into former farming areas near cities, some land became too valuable to farm. As a result, meat producers were pushed further away from the majority metropolitan populations than ever before. Second, as farm economics changed with increased industrialization as the century progressed, small farms that relied heavily on raising domesticated animals became all but obsolete, and many of them consolidated, evaporated, or switched to other crops. Too, the declining number of family farms as new generations moved to cities or suburbia helped - along with new animal 
management techniques, increasing corn-growing capability per acre, and the proliferation of corporate agriculture - to facilitate the expansion of Concentrated Animal Feeding Operations (CAFOs) in isolated locales and forge a greater separation between the general public and living farm animals. Distanced from human eyes, cows, chickens, turkeys, and pigs were either photographed as whole when alive or as neatly wrapped meat products when slain. CAFOs enabled meat producers a way to shield the public from the realities of animal deaths while making more meat products available at lower prices and increasing their availability. This was a win-win situation, as meat producers could provide more cost-effective meat products and at the same time keep the public's gaze away from the stages of whole animal to packaged meat. Consequently, there was an increasing human distance from the treatment of farm animals and their deaths. The hidden deaths involved in corporate meat production contribute indirectly to the literary representational problem with hunting. A modern educated readership deliberately shielded from the lives of farm animals they eat remains disconnected from animal deaths beyond the loss of a companion animal or an encounter with road kill. Because of the close human-animal relationship, a pet's death is quite different from either witnessing a dead animal on the roadside or killing one accidentally. With animal butchering and hunting remaining on the fringes of society, killing an animal on the road is the closest the average American gets to hunting.

These cultural changes leave a small and aging audience for hunting stories, but as I aim to show, this does not mean that fictional and nonfictional hunting stories are unworthy of consideration within environmental literature and animal studies. Hunting stories comprise part of American environmentalism's earliest beginnings and they depict how humans have approached hunting in America since the country's founding. Unlike other examples of 
environmental literature that stress sublime, pastoral, or travel approaches to the outdoors, hunting stories reaffirm the importance of physically and mentally engaging with the environment, both in local and distanced, wilderness-oriented contexts, and they force readers to unpack the relationships among humans, companion animals, and prey animals throughout the course of American history. In presenting direct engagements with nonhuman life and in revealing the dangers of overhunting, of ignoring the lives of animals, and of not developing discernible, geographic-specific ethics and legislation, hunting stories ask readers to consider what humans take from the natural world and what they should be prepared to give if the sport is to continue to remain sustainable. For these reasons, hunting stories should become a larger part of environmental literature as the canon seeks to expose and elucidate human relationships with the natural world.

\section{An Analysis of Two Environmental Literature Anthologies}

Nature writing and environmental literature have increased in popularity over the past twenty years thanks to both the work of a variety of writers and scholars and worldwide environmental crises. Two major anthologies, The Norton Book of Nature Writing, published in 1992, and the Library of America's American Earth: Environmental Writing since Thoreau, published in 2008, represent the primary canonical overview of the field. Both feature marvelous work, yet each of the editors involved exclude or minimize the accounts of noted hunting writers from the contents, particularly in regards to the nineteenth century. The Norton's editors balance writers mostly from the nineteenth and twentieth centuries in America and England, but emphasize accounts of travel writings, natural history, Romantic writings and poetry, regionalized observations, or first-hand observations of environmental abuse or degradation. When they do include a brief account of hunting, as in the case of a six-page excerpt from 
Washington Irving's A Tour on the Prairies, the selection they choose reveals remorseful feelings about hunting buffalo without more elaboration or greater contextualization. Given the Norton's early date of publication with respect to the field and its novelty as the first major environmental literature collection, this is somewhat understandable. Additionally, as nature writing's focus is primarily on appreciating the mysteries of the natural world, the editors may have imagined that nature writing might not need to include representations of hunting, which depicts a form of outdoor appreciation different from the anthology's more narrowly defined field.

Less forgivable is the editorial work in the Library of America's American Earth: Environmental Writing since Thoreau, which suggests that environmental literature has disregarded hunting stories to the point of weakening the canon's greater goals. Edited by noted environmentalist Bill McKibben with an introduction by $\mathrm{Al}$ Gore, this anthology proposes to contain a broader scope. When asked to explain the difference between nature writing and environmental writing during an interview regarding the anthology, McKibben replied, In American Earth I've focused on writing that really gets at some of the conflicts between people and the natural world, and not just the appreciation of the glories of nature. Environmental writing asks searching questions about what happens when people collide with the rest of the world. What are the effects? Are they necessary? Might there be a better way? While it often celebrates nature, environmental writing also recognizes that nature is no longer innocent or invulnerable. (McKibben, "Interview")

Based on the anthology's selections, however, McKibben's conception of human-environment conflicts does not include hunting accounts. Theodore Roosevelt also makes a head-scratchingly 
brief appearance. When introducing Roosevelt, McKibben writes, "[he is] the most significant environmental president in American history, and the most engaging writer ever to sit in the Oval office" (American Earth 129). Yet, Roosevelt's allotted space is four pages, and McKibben seems apprehensive about including Roosevelt at all for personal and political reasons, stating that there is "much to dislike about Roosevelt — he is bellicose and jingoistic" (American Earth 129). Despite Roosevelt's excesses, this move is at the very least problematic, given his contributions to environmental legislation, and it becomes more so when one considers his extensive outdoor experiences and hunting writings even before he became president in 1901 . During the 1880s and 1890s, Roosevelt published several, full-length works of hunting literature, including Hunting Trips of a Ranchman (1885) and The Wilderness Hunter (1893). To put this in a greater perspective within the framework of the anthology, each example of McKibben's and Gore's own environmental writing, appearing as separate from their foreword and introduction contributions, occupies more space than Roosevelt's and it raises a question about his minimal presence.

If this is puzzling, so are some of the other selections. The editors of American Earth devote the majority of the book's contents to twentieth-century authors, but when they include writers known for their hunting literature such as Aldo Leopold or Rick Bass, they choose passages that do not relate to hunting. Too, whereas modern environmental hunting writers or theorists Paul Shepard, James Swan, and Mary Zeiss Stange do not appear, environmental historian William Cronon garners twenty-five pages, and Woody Guthrie, Joni Mitchell, and Marvin Gaye provide song lyrics for an environmental celebration that features one of modern hunting writer, celebrated anthropologist Richard Nelson. Nelson credits his experiences living with Inupiaq Eskimos in Alaska for teaching him about hunting, which Nelson notes helped him 
to "deepen my sense of connection with the surrounding natural world" ("Introduction" 1-2).

However, McKibben excerpts a portion of Nelson's noted book about deer where Nelson witnesses the birth of a fawn rather than any of his hunting writings.

American Earth suggests that the environmental literature canon still has room to expand, and a starting place for this improvement is within the nineteenth century, where there exists more pre-environmental movement literature about the environment than previously thought. Here, there is a neglected and forgotten history, when beginning efforts to conserve the environment - in terms of the genesis and establishment of popular conservationist-minded periodicals, the early pleas for conservation spearheaded by recreational hunters, and later federal government legislation — outpaced the work of the nineteenth century's most championed environmental retrospective writers, Henry David Thoreau and John Muir, and prefaced their twentieth century successor, Aldo Leopold, in popularity. These three pioneering thinkers are but one side of a coin that includes many nineteenth-century writers whose works forecasted, and in some cases inspired, the major nationwide environmental legislative work inaugurated by Theodore Roosevelt.

\section{Environmental Criticism, Animal Studies, and the Formation of the Environmental}

\section{Literature Canon}

The above does not mean to suggest that we dispense with work of Thoreau, Muir, Leopold, or even McKibben and Gore, but rather that we reevaluate the formation of the environmental literature canon and then expand it not only through ecocriticism, its closest theoretical branch, but also other related disciplines such as animal studies or posthumanism. Cheryll Burgess Glotfelty ignited ecocritical scholarship with a presentation at the 1989 Western Literature Association and her influential anthology The Ecocriticism Reader in 1993. 
Explaining part of her motivation for the project and for engaging others like-minded scholars, Glotfelty wrote,

Many of us in colleges and universities find ourselves in a dilemma. Our temperaments and talents have deposited us in literature departments, but, as environmental problems compound, work as usual seems unconscionably frivolous. ... Literary scholars specialize in questions of value, meaning, tradition, point of view, and language, and it is in these areas that they are making a contribution to environmental thinking. (xx-xxii)

Encouraging literary scholars to investigate interconnections between literature, the natural world, and other academic disciplines, Glotfelty suggested a broad range of voices and approaches in forming a basis for environmental criticism. From these interactions, Glotfelty imagined scholars designing a literary curriculum to honor human-environment encounters within the natural world and to facilitate stronger senses of environmental awareness among future generations of colleagues and students. Scholars responded enthusiastically_ as evident in the success of the growth of the Association of Literature and the Environment (ASLE), the founding of ecocriticism's primary academic journal (ISLE), the general increase of environmental humanities publications, and the popularity of place-based studies.

Twelve years later, Lawrence Buell published The Future of Environmental Criticism: Environmental Crisis and Literary Imagination (2005), an important retrospective of the field that included much speculation about its future. Buell articulates the difference between the two waves that characterized the first fifteen years of environmental criticism. The first wave, ecocriticism, consisted of work "synchronous with the aims of earthcare" (21). In practice, this meant a critical emphasis on nature writing, wilderness retreats, and general defenses of natural 
world, as found in literature, from human aggression or destruction. Buell renamed the second wave environmental criticism for its embrace of a broader conception of human-environment relationships beyond some of the monastic qualities of early ecocriticism. The second wave's new focus areas include: the natural world in urban cityscapes and suburbia, which contain the majority of the United States human population; both the external clashes or conflicts and the fundamental pliabilities between humanity and the environment; finally, the necessity of a commitment to planet-wide problems solvable only through means of environmental justice and awareness (Buell 21).

These two broad movements directly influenced the present environmental literature canon and simultaneously allowed the vast reservoir of hunting accounts to slip through the cracks by postulating a history of environmental thought and writings devoid of many sportsmen writers who lobbied for American environmental protections both before and throughout the twentieth century. Like later environmental critics, these well-known sportsmen pushed to conserve the environment and were generally more formally educated and wealthier than their peers. In woods, fields, and along the banks of rivers, they first intuited unsustainable losses of wildlife due to unrestricted hunting and overfishing, and far in advance of the dominant issues that galvanize environmentalists today, they pushed for change and sought to distill concern in the minds of future generations. Their primary reasons for concern, the conservation of game and wildlife, may be significantly different from their modern environmentalist successors, but it emerged from similar observations and feelings of needing to take action. However, given hunting's per capita decline in the twentieth century and the increase in popularity of other recreational interests among environmentalists, such as camping or hiking, their claims and work may seem more distant from more current environmental thought. Their game management 
motives for conservation, too, make sportsmen literature unappealing to their environmental critic descendants in the first wave, collectively a group of people influenced more by nature writers, the work of Rachel Carson, the 1960s and 1970s counterculture environmental movements, because of a large historical gap and differences in socialization. And even though their hunting stories or accounts best fit within the aims of second wave environmental critics, who express concern for human-environment entanglements or encounters beyond nature appreciation or reverence, some past sportsmen's elitist, racist, and sexist attitudes toward oppressed groups of people and animals remain equally off-putting. To add further insult to offense, some hunting accounts are complicated by the notion that they also privilege or implicitly support a sort of hyper-individualism long ago made a bull's-eye of academic critique throughout the study of the humanities.

If generational and worldwide change and the needs of twenty-first century politics help steer the formation of the environmental literature canon clear of hunting literature, conceptual understandings imbibed from studies of the American environment before the advent of environmental criticism also contribute to its relative absence. Roderick Nash's Wilderness and American Mind, originally published in 1967 and subsequently revised in 1973, 1982, and 2001, is an undeniably innovative and valuable example with a far-reaching impact. Nash traces the development of the word wilderness throughout American history using an array of historical, cultural, and literary artifacts. Within his study, he provides extensive coverage of the lives and influential thinking of Henry David Thoreau, John Muir, and Aldo Leopold, his three major environmental heroes.

The book has its shortcomings, though, and they begin with Nash's primary interest in non-hunting outdoor recreation and the social context of the 1960s, when he composed the heart 
of his study. While it would be wrong to assume that Nash disdains hunting, he does not place it on equal terms as other non-hunting recreational activities. Nash notes that Wilderness and the American Mind was inspired by his father's scholarly work about reaction and leisure while at New York University, his subsequent service "on the Outdoor Recreation Resources Review Commission" in the 1960s, and his general desire to improve recreation and leisure opportunities for all Americans (387-8). This information is not meant to detract from Nash's work-it is only to suggest that, if written by Aldo Leopold for example, the son of hunters, a hunter himself, and later a game management specialist for the University of Wisconsin prior to being hailed by both environmentalists and conservationists, Wilderness and the American Mind would have been a much different book. Nash also acknowledges being in the right place at the right time in the first paragraph of his preface: "I caught the wilderness wave as it began to crest and became the beneficiary of the very intellectual revolution I described" (vii). In his introduction, Nash identifies the cultural factors in America that enabled his book's publication and successful reception: the work of Rachel Carson, Aldo Leopold, and Bob Dylan; ecological ideas and the emergence of an ecocentric American counterculture; and the Wilderness Act of 1964 (vii). Again, as these cultural markers also shaped the minds of many first wave ecocritics who identified with Nash, they also factored into the creation of Wilderness in the American Mind and account for its phenomenal success and influence.

Avoiding hunting aside from an occasional brief reference, Nash's book makes two primary contributions to what would later develop as environmental literature - it validates and implants the work of Henry David Thoreau and John Muir as immensely valuable beyond the limited ranges of late 1960s nature hobbyists, environmentalist readers, and literary critics, and in upholding Thoreau and Muir, the book-with an even greater, long-lasting theoretical effect- 
designates an arguably too-sharp division between preservationists and conservationists. Nash views Muir, the foremost preservationist, as a more historically fortunate extension of Thoreau. He writes of Muir, "[he] was highly successful and nationally acclaimed in spite of the fact that most of his thoughts were simply restatements of the Transcendentalists' case for wilderness" (160). Here, Nash firmly links his mid-nineteenth-century hero Thoreau with his late nineteenthand early twentieth-century hero Muir, depicting Muir as earning the prestige and influence that eluded Thoreau because of the increase in environmental interest with the closing of the frontier and the rapid exploitation of natural resources. Positioning himself with Thoreau and Muir within a preservationist camp, Nash devotes a chapter to the Hetch Hetchy controversy that pitted Muir versus conservationist Gifford Pinchot in a bitter fight for the support of President Theodore Roosevelt and others. Following extensive devotion to Thoreau and especially Muir, this chapter falls rhetorically on the side of the preservationist divide, but more strikingly, it charts a bitter and deep separation regarding two different approaches to land use that still divide the two groups of environmentally-minded people more than a century later. Too, in writing about Thoreau's and Muir's contributions to preservationist history, Nash neglects the more complicated relationships each writer had with hunting, an activity more traditionally associated with conservationism.

In critiquing Nash's work in his seminal essay “The Trouble with Wilderness" in 1995, William Cronon pointed environmental critics in a new direction that invited more consideration for conservation rather than preservation. Like Nash, Cronon credits Henry David Thoreau and John Muir for helping Americans reimagine wilderness areas as sacred rather than "the antithesis of all that was orderly and good" at the turn of the twentieth century ("Trouble" 72). However, he posits that designating the wilderness as sublime or exotic environments far out of the average 
human's reach reinforced behaviors detrimental to the environment. Cronon writes, "Idealizing a distant wilderness too often means nor [sic] idealizing the environment in which we actually live, the landscape that for better or worse, we call home" ("Trouble," 81 ). One of the worst prospects for Cronon, in other words, is the inaction that comes from committing resources to protect distant wildernesses and inadvertently justifying the ignorance of one's everyday surroundings. In calling for people to become more active in improving their everyday surroundings, Cronon pushes for more human energy toward the conservation of immediately accessible resources, or perhaps what a decade later would be referred to among businesses and eco-minded companies and organizations as sustainability, but in the process he fails to consider how outdoor enthusiasts with interests in preserving hunting or fishing experiences contribute to the conservation of areas designated as wilderness or not.

If ecocriticism largely bypassed hunting literature and if prior environmental studies' emphasis on wilderness failed to consider the positive contributions of hunters amidst the negative impacts of the hunting industries of the nineteenth century and beyond, both fields could benefit from an intersection with animal studies, a more recent critical field which informs significant portions of this dissertation and that encourages inquiry about human relationships with animals throughout the hunting process. The field of animal studies allows environmental critics and scholars to consider hunting beyond frames of killing, reckless behavior, and antipreservationist or anti-conservationist sentiment. Brought about by philosophers and animal rights activists, and then developed by prominent theorists such as Jacques Derrida, Donna Haraway, and Cary Wolf, animal studies encompasses a wide range of discourse that seeks to dissolve the human-animal binary to prompt better understandings of how animals see the human world, how humans should approach or treat animals, and what animal lives contribute to 
posthumanist inquiry. Though many animal studies theorists might find hunting archaic at best and reprehensible at worst, human-animal relationships to some degree define many forms of hunting that feature a human hunter, animal companion, and prey animals. Looking closely at how hunting facilitates those human-animal relationships, and then how those relationships function in regards to the way humans perceive and treat their environment is one broader themes of this project. In the context of hunting history, there are few people who championed the outright annihilation of entire species of game animals. Hence, if not a full-scale war against species, this projects asks what has hunting meant to Americans, how have their relationships with companion and prey animals shaped their beliefs, and as a result, why and how have some of them worked through writing to portray human-animal relationships and encounters as central to the hunting experiences. This study begins with analyses of hunting in regards to the three paragons of nineteenth- and twentieth-century environmental thought. In regards to Henry David Thoreau and John Muir, I demonstrate how these authors' espoused and commonly referenced positions against hunting remain more simplified than previously thought; in reference to Aldo Leopold, I show how his theory of a land ethic derives partly from a passion for hunting and his career in wildlife management.

\section{Henry David Thoreau and Hunting}

Henry David Thoreau, Nash's first hero, devoted part of Walden to exploring his complicated thoughts about hunting. In "Higher Laws," Thoreau begins with an anecdote describing a homeward trek after a successful fishing trip. Carrying a string of fish, he observes a woodchuck cross his path and immediately becomes seized with the desire to kill it and to “devour him raw ... for that wildness he represented" (136). He quickly realizes the absurdity of situation, as he has no physical need for the woodchuck. Instead, Thoreau attributes this feeling 
to the tension between human yearning for wildness and a higher, spiritual state; it is this tug-ofwar that ignites an internal debate. Supplied with food, Thoreau's desire to destroy life is a rash feeling explainable only by some innate predisposition to assert dominance over lesser beings. From this situation, Thoreau begins to contemplate hunting and fishing, the two activities to which he owes his first "acquaintance with nature" (136). The central problem is though hunting and fishing may be incompatible with an enlightened higher human mental state, they factor heavily into Thoreau's interest in the natural world. Along with woodchoppers and other outdoor laborers, hunters and fishers enter the outdoors expecting something different than poets or philosophers (136). Here, we might criticize Thoreau for not clearly articulating particular differences at this point in the essay. He implicitly posits that outdoor work or recreation enables participants, without the expectation of something grand to write or think about, to see the natural world differently. Though Thoreau implicitly suggests a critique of the spirit of English Romanticism and perhaps shallow, poor, or uninformed environmental writing, he does not explicate the differences in ways of seeing between outdoorsmen and artists.

Instead of fleshing this out, Thoreau harkens back to hunting and fishing in his youth as a way to consider their worth. Thoreau notes that in his vicinity almost every New England boy "shouldered a fowling piece between the ages of ten and fourteen" (137). Without allotted places to hunt or laws as in England, he and his peers pursued game freely and savagely to the point of a reckless reduction of local animal populations. As a result, the scarcity of game inaugurated other forms of more socially profitable recreation. Yet, looking back, Thoreau does not deny the value of hunting and fishing. He writes,

Yet not withstanding the objection on the score of humanity, I am compelled to doubt if equally valuable sports are ever substituted for these; and when some 
of my friends have asked me anxiously about their boys, whether they should let them hunt, I have answered, yes,--remembering that it was one of the best parts of my education,- - make them hunters, though sportsmen only at first, if possible, mighty hunters at last, so that they shall not find game large enough for them in this or any vegetable wilderness,- - hunters as well as fishers of men. (137)

This is a pivotal sentence, the turning point where Thoreau proclaims the value of these recreational sports only to confine their usefulness within one developmental stage for modern New England young men. In other words, hunting and fishing function as a step, similar to a highchair en route to sitting in chair and eating at a dinner table, toward more grown-up ways of thinking, with Thoreau counting on boys to "soon outgrow it" (138).

This sentence also repositions the focus from boyhood to adulthood that corresponds with boys leaving the primitiveness of hunting and fishing behind for higher purposes, ostensibly spiritual pursuits to better the world. Though Thoreau does not explore it explicitly beyond himself, given his Walden Pond experiment, he implies that one problem with taking hunting and fishing seriously as an adult is that recreational time often diminishes with life's increase in social responsibilities. Consequently, adult sportsmen become limited in the ways they are apt to see the environment when contrasted with their unencumbered children. The idea of the effect of social obligations upon environmental perception seems to complicate Thoreau's prior assertion that outdoor laborers and sportsmen are capable of seeing the natural world in a different way than poets or philosophers. But by this point in the essay, Thoreau is more concerned with his fellow citizens' behavior, and in particular the ways that social positions and job requirements impact their perceptions of the outdoors. For example, he notes that Walden Pond's main attraction for townspeople is recreational fishing, and the resulting problem: "Commonly they 
did not think they were lucky, or well paid for their time, unless they got a long string of fish, though they had the opportunity of seeing the pond all the while" (138). Fishing only occasionally and then gambling the worth of one's day on the number of fish caught leads to a sort of arrested development that blocks deeper experiences within the natural world.

Consequently, by taking the adult social obligations that he eschews during his experiment into account, Thoreau can more easily align and then condemn hunting and fishing as part of a primitive phase of humanity.

Thoreau devotes the remaining half of "Higher Laws" to providing reasoning for and then offering suggestions about how to reach for a greater form of human purity — achieved only by elevating oneself above the crudities of the animal world. Central to this argument are two sentences: "We are conscious of an animal in us, which awakens in proportion as our higher nature slumbers" and "He is blessed who is assured that the animal is dying out in him day by day, and the divine is being established" (138). Practically, for humans to move further away from the inner animal means they should avoid partaking of meat, wine, coffee, tea, and music. Thoreau's devotion is a reaching toward the divine, which separates us from the animal world, makes us better earthly stewards, and offers the only hope for enlightenment and purity.

Thoreau's aim is commendable and spiritually rich, if problematic. He means to shake us free from our assumptions about consumption and to call attention to the tainting possibilities of our lesser habits or dependencies. This lofty spiritual high, enlightenment to the highest degree, also facilitates a viewpoint built on prohibitions in the forms of actions or consumption. It is restrictive in its own way. To return to the beginning of the essay, poets and philosophers step into nature differently than woodchoppers, outdoor workers, or regular sportsmen. Their trades and sporting adventures, like engagement with a higher form of pure spirituality, enable 
alternative forms of experience that develop through the processes of their daily work. The same could be said of Thoreau's spiritual followers, although they too are limited by their own sets of parameters. Thoreau readily admits the animal within us is always present, but that we should aim to overcome it through cleansing ourselves of impure intoxicants to envision great enlightenment. However, in a later and less popular essay entitled "Chesuncook" in The Maine Woods (1864), he would again examine hunting and puzzle more about its complexities. Here, Thoreau acknowledges the potential benefits of human-environment intimacy and environmental education afforded by hunting and makes room for the possibility of hunting so long as it is responsibly overseen or managed (Williams 2). In remaining skeptical, but not rigidly ideological, Thoreau reveals that his thinking about the complexities of hunting extended beyond his reflections in Walden.

\section{John Muir and Hunting}

Nash devotes his lengthiest personal account in Wilderness and the American Mind to John Muir, his second environmental hero, and since the book's original publication, environmentalists and environmental historians have heaped even more praise on Muir. Following the general line of thinking, as mentioned above, Muir became the preservationist successor to Thoreau who accomplished much more than his predecessor because of westward expansion and the drastic increase in resource use and depletion in the latter half of the nineteenth century. Bill McKibben describes Muir's first summer in the Sierra Mountains as the "most crucial stretch of time in the history of what we now call the environmental movement" ("Introduction," xvi). Most people remember Muir for trying to prevent the flooding of the Hetch Hetchy Valley and for his much more accessible writing style and more approachable personality than Thoreau. Though environmental historians and literature scholars cite My First Summer in 
the Sierra (1911) and Muir's additional essays about the Sierra Mountains as his principal writings, The Story of My Boyhood and Youth (1913), conveys a clearer picture of Muir's thoughts about domesticated animals and hunting. In this regard, Muir's autobiographical writing offers as much complexity as Thoreau's, though he too ultimately comes to the same conclusion that hunting worsens the human spirit.

Muir composed and revised much of his written work as he approached and surpassed seventy years of age, and like Thoreau, he had little use for hunting as he matured, in part because of his childhood farm experience. His memoir The Story of My Boyhood and Youth, which is devoted to the years from Muir's birth in 1838 through 1863, when he leaves the University of Wisconsin for the "University of the Wilderness," stresses human-animal tension (162). Dictated to a friend in 1908 and then revised for publication in 1913, this work contains Muir's most significant reflections about hunting that echo Thoreau's message in greater detail and appear to create a crevasse-like divide between preservationist-oriented nature writing and outdoor hunting stories. In the intervening years after 1863, Muir would witness greater levels of animal destruction and environmental degradation far away from the Wisconsin farm of his youth, which likely influenced his mindset as he was recounting his youth. While Muir appears candid and humble throughout his memoir, much of which takes place on a Wisconsin farm, his recollections depict the flawed understandings of wildlife by mostly immobile farmers, the repugnant abuse of domestic animals by savage children, repeated anti-hunting anecdotes where Muir portrays himself as a failed hunter engaged in criminal acts coupled with accounts of animals hunting other animals more successfully and interestingly, and finally, a call for humans to abandon participation in hunting or trapping. 
Muir's description of the adult community in The Story of My Boyhood and Youth details foremost how farming shaped the ways men and women understood animals. He shows farmers' limited interaction with some species and how farms impacted local animal populations. Though they occasionally appear at the edges of his father's wheat fields, deer are mostly non-existent, and pushed out toward safer habitat; Muir is eight or nine before his brother hunts and kills one. Seeing a swan, for example, was so rare that when a hunter shot one, many in the community took a break to come see the bird. Infestations of other species occurred more often than these rare sightings. The bobwhite population increased dramatically with the cultivation of wheat, but suffered during the heavy snows of winter. The fields supported too large a population during prime weather and Muir recounts small flocks of birds approaching farmer's houses starved and incapable of flying, and later "frozen to death like settlers caught in blizzards" (76). Muir seems much more sympathetic toward the bobwhites than his community members, whose disinterest reminds readers just how dependent they were on farming to survive.

Hunting far and away from the immediate vicinity was rare, while shooting to kill at the farm was quite common. Most of Muir's adult neighbors "seldom took time to hunt," though two or three ventured each fall to northern Wisconsin to pursue deer and bears and to gather berries (84). Instead, most farmers used their ammunition locally to hunt pests: gophers and passenger pigeons. Like bobwhites, the gopher population expanded because of agriculture, as their diets changed from foraging for seeds of wild grass and weeds to gorging on wheat and corn. Here, Muir describes the gophers' work and, for once, sympathizes with the farmers' plights against the "cunning robbers":

Increasing rapidly in numbers and knowledge, they became very destructive, especially in the spring when the corn was planted, for they learned to trace the 
rows and dig up and eat the three or four seeds in each hill as fast as the poor farmers could cover them. And unless great pains were taken to diminish the numbers of the cunning little robbers, the fields had to be planted two or three times over, and even then large gaps in the rows would be found. (94-5)

In this situation, the gophers' threat to the harvest forced farmers to take action - they reseeded fields numerous times and killed as many as possible. Gophers presented a greater foe than the passenger pigeons that visited once a year during the summer and prompted the one annual community-wide hunting party. Given the passenger pigeons' extinction in the early part of the twentieth century, Muir's chaotic account of the pigeon shoot is chilling, as farmers wasted thousands of pigeons, using some for food and leaving the remainder for their hogs. Muir notes that this time of year, too, was the only moment when the farmers questioned killing animals because of the passenger pigeons' beauty, though the damage by the passenger pigeons to their wheat and oats tempered this sentiment.

The rituals of animal killing and hunting become normal for farmers' children, who embrace killing wholeheartedly as sport as much as a duty. The resulting impact on the individual child is what Muir finds most objectionable. Unlike Thoreau, who viewed his early hunting and fishing experiences as integral to his learned appreciation of nature, Muir depicts them as savage acts sanctioned by agrarian culture that must later be rebelled against and overcome. Depicting what Muir refers to as the "natural savagery of boys," he recounts a common ritual of trapping hares, letting them go, and then running them with dogs to see if they could escape (18). Worse, Muir recounts childhood headhunts:

In older eastern States it used to be considered great sport for an army of boys to assemble to hunt birds, squirrels, and every other unclaimed, unprotected live 
thing of shootable size. They divided into squads, and, choosing leaders, scattered through the woods in different directions, and the party that killed the greatest number enjoyed a supper at the expense of the other. The whole neighborhood seemed to enjoy the shameful sport especially the farmers afraid of their crops. With a great air of importance, laws were enacted to govern the gory business. For example, a gray squirrel must count four heads, a woodchuck six heads, common red squirrel two heads, black squirrel ten heads, a partridge five heads, the larger birds, such as whip-poor-wills and nighthawks two heads each, the wary crows three, and bob-whites three. But all the blessed company of mere songbirds, warblers, robins, thrushes, orioles, with nuthatches, chickadees, blue jays, woodpeckers, etc., counted only one head each. The heads of the birds were hastily wrung off and thrust into the game bags to be counted, saving the bodies only of what were called game, the larger squirrels, bob-whites, partridges, etc. The blood-stained bags of the best slayers were soon bulging full. Then at a given hour all had to stop and repair to the town, emptying their dripping sacks, count the heads, and go rejoicing to their dinner. Although, like other wild boys, I was fond of shooting, I never had anything to do with the abominable headhunts. (83) By the time that Muir wrote this autobiography, this sort of rampant slaughter had greatly reduced animal populations throughout the United States. Looking backward, Muir points out that the problem was that boys were not taught to respect animal lives and that they, like their farming families, could not comprehend the effects of over-hunting beyond the range of the immediate community. Worse, the repeated acts of wanton killing cultivated poor and dangerous understandings of animals. For example, when a hog gets butchered in the community, Muir 
describes boys rejoicing at the possibility of receiving the bladder for a new football. Underlying all of the killings is an anthropocentric vision of dominion over animals that Muir, nearing the end of his life, sought to upend.

Opposed to these forms of hunting and slaughter, Muir breaks from the tradition of celebrating the savagery of his youth by showing how he learns compassion for animals and emphasizing his hunting failures. One of Muir's more memorable moments occurs when nearby Indians kill one of his family’s pigs in the woods near their farm. Muir recounts the story of a mother pig and her piglets scouring the woods for acorns and roots. One day, Muir hears an unexpected gunshot and then sees the mother pig and all but one of her brood rushing toward the family shanty for protection. The incident shocks Muir, and he is surprised by the "awe and fear in the eyes of that old mother and those little pigs...deadly a fear as I ever saw expressed by any human eye" (46). He begins to consider animals as much closer to humans after this incident, and he describes failed hunts as a way to further advance this theme. In "one of my strangest hunting experiences," Muir describes a gray goose attacking him for wounding one of its comrades. After Muir shoots but does not kill the goose, he runs to retrieve it unarmed. Suddenly, the leader of the flock attacks and he must duck and protect himself from the goose's blows. The goose surprises Muir, who never considered the capability of a goose for "such noble self-sacrificing devotion" (75).

Two additional hunting mishaps scar Muir. He shoots a hawk sitting on an oak branch and preying on the family's chickens twice - the first time, the hawk falls halfway down the tree and lands on another branch; the second time, the shot prompts the hawk to fly a short distance before perishing mid-air and falling to the ground. Muir stands amazed by the hawk's resilience and his poor marksmanship. Finally, he details an astonishing account of a woodpecker he was 
certain he killed thrice. When it threatens a cornfield, Muir shoots the bird while it perches on a tree branch and it falls to the ground. When he discovers that it is not dead, Muir attempts to wring its neck a few times and then throws it hard on the ground to ensure the bird's death. When the woodpecker hits the ground, it suddenly flies back to the branch where it had been sitting. Muir writes, "[it] began to adjust his ruffled feathers, nodding and chirping and looking down at us as if wondering what in the bird world we had been doing to him...[and] we all heartily congratulated him on his wonderful, triumphant resurrection from three kinds of death,- - shooting, neck-wringing, and destructive concussion (87). Muir surmises that only one pellet grazed and then dazed the bird, but in awe he is incapable of attempting to kill it once more.

Muir finally comes to the conclusion that hunting is better left to the animal world because of its detrimental affect on human maturity. From this memoir, readers are left to consider two questions. Did Muir's professed poor marksmanship and hunting ability in any way affect his later reflections about it? Or, were the failed attempts at hunting included strategically to advance his anti-hunting position expressed many years removed from farm life? The latter is more likely, though Muir also devotes space to observing successful hunts by a cat and a shrike. A family cat kills squirrels regularly to feed her kittens and Muir witnesses a shrike enter a gophers' burrow, scare out a few of them, kill one, and then fly off with it. These hunts fascinate Muir primarily because he views them as instinctual. They seem more natural when contrasted with calculating humans who use steel-toothed traps to capture muskrats for their skins. This practice, "like shooting boys or girls for their garments," enrages Muir (88). He expresses hope that in the future humans will be more considerate of wild animals and cease hunting altogether. Until then, Muir writes, 
All hale, red-blooded boys are savage, the best and boldest the savagest, fond of hunting and fishing. But when thoughtless childhood is past, the best rise the highest above all this bloody flesh and sport business, the wild foundational animal dying out day by day, as divine uplifting, transfiguring charity grows in.

This passage reflects Muir's most forceful position against hunting, and it extends and improves Thoreau's articulation against hunting in "Higher Laws" because Muir combines more numerous and detailed personal examples in more accessible language. Unlike Thoreau, Muir remains unconvinced that hunting and fishing are ever worthy of children's time, as these activities are more apt to be detrimental than instrumental. He hopes that in time humans will overcome the urge. Yet, to fully accept Muir's philosophy one must gloss over the fact that once he leaves the family farm, he no longer must farm to live. In short, he becomes a traveler who occupies a more functional place to encounter and observe wildlife than to need to combat it. Arguably, this sentiment developed and then deepened for Muir once removed from agrarian necessity, adventuring for many decades prior to beginning to dictate this memoir. More severely than Thoreau's meditation on hunting in "Higher Laws," Muir attacks and then denies hunting as a legitimate way to appreciate and engage with the non-human environment, an important position when he and Thoreau later becomes crowned via Nash as the co-kings of nineteenth-century environmental thought. Having lived to see greater decimation wrought by hunters, Muir cannot find a way to clearly locate it within his environmental philosophy even though it comprised a memorable and foundational portion of his youth. However, if Muir's writings speak against hunting and by contrast place Thoreau's beliefs in a more nebulous middle ground, twentieth century environmental writer Aldo Leopold offers an opposing perspective. 


\section{Aldo Leopold and Hunting}

If Henry David Thoreau and John Muir both leave towering environmental legacies that extend from the nineteenth century, Aldo Leopold represents a third major figure from the middle of the twentieth century whose writings still remain foundational to environmental literature. Unlike his predecessors, Leopold is routinely categorized as a more of conservationist than a preservationist because his writings stress environmental restoration. Leopold's most important contribution to environmental literature is his concept of "land ethic," an ecologicaloriented view of environment that Leopold suggests "enlarges the boundaries of the community" to encompass "soils, waters, and animals, or collectively: the land" (A Sand County 239). He modeled his theory of stewardship by spending more than a decade repairing a damaged farm, and his writings during that time comprise his second major publication, A Sand County Almanac (1949), which was published posthumously a year after his death, and a third publication, Round River (1953). In the latter work, Leopold documents one year's worth of his observations of the changes in the flora and fauna at the farm in Wisconsin with the hope of inspiring Americans to consider and then to respond to the increasingly damaged natural world that encompasses them. Calling for better understandings of ecology, Leopold notes that rethinking the environment enables humans to "see the land as a community to which we belong," which encourages "love and respect" rather than mindless exploitation (A Sand County xviii-xix). Because of the then newfound human capability to better understand the environment and effect positive change, Leopold redefined human responsibilities and inspired a generation of land stewards that includes the likes of Wendell Berry and hosts of modern organic farmers.

Like Thoreau and Muir, Leopold's perspective of hunting rarely receives much attention among environmental literature scholars and environmentalists, and, in his case a bit more than 
his predecessors, it seems egregiously ignored because he spent much of his life dedicated to conservation instead of preservation. Leopold's interests in interacting with the outdoors and paying close attention to environmental changes derived from his childhood passion for hunting (Lorbiecki 9). When he passed unexpectedly from a heart attack just after helping fight a forest fire in 1948, Leopold was awaiting notice to know whether or not the manuscript for what became A Sand County Almanac would be published. At the time of his passing, writing was a small part of a life that included working for the U.S. Forest Service, within the forestry industry, and serving as a professor of wildlife management at the University of Wisconsin-Madison before working to restore the farmland he purchased in rural Wisconsin. In short, Leopold's reputation at the time of his death was much different than in the present. When he passed, Leopold had only published one book — the widely respected Game Management (1933), which appeared during the same year he was named Professor of Game Management at the University of Wisconsin.

Game Management does not merely represent a Mr. Hyde to Leopold's ecological-minded Dr. Jekyll, but instead reveals the beginnings of what eventually surfaced in A Sand County Almanac and Round River. Leopold came to appreciate and champion conservation through hunting; moreover, he realized that restoring animal populations and improving lands that supported their lives would be pivotal to ensure the future of hunting. He writes, "The central thesis of game management is this: game can be restored by the creative use of the same tools which have heretofore destroyed it—axe, plow, cow, gun, and fire" (Game Management xxxi). To accomplish the goals of the book, Leopold's novel contribution was to suggest a way of approaching the conservation of animals from a hunter's viewpoint. He realized that much of the prior discussion, studies, and legislation attempted to make progress simply by lessening the 
number of animals taken in the field through imposed limits. This, however, did not address his larger concerns about making a greater impact by doing more than monitoring animal population numbers. If Muir and Thoreau helped to theorize preservationist precedents that inspired macrolevel legislation to curtail environmental abuses, Leopold called for his own form a microrevolution by encouraging individual landowning hunters, farmers who leased their lands for hunting, and even some non-hunters to understand how to modify acreage for the benefit of wildlife and game animals.

Leopold kept environmental balance in mind and thought that it should be central to the way that hunters approached their relationships with the land. He imagined hunting as a hobby that at its best might engage humans to improve the overall health of damaged lands, a call for a form of outdoor recreation "not as widely pursued as mountain biking or jet skiing," but more beneficial and more engaging for some people (Knight 34). Leopold's notion of habitat improvement may appear to have a greater link to human hunting interests than animals, but it would also be the early genesis of what would later comprise the heart of his famous "land ethic" concept. In an essay published in 1943, five years before his death, and later reprinted in A Sand County Almanac, Leopold writes, "The experience of managing land for wildlife crops has the same value as any other form of farming: it is a reminder of the man-earth relation ("Wildlife" 4). Like a generation of environmentally-minded hunters in the nineteenth century who sought to conserve and improve spaces for game, Leopold believed that humans could alter and improve area for game animals; that participating in this form of improvement could benefit humans and not negate the original purpose of hunting. Leopold imagines hunters as improving lands not entirely for their own purpose, a notion that he would later expand to encompass a greater "land 
ethic," which would alter the principal role of humans from "conqueror of the land-community to plain member and citizen of it" (A Sand County 240)

Leopold also theorized that for hunting to continue to be sustainable, it must come to terms with improving technologies that threatened to put more game animals at risk and that might hasten a return of destructive hunting practices from the nineteenth century. He worried about the ease in which hunters had access to bullets, contrasting the long hours and work required of primitive hunters such as falconers with a gun cartridge, which Leopold describes a "perfect product of industrial chemistry" (Round River 5). Like Thoreau and Muir, Leopold feared that hunting could devolve into something destructive for both humans and various landscapes, but he did not completely rule out its potential benefits. Rather, he implored environmentalists and conservationists to consider how their actions might improve rather than damage their landscapes. The care for lands that he imagined and that would later comprise the "land ethic" emerges from concern about recreational hunting's sustainability. If Leopold imagined that the greater human population might not be as interested in hunting as people of his generation, and that a "land ethic" was therefore more useful and had the potential for a larger impact, he did not rule out hunting management as a means to continually modify environments in ways that benefitted both animals and humans.

\section{Chapter Overview}

Hunting literature merits greater inclusion as part of the environmental literature canon for multiple reasons. It demonstrates some of America's earlier authors and environmentallyminded people interacting with the outdoors, and it broadens a strand of environmental literature that features humans seeking greater understandings of geographies for subsistence and recreational purposes. Alongside farming literature, hunting stories portray humans actively 
engaging with other nonhuman life throughout the development of the United States and into the present. They document an entire physical process that involves advanced preparation, the body, the senses, and extended trips and hours spent outdoors. They also capture the lives and personalities of people who believed hunting to be integral to American democracy, as well as continuing debates about the recreational sport. Hunting stories also capture the spirit of a pursuit that sometimes involves humans collaborating with companion animals in pursuit of successful hunts. The relationships among hunters and dogs offer new insight into both hunting literature and animal studies. They encourage readers to consider the relationships among humans, companion animals, and prey animals, and how hunting contributes to the environmental perceptions of both adults and children throughout the course of American history. In the process, they also enable greater understanding about how the American environment and our perceptions of animals have changed, and they encourage Americans to think more about the origin of the meat that they consume and the demands that an increasing population places on the environment.

This dissertation traces a history of prominent hunting literature throughout the nineteenth and twentieth centuries before and after Henry David Thoreau and John Muir, and it shows that as American culture evolved, hunting took on a variety of forms and imparted different meanings for different groups of Americans in regard to human relationships with the environment, companion animals, and prey animals. It focuses on hunters in a broader sense, ranging from extraordinarily capable figures such as Natty Bumppo from James Fenimore Cooper's The Leather-Stocking Series to inept, but purposeful hunters such as Boon Hogganbeck from William Faulkner's “The Bear” to Georgia Pellegrini, a twenty-first century chef whose interest in hunting relates to the culinary world. Throughout each of the chapters, I argue that 
hunting literature allows readers to better understand human relationships to animals and American landscapes and that it reveals the lives of people who embraced hunting as central to their childhood and adulthood for the purposes of recreation, subsistence, and their livelihoods.

Chapter one explores the American literary foundations of what it meant to be an American hunter. I focus on the various hunting writings published throughout Washington Irving's career, and I argue that in addition to his prior literary accomplishments, Irving should be elevated as the preeminent early American hunting writer for the breadth and variety of his fiction and nonfiction reflections. Drawing from his boyhood, lifetime experiences, and an elongated sojourn as an expatriate, Irving investigates the transition of European hunting traditions to America, probes at what hunting revealed about Americans in the early nineteenth century, and charts the way that hunting would come to align with American character throughout the nineteenth and twentieth centuries. Unlike early backwoods hunting heroes such as David Crockett or fellow popular writer James Fenimore Cooper, Irving sought to account for the past, present, and potential future of hunting.

Chapter two focuses on American literature's most thorough hunting saga: James Fenimore Cooper's The Leather-stocking Series. Pushing for a reassessment that focuses on Cooper's engagement with his hunter-hero Natty Bumppo, I argue for something greater than a reductive, two-dimensional reading that limits Bumppo as infantile or stunted in the face of the coming of the American Industrialization. My larger area of analysis is Natty Bumppo's relationship with his dogs through the lens of Donna Haraway's emphasis on "co-shaped" lives among humans and companion animals. In two of the first three novels from the series that Cooper composed between 1823-1827, The Pioneers and The Prairie, the author depicts how companion animals support an aging Natty Bumppo, who continues to hunt and explore new 
territories despite bodily limitations. Although Cooper is often characterized and sometimes decried as a sentimental writer, I argue that his focus on the relationship between an aging man and companion animals reveals strands of realism that later became more thoroughly explored by other writers during the twentieth century. More than a decade after The Prairie (1827), Cooper returned to write two more Leather-stocking tales, The Pathfinder (1840) and The Deerslayer (1841). Here, Natty Bumppo's dogs help him at much younger ages in responding to a major loss of a potential human companion and to the destructive influences of others. Altogether, Cooper suggests that hunting with dogs encompasses formative moments within his hero's life that help shape his personal and environmental beliefs.

Chapter three addresses how the widespread environmental disasters of whaling and market hunting in the nineteenth century changed the hunting scene in America. As animal-based products became increasingly profitable and in-demand, industries relied on concepts of imagined ownership, dominion, distancing, and ritualized masculinity to uphold mass killings of animals that led to collapses in populations. Using nonfiction accounts of market hunting and whaling, with a specific focus on Francis Parkman's The Oregon Trail (1849) and two versions of the Essex whaling disaster of 1820, I show how these concepts strengthened a human-animal boundary as a means to facilitate an interspecies war that profited capitalists, but that also forewarns future generations about how exploitative hunting can negatively impact large portions of the earth. As a means of contrast, this chapter also details nineteenth-century hunters who cultivated different relationships with animals and the environment because of their reliance on subsistence hunting. In African-American slave narratives and two autobiographies of Appalachian hunters, I argue that African-American slaves occupied a unique space as theoretically animalized humans, and that they and Appalachian hunters demonstrate a sense of 
self-reliance during this time period inseparable from close interdependencies with wild animals, a notion that some present-day hunters still cling to.

In a similar vein as the second chapter, chapter four emphasizes companion animals involved in hunting, but it revolves around twentieth-century coming-of-age hunting stories in the writings of modernist William Faulkner and children's authors Fred Gipson and Wilson Rawls. These authors write about the ways that companion animals become central to the hunting experiences and the educations of young hunters. To a greater degree and with a sharper focus on the lives of specific dogs, and finding inspiration in the increased role of the companion animal within American families than during prior centuries, Faulkner, Gipson, and Rawls blur the human-animal line to show not only — as Cooper did — that canines influence individual hunter's lives, but that they play a role within families and the accumulation and passing of generational knowledge. The authors assert that particular dogs are as unique as their human companions, and that they help rural children comprehend the notions of family, mourning, and regeneration.

Chapter five attempts to chip away at hunting's centuries-long association with boys and men. Addressing the absence of women's writing about hunting and an increase in women hunters in America the twenty-first century, I explore women's contributions to hunting literature amidst the twentieth's century's focus on conservationism, the advances of feminist movements, and the evolution of environmentalism from Earth Day through a present-day emphasis on localism and food. In Paulina Brandreth's Trails of Enchantment (1930) and Lily Raff McCaulou's Call of the Mild (2012), I trace the changing nature of the hunting trophy with a posthumanist emphasis. Whereas Brandreth writes within a tradition that views the trophy as the premier emblem of one human's full experience of one hunt, McCaulou deemphasizes the 
trophy to suggest that there should be a greater stress placed on the prey animal as a co-creator in a human's full life. In lieu of trophy collecting, McCaulou privileges greater consideration for the entire animal and eating as a more productive way to celebrate the taking of animal lives. Similarly, but to a greater extent, Georgia Pellegrini's Girl Hunter (2011) focuses on hunting for consuming more purposefully and as a means to expand people's palates and culinary skills. Like her predecessor Courtney Borden's Adventures in a Man's World: The Initiation of a Sportsman's Wife (1933), Pellegrini writes about life as a travelling hunter in pursuit of varieties of game animals, but cooking and the foodie movement more than hunting's benefits for the body encourages her to travel and continue hunting. Sitting at the forefront of twenty-first century hunting concerns, McCaulou and Pellegrini challenge prior notions about what it means to hunt and how to honor both the process and the prey animals that shape human experiences. 
"The librarian now stepped up to me and demanded whether I had a card of admission. At first I did not comprehend him, but I soon found that the library was a kind of literary 'preserve,' subject to game laws, and that no one must presume to hunt there without special license and permission. In a word, I stood convicted of being an arrant poacher, and was glad to make a precipitate retreat, lest I should have a whole pack of authors let loose upon me." -Washington Irving (“The Art of Book Making” 814)

\section{Chapter One:}

\section{Washington Irving and the Literary Formation of Hunting in America}

The hunter figure is central throughout Washington's Irving's writing, yet there is currently an absence of scholarship that explores its importance to his work and to American hunting literature. Irving's oeuvre features multiple fictional hunters and, in one nonfiction account, a portrait of himself as hunter. Hunters appear as both central and supporting characters, especially during the height of his popularity in the 1820s and 1830s. Unlike his contemporary James Fenimore Cooper, whose Natty Bumppo was the most popular fictional hunter from nineteenth-century literature, Irving's writings lack one particular, recurrent hunter who appears in multiple works; unlike fiction and nonfiction related to Daniel Boone and David "Davy" Crockett, Irving fails to produce a character defined by hunting prowess or humor. Yet, Irving's collected writings about hunter figures offer a broader panorama of the evolution of American hunting culture.

In this chapter, I begin by suggesting that Irving's meditations about hunter figures should be foundational to modern American hunting literature because far better than stories 
about Boone, Crockett, and Bumppo, they situate the American hunter in a wider array of contexts that encompass the past, present, and future. Exploring early American history and nineteenth-century American culture, Irving writes about hunting in relation to American boyhood. He traces the transition of the aristocratic hunter figure in Europe to American subsistence hunters, and then portrays the evolution of hunting into an extractive activity in the Western United States. If Boone and Crockett were known for their pioneering hunting exploits, and if Cooper's Natty Bumppo occupied the liminal space between Native Americans and Americans, Irving's heterogeneous band of hunters capture the various degrees of archetypal American hunters in the context of coming pressures of an Industrial Revolution and its impact on American hunting. They demonstrate that American hunters defined themselves in different ways based on where hunting fit within their social hierarchies and their relationships to animals. Moreover, some of Irving's later work also interrogates his own position as a hunter and reveals his changing understanding of hunting from childhood to hunting as a celebrity writer who travelled and wrote overseas and then to a writer who, in attempting to resurrect his "Americanness," resorted to a western adventure that included big game hunting and that inspired a new phase of his career that included three works.

Irving's writing traces these differences that began to form in his mind beginning from his youthful adventures, and he later addresses the hunter figure from four different vantage points throughout five works. In The Sketchbook of Geoffrey Crayon, Gent. (1819-20), Irving contrasts his two most famous characters, Rip Van Winkle and Ichabod Crane, to consider what it means to be an individual hobbyist hunter in rural New York in eighteenth-century America amidst an atmosphere that produced the American Revolution and the Age of Reason, when a great acceleration of the division between the value of a formal education and woodcraft 
knowledge proliferated. In Bracebridge Hall (1821), he explores and then analyzes an English aristocratic form of hunting to find a leisurely, elitist hobby containing hierarchical roles that help solidify a cultural tradition, but that also appears to be threatened by the continued cultural changes associated with industrialization. After spending seventeen years in Europe, Irving returned to America, journeyed on a hunting expedition, and composed A Tour on the Prairies as a means to renew his popularity at home. Here, he considers hunting for sustenance at length, while also participating in big game hunts. Afterwards, Irving notably lost his desire to hunt, but his interest in the adventures of hunters and trappers in American West remained and appeared in Astoria (1836) and The Captain Bonneville (1838). These two works comprise a fourth phrase where Irving sheds light on extractive hunting in America, even though he downplays its impact by focusing on business expeditions orchestrated by fur magnate John Jacob Astor and the stories of fur trapper Captain Benjamin Louis Eulalie de Bonneville.

\section{Hunting as Leisure: Youth and The Sketchbook of Geoffrey Crayon, Gentleman (1819-20)}

Washington Irving was a venturesome teenager, prone to sneaking out of the window of his second-floor room after nightly prayers with his father and mother to explore his New York City hometown, but it was a chance family alliance that precipitated his interest in hunting and the outdoors. As the youngest of seven children, Irving received an abundance of attention from his older siblings, and when his older brother William married Julia Paulding in 1793, the tenyear-old Irving became friends with his new brother-in-law, James Kirke Paulding (1778-1860), then an aspiring poet and later a novelist, essayist, and one of Irving's literary companions. Paulding experienced much more of a rural upbringing than Irving as a child living thirty miles north in Tarrytown, New York. In 1796, Paulding moved to New York City; from this time 
forward, he and Irving spent much time roving the Hudson River Valley together. ${ }^{1}$ By 1798 , Irving and Paulding had spent many leisurely hours hunting squirrels on the eastern shores of the Hudson River, not far from a Dutch village known as Sleepy Hollow, and Irving had become deeply attached to the area and the rural Dutch communities north of the city. This locale and these small villages invigorated Irving in a similar manner as Walden Pond inspired Henry David Thoreau or the Mississippi River influenced Mark Twain, and they would continue to be "Washington Irving's solace and stimulus" throughout childhood and young adulthood (Brian Jay Jones 16). Irving's experiences hunting and hiking alongside the Hudson occupied his mind long after he returned to New York City. During 1799 and over the course of the following few years, Irving worked unhappily as a law clerk and yearned for travel and outdoor recreation.

Irving finally got a chance to travel in 1803 and his trip inspired the New York journal, one of his early attempts at writing. Irving wrote in journals sporadically and mostly while travelling (Wright xv). The New York journal offers the only account of the interest and excitement of Irving's early hunting experiences. Irving travelled with a company headed by his employer and former Federalist attorney general of New York Josiah Ogden Hoffman and Hoffman's cousin and business partner Thomas Ogden. Typical of characteristics found in Irving's later writing, the young writer pays close attention to his comrades, but he also focuses specifically on his hunting experiences.

Irving had a complicated relationship with big game hunting that appeared early on in his journals and would ultimately steer his interest away from hunting later in life. Irving's August $11^{\text {th }}$ entry captures an accidental hunting event, a cartoonish pursuit of one wounded deer that Irving joins excitedly. He begins the morning hunting ducks with Mr. Ogden, and while

\footnotetext{
${ }^{1}$ These adventures would leave strong impressions in Irving's mind that would last throughout his lifetime. For example, during one trip along the Hudson River, the young Irving first glimpsed "Wolfert's Roost," where he would later choose to build a home in 1836 from the proceeds he earned from writing Astoria (Burnstein 10-11).
} 
canoeing later in the afternoon, they hear of people chasing a wounded and fleeing animal in the water. Irving writes,

This we soon found out to be a deer and we rowed with all our might to get in at the death. A canoe in which was a man and woman at last come up with the animal and the woman hit it two or three times on the head with a paddle — in the eagerness of her exertion however she missed her aim and threw a somerset (sic) over into the river (Journals v.1 15)

"Get in at the death," Irving's first description of the pursuit of larger wild game, captures his general awkwardness facing and then acting in this surprising situation. The failed joint effort by the couple to capture the deer and the woman's fall into the water drives the deer toward Irving and Ogden's direction. After another series of escape attempts both offshore and onshore, the deer jumps again into the water and Irving, now ashore, tosses his coat aside and goes after it. He continues,

...Mr Ogden \& myself ran along shore endeavoring to find clubs. Mr. Ogden threw one at the Deer [.] when the man who had contrived to get out of the water, sprang in once more \& made a grasp at the animal he missed his aim, and I jumping after fell on his back and sunk him under water <while> at the same time I caught the deer by one ear and Mr. Ogden seized it by a leg (Journals v.1 15-6) Ogden and Irving help bring the deer to shore and receive a haunch for their part in the chase, which "made very fine Steaks... after two days living on crackers \& gingerbread" (Journals v.1 16-17). Here, the scant 1803 New York journal stops abruptly en route to the New York-Canada border, but Irving would later spend part of his time there conversing with officials from the Northwest Fur Company, later central to Astoria, and would embrace the rugged hinterlands and 
hunting with a romanticized, if complicated spirit that would be the basis for his more wellknown writing about hunters a little more than fifteen years later.

\section{Diedrich Knickerbocker and Fictionalizing American Rural Histories}

Nowhere did Irving demonstrate the tension between hunting-related woodcraft and agrarian knowledge versus book knowledge among people in a rapidly changing America than in The Sketchbook of Geoffrey Crayon, Gent.'s two most enduring short stories, "Rip Van Winkle" and "The Legend of Sleepy Hollow." Each of these two sketches is purportedly found among the papers of Diedrich Knickerbocker, an older New York man interested, like Irving, in rural Dutch settlements north of New York City and the narrator of Irving's A History of New York (1809). Knickerbocker's position is worth considering in regards to his imagined role within his community. Irving writes in an introduction that Knickbocker's "historical researches, however, did not lie so much among books as among men; for the former are lamentably scanty on his favorite topics; whereas he found the old burghers, and still more their wives, rich in that legendary lore, so invaluable to true history" ("Rip" 30). There are at least two ways of understanding Knickerbocker here. On the one hand, he acts as an "heirless remnant of bygone Dutch ancestors whom he chronicles to assert his immortality" (Warner 774). From this angle, Knickerbocker is a wandering bachelor finding purpose penning accounts of the past. Yet another way of viewing Knickerbocker, though, is as a minor participant in a debate over what constitutes history. Referring to Knickerbocker's “true history," Irving implies that readers consider the types of histories that receive attention from historians in contrast with others that often remain unnoticed and undocumented. In short, he signals that Knickerbocker's accounts are out of normal historical bounds. Yet even though Irving's preface notes that Knickerbocker has passed at the time of the Sketchbook's publication, the historian's memory “is still held dear 
by many folk, whose good opinion is well worth having; particularly by certain biscuitmakers, who have gone so far as to imprint his likeness on their new-year cakes; and have thus given him a chance for immortality" ("Rip" 31). The longevity of Knickerbocker's memories exists at a local level as his writing archives the lives of a small group of rural inhabitants whose traditions seem destined to fade away, traditions that fascinated Irving since his childhood escapades with James Kirke Paulding.

A portion of Diedrich Knickerbocker's prized position is contingent upon his preserving the lives and lore of small communities Irving loved but suspected that time would forsake. Knickerbocker notices that as people hive together in larger, more tightly compact groupings in what become central human population centers, outlying rural traditions, behaviors, and perspectives can be neglected, minimized, and forgotten. As a local historian or recorder dedicated to the customs and rhythms of rural Dutch New York lifestyles, Knickerbocker commits himself to what inevitably appears to be an eventual demise in the face of an expanding New York and America. As in the case of later nineteenth- and twentieth-century English and American rural novels celebrated more for their window into a certain culture's customs more than their politics or drama - think Thomas Hardy's Under the Greenwood Tree (1872) instead of Return of the Native (1878) or Tess of d'Urbervilles (1891) and Susan Fenimore Cooper's Rural Hours (1850) or Sarah Orne Jewett's The Country of Pointed Firs (1896) as opposed to any critically celebrated novel by William Faulkner or other likeminded works that emphasize rural grotesque, decay, or degeneracy_Knickerbocker's slower-paced, ponderous storytelling attempts to capture what readers are either apt to forget or may even have trouble comprehending: the pace of (in this case Dutch) country life. This perspective also foregrounds 
the tension between hunter figures and emerging status quo or outsiders within "Rip Van Winkle and "The Legend of Sleepy Hollow."

\section{"Rip Van Winkle"}

In some ways, Rip Van Winkle lives in the shadow of Leslie Fiedler's infamous pronouncement from Love and Death in the American Novel (1960). Fiedler notes that Van Winkle is the pivotal model that became the "typical male protagonist" in American literature: "on the run, harried into the forest and the sea, down the river or into combat - anywhere to avoid 'civilization'” (xx-xxi). Influenced by Freudian analysis, Fiedler would further conclude that Rip's trek away from his community, which created a pathway for Huck Finn and many others, was an evasion of the relationship between man and woman that would involve "sex, marriage, and responsibility" (xxi). The archetypal American escape to the hinterlands myth that Fiedler identifies appears throughout American literature, and admittedly carries great weight in how we understand the American experience and our literary canon. However, it also helps our understanding if we assume Fiedler's idea of reproduction, sexuality, and personal responsibility as the central, normative functions of the civilized American man. Here, I propose an alternative perspective than Fielder's, primarily because it is outside the scope of his groundbreaking thesis. To his detriment, Rip Van Winkle may have just loved to go hunting. This recreational activity is more central to the story than previously thought, an idea supported by Irving's addition of a postscript in 1848 , nearly thirty years after he published the story.

Knickerbocker notes that Rip Van Winkle's trek happens in response to two things he fails to do. First, he struggles with the common work available to him in his community: "The great error in Rip's composition was an insuperable aversion to profitable labor" (770). Illequipped in disposition in regards to farming, Van Winkle is content to avoid agrarian labor and, 
as a result, his house and its surrounding farm area appear to be the worst in his area. Second, Van Winkle does not meet his wife's social expectations, and she continually chastises his inability to accomplish what she expects him to do. Treated as an entropic virus within the domestic sphere, Van Winkle's only consolation is “outside of the house - the only side, which, in truth, belongs to a hen-pecked husband" (772). If he escapes to town, his wife follows him there and criticizes his friendships with other idle town folks, which leaves Van Winkle's wanderings into the surrounding mountains as the only safe retreat.

While the first few pages of "Rip Van Winkle" suggest that his impetus to escape to the woods is motivated by his wife's frustration, there is also the possibility that he better understands and relates to his surroundings through hunting. In assessments of Van Winkle, this aspect of his life has been largely set aside, but the story begs the question about what attracts Van Winkle to the woods. It is not antisocial or reclusive behavior a la Henry David Thoreau. For example, children treasure and dogs respect Van Winkle:

The children of the village, too, would shout with joy whenever he approached. He assisted at their sports, made their playthings, taught them to fly kites and shoot marbles, and told them long stories of ghosts, witches, and Indians. Whenever he went dodging about the village, he was surrounded by a troop of them, hanging on his skirts, clambering on this back, and playing a thousand tricks on him with impunity; and not a dog would bark at him throughout the neighborhood. (770)

As a result of Knickerbocker's focus on Van Winkle's marriage and community relationships, many critical readings of Van Winkle before and after his infamous twenty-year sleep center on his human-to-human adult role within family or community life. Bryce Traister, for example, 
argues that when Van Winkle later emerges from his twenty-year sleep he is capable of being more esteemed in the village because his only "life skills," i.e. "his ability to be idle and to tell stories," have become more valuable (125-6). Following this reading, Van Winkle's sleep enables him to forgo twenty years of progress so that he can finally be of value as a storytelling remnant of past times - in other words, a variation of Knickerbocker himself. Or, there is a more incriminating possibility - that Van Winkle is "the adolescent who refuses to grow up and gets away with it" (Ferguson 530). Following this idea, Van Winkle resists social demands, journeys into the mountains, and returns to find his wife and all of his former problems gone. The idle, loafing storyteller is then finally capable of thriving on his own terms. Both of these accounts focus more on what Van Winkle's disposition toward village social progress or domestic life rather than his recreational activities tell us about him, and neither get beyond a simplistic assumption that Van Winkle's hunting is only an excuse to evade his social and family responsibilities.

While these readings are valuable to discussions about "Rip Van Winkle," Irving also explores the fate of the small village recreational or perhaps partial subsistence hunter too occupied with his sport, and he bases Van Winkle's predilections from his own experiences. He describes Van Winkle on the fateful day that he falls asleep pursuing "his favorite sport of squirrel hunting," which was also Irving's and Paulding's hobby many years before the former's lengthy stay in Europe (773). Nonetheless, critics tend to simplify the meaning of Van Winkle's recreational hunts. Susan Catalano, for example, writes that hunting for Van Winkle is a "paradigm of masculine control ... [that] seemingly elevates him above his wife's reproach" (112). If Catalano's position supports the alignment of rural patriarchy with hunting and Van Winkle's pastime with a lackadaisical attempt to avoid efforts at home, it underestimates what 
happens for Van Winkle while he is in the woods. In Knickerbocker's account, the allure of hunting (and fishing) transforms Van Winkle. Surprisingly, perseverance surfaces: “...for he would sit on a wet rock, with a rod as long and heavy as a Tartar's lance, and fish all day without a murmur, even though he should not be encouraged by a single nibble. He would carry a fowling-piece on his shoulder for hours together, trudging through woods and swamps, and up hill and down dale, to shoot a few squirrels or wild pigeons" (770-1). He also develops his closest friendship with his dog Wolf: "Wolf would wag his tail, look wistfully in his master's face, and if dogs can feel pity I verily believe he reciprocated the sentiment with all his heart" (773). Too, Van Winkle also finds an outlet away from the "drowsy tranquility" of the town and exerts more energy than at any other time (779). Finally, Van Winkle may also be a partial subsistence hunter. It is certainly possible — as in the case in some nineteenth-century nonfiction accounts of hunters living in small rural towns - that wild game supplemented his family's food supply, especially in light of the fact that they never appear hungry despite Van Winkle's poor farming habits or skills. Altogether, Van Winkle finds relief and a way to define himself as part of the natural world separate from human interaction while in the woods.

His pursuit of wild game alongside his dog also allows Van Winkle to forgo the immediate effects of the Revolutionary War, but he feels the cultural upheavals afterwards. Sarah Wyman suggests that upon awaking, Van Winkle becomes a critique of how a postRevolutionary War emphasis on liberty lessened "the human need for continuity, community, and connection to history," helping pave the way for the hyper-individualism that later defined Jacksonian Democracy (218). Indeed, Irving depicts him as quite different from a reckless individualist. When he returns to town with a grizzled appearance, with a long beard and a rusty rifle, the townspeople quickly attempt to categorize him by asking him about how he voted and 
whether he is a Federalist or a Democrat; when Van Winkle unknowingly expresses his allegiance to the king, the crowd responds vehemently: "A tory! a tory! a spy! A refugee! hustle him! away with him!" (780). Van Winkle tries to articulate himself through questions pertaining to local rather than national history, asking the whereabouts of his neighbors, and he appears more and more confused by the change in town. While he ponders who and where he is, there emerges "a whisper [amongst the crowd], also, about securing the gun, and keeping the old fellow from doing mischief" (781). The armed and possibly crazed Van Winkle appears out of date and destined for trouble before his daughter saves him at a "critical moment" (781). Later, he also reunites with his son, who, as "ditto of himself," behaves in a similar fashion and suggests there might still be room for a hunter in the community, before "resum[ing] his old walks and habits" (783). Though Knickerbocker does not elaborate, readers can assume that Van Winkle returns to hunting rather than merely spending the rest of his life sitting around and telling stories.

Although it was not included in the story's original release, Knickerbocker's 1848 postscript to "Rip Van Winkle" reemphasizes the role of hunting in the story and situates rural local history within the greater context of national history from far before the tumultuous Revolutionary War years. Here, in describing the Catskill Mountains where Van Winkle hunts, Knickerbocker writes more about how the sport and Native American beliefs influenced human interactions with the land. According to Knickerbocker, Native Americans believed that the successful or unsuccessful hunting seasons here depended on the moods of the spirits. The most infamous spirit is a "a kind of Manitou" who plays tricks on Native Americans during their hunts by assuming the form of their prey and leading them along a lengthy chase before "leaving them aghast on the brink of a beetling precipice or raging torrent" (785). Once, when a hunter 
accidentally trespasses on the Manitou's favorite abode, where braver hunters never dare to roam, and a takes a gourd and rushes away, the Manitou punishes him by causing a large stream to sweep "him down precipices, where he was dashed to pieces" (785). Knickerbocker claims that this stream gave the Catskill Mountains its name. Following in the footsteps of prior generations of Native Americans, Van Winkle defines himself in part by his love of hunting in the Catskill Mountains, and though the recreational sport appears at the periphery of the story, Knickerbocker's informative postscript demonstrates that for Rip and some of his predecessors, hunting provided a way to understand themselves in relation to nonhuman animal world around them.

\section{"The Legend of Sleepy Hollow”}

One of Washington Irving's primary contributions to hunting literature in American literature in "Rip Van Winkle" and "The Legend of Sleepy Hollow" is the implication that a fastpaced, industrialized economy affects Americans in ways that in the course of time will change their views about hunting, particularly in outlying communities within proximity of metropolitan areas. Irving's Diedrich Knickerbocker is an ornery curmudgeon who privileges and seeks to honor Dutch lifestyles from the past, but he also suggests that there is something special about hunting and woodcraft that recedes or even becomes obsolete as industrialized marketplaces encroach upon small, insular communities. Knickerbocker expresses what Irving envisioned would happen in time, when speculation-minded people like Ichabod Crane would succeed hunters such as Rip Van Winkle. An amalgamation of Dutch customs and German folklore, "The Legend of Sleepy Hollow” propelled Washington Irving from “a mere man of letters to an international superstar" (Brian Jay Jones 187). The story remains Irving's most well-known primarily for the iconic headless horseman that chases out-of-place Yankee newcomer Ichabod 
Crane out of town and toward a more promising livelihood, and as fodder for animated and live action visual adaptations that focus on villain far more than Irving's story does. Traditional readings of the story position Ichabod Crane versus Brom Bones in a duel to win the hand of Katrina Van Tassel, daughter of a wealthy farmer in Sleepy Hollow. While the outward struggle between Crane and Bones prompt the appearance of the Headless Horseman, Irving's story also contains another simmering conflict beneath the surface between Ichabod Crane, the unnamed storyteller, and recorder/ narrator Diedrich Knickerbocker. The story details a clash between the rural social class that the narrator and Knickerbocker represent and Crane, an outsider educator and speculator who embodies what would help define and enable monetary success in a future industrial America. Within this tension, Irving offers a blueprint for a critique of a nationalized form of education that in time would leave no room for the study of woodcraft and would denote knowledge of hunting and blood sports as antiquated in some instances and barbaric in others.

Though they are both community outsiders, Knickerbocker perceives Sleepy Hollow differently than Ichabod Crane because each of them first encounters the rural enclave for separate reasons. Knickerbocker's perception of Sleepy Hollow begins with a childhood hunting experience after he stumbles onto the small town while squirrel hunting. He envisions it as the perfect place to retire and reflect upon life's frustrations, and therefore worthy of preservation. Knickerbocker says, "If ever I should wish for a retreat, whither I might steal from the world and its distractions, and dream quietly away the remnant of a troubled life, I know of none more promising than this little valley" (1058-9). He suggests in an ideal world, Sleepy Hollow would remain unencumbered by a tide of technological and economic change. By opening the story from this point of view, Knickerbocker hints that there is another way of viewing Sleepy 
Hollow — not as a supernatural enclave, but rather as a relatively secluded location at risk because of financial speculation.

While in some respects the gothic elements of the "The Legend of Sleepy Hollow" are inseparable from its atmosphere, mystery, and cultural longevity, they also obscure additional understandings of the story, particularly in relation to Ichabod Crane. Scholar David Anthony comes the closest to unpacking the financial context that influenced Irving's story. Anthony argues that Ichabod Crane should be understood as "the embodiment of a 'gothic' form of selfhood emerging in relation to the new economy ... [characterized by] ... modern, credit-based commerce [that] confronts Ichabod with the terrifying implications of the increasingly alienable form of male selfhood emerging as part of the 'game' of the new economy" (115). Readers know that upon leaving Sleepy Hollow, Crane begins teaching elsewhere and studying law before becoming a lawyer, politician, and court justice. Anthony’s reading of the story highlights Irving's point that the pathway to success for men in America depends on an evolution away from rural customs and small town relationships and toward formal education, finance, and speculation.

Ichabod Crane appears at odds with both the narrator of the story and Knickerbocker. Knickerbocker's fascination with lost history from the Dutch community clashes with what most fascinates Crane about Sleepy Hollow: personal desire. In addition to the immensity and variety of food he craves while staying in Sleepy Hollow, Crane salivates at the possibility of marrying Katrina Van Tassel and the resulting potential speculation: "his heart yearned after the damsel who was to inherit these domains, and his imagination expanded with the idea, how they might readily be turned into cash, and the money invested in immense tracts of wild land, and shingle palaces in the wilderness" (1067). Ultimately, if one rejects the story's supernaturalism, Crane 
consequently appears undone after misreading the town's social dynamics and misconstruing his imaginative fears and horrors with reality. Unlike the narrator or Knickerbocker, he views Sleepy Hollow as a transactional location, or a small town destined to be reconfigured in the process of accruing wealth to visionary participants. Consequently, Crane merits no sympathy from either the narrator or Knickerbocker, and his investment-minded mentality repulses both of them.

This tension solidifies in the short story's mysterious postscript, where readers first learn that Knickerbocker's story is actually the unnamed narrator and that the teller shared the story in a meeting at a corporation in Manhattan. From Knickerbocker's perspective, the narrator, who dresses shabbily and who expends such an incredible amount of energy recounting what happened, speaks to a room full of clowns. The listeners who clap the most sleep throughout the story; there is one man who, encumbered by reason and law, fails to understand the story's moral and doubts some of its details. When he questions the narrator about the story's truth, the narrator, sensing his inability to grasp the account, replies, “"Faith sir ... as to that matter, I don't believe one half of it myself"' (1088). Greg Smith notes that this final line is a pivotal point because it forces readers to reevaluate all that they have read to side with either a natural or supernatural explanation (180). Yet, in addition to what one thinks about what really happens to Ichabod Crane, Irving also comments on the nature of the storyteller and the corporate listeners. So far removed from the culture of Sleepy Hollow, many fall asleep and fail to comprehend the story's meaning. Here, Irving alludes to the problem of the increasing distance between rural and urban New York to show that the impossibility of a speculative class to comprehend the value of a story rooted in hinterlands traditions. In Knickbocker's presentation of old traditions facing appreciative challenges from a new class of Americans, Irving would place himself on the side of 
the past, which he continued to explore in a more extensive manner in his depiction of an older, more aristocratic hunting culture in his subsequent work, Bracebridge Hall.

\section{Hunting as an Established Cultural Tradition: Bracebridge Hall (1822)}

As Irving's follow-up work to The Sketchbook, Bracebridge Hall focuses extensively on an aristocratic English family and the functions of hunting in their lives. The collection of short pieces is similar to The Sketchbook, but it has received scant attention from literary scholars. Since it lacks any memorable American stories, Bracebridge Hall is best remembered for its short pieces about the English Christmas tradition that would later inspire Charles Dickens's $A$ Christmas Carol (1843) (Kelly, A Christmas Carol 20). Yet, despite critical neglect, this collection of stories and sketches remains of interest to American hunting stories for two reasons. First, it provided Irving a means to show how the English aristocracy perceived hunting as a wealthy tradition associated with family, leisure and a manicured, respectable experience in contrast to hunting's more individualist nature in his American stories. Second, in witnessing firsthand the struggles that English hunters experienced at this time as part of the genesis for Bracebridge, Irving would gain context that would later help him understand how hunting might change in America with the coming American Industrial Revolution. In his portrayal of Squire Bracebridge, Irving reveals a hunting fanatic torn by the disruptions of his passion with the coming of the Industrial Revolution, a novel sentiment not yet found in 1820s America, and in his depiction of the squire's gamekeeper Christy, Irving demonstrates the early formation of the hunting historian or archivist with a rich understanding of hunting lore accumulated from throughout a lifetime of devotion to a sporting tradition.

In the century leading up to the Industrial Revolution in England, there was a massive shift in land ownership that impacted recreational hunting, in terms of who could hunt and when 
and where they could hunt. During the eighteenth century, an increasing number of landowners lost their land and became laborers, while a smaller percentage of country estates expanded and fostered an aristocratic culture characterized by the wealthy country squire and a very settled hierarchy of his dependents. Describing this massive cultural transformation, Raymond Williams notes that in 1690 for every three landowners there were five landless workers and that by 1831 there were two for every five (97). Coupled with a large increase in people moving closer to the cities, the consolidation of larger estates and the loss of the commons fostered a private familyoriented hunting culture among the wealthy as the commons passed by the wayside.

Irving certainly did not come of age experiencing any part of this social upheaval or its impact on English hunting tradition, but the latter fascinated him because it appeared in the literature he read and because it served as a backdrop for considering American hunting traditions. As in other areas of English social life, even hunting felt more refined. Ostensibly, it was more monitored, controlled, and orchestrated, which produced a much different hunting environment than the relative openness of the frontier or the commons in America. Irving wanted to explore the inhabitants of Bracebridge Hall from an American perspective, so he chose the persona of Geoffrey Crayon, who unlike Diedrich Knickerbocker, freely admits that he is "no sportsman” (97). Despite his strong devotion to Republican principles, Crayon comes to appreciate the life of the country squire: "Indeed, I do not know a more enviable condition of life than that of an English gentleman ... who passes the greater part of his time on a hereditary state in the country. ... He has ample means of occupation and amusement within his own domains; he may diversify his time by rural occupations, by rural sports, by study, and by delights of friendly society collected within his own hospitable halls" (192). This appreciation, however, develops over the course of time through an episodic narrative that is full of sketches, asides, and 
details and short on narrative momentum. The use of Crayon, as Herbert Smith notes, enables Irving to both honor his own experiences as a guest at a few English manors, including his most memorable stay with Sir Walter Scott, and to skeptically criticize the conservatism of the English aristocracy. Under the guise of Crayon, Irving attempts a transatlantic venture by catering to both English and American audiences, honoring past English customs while questioning the contradictions of a small population of English "landed society pursuing a pastoral existence in the age of steam" (H. Smith xvi-ii).

In his presentation of Squire Bracebridge, Irving brings the tension between the art of hunting and the use of relatively newer technologies to the thematic forefront, and poses a dilemma that characterizes nearly two subsequent centuries' worth of hunting literature. What's most notable is that Irving's depiction differs from other hunting narratives prior to Bracebridge Hall in regards to literary canvas. Looking closely at this tension in England enables him to introduce a concern that would become more prescient in America toward the end of the nineteenth century, after the dwindling of game populations because of overhunting and with the official closing of the frontier, and certainly during the present as well. At least in part, Irving wanted American readers to take some of Squire Bracebridge's ideas about the non-game animal elements of hunting seriously, and this first becomes evident in the way the squire views trees in "Forest Trees." Taking pride in the health of his trees is one of the squire's favorite things about Bracebridge Hall; this sentiment inspires Crayon to reflect upon his thoughts of trees in America: "Though brought up in a country overrun with forests, where trees are apt to be considering mere incumbrances [sic], and to be laid low without hesitation or remorse, yet I could never see a fine tree hewn down without concern" (71-2). Crayon notices that the squire struggles to have any tree cut down without experiencing regret. "A few strokes of the axe," he explains prematurely 
ends "what it has cost centuries to build up" (71). The implications also stretch beyond the caretaking of trees and directly relate to the art of hunting.

The squire's chief concerns are how the evolution of hunting in the Industrial Age impacts the relationship between hunters and prey and how to preserve hunting traditions when confronted by non-hunters who decry hunting as a relic of the past. Until Irving later wrote his own hunting experiences in A Tour on the Prairies (1835), the squire would convey Irving's most thoughtful writing about hunting. The squire fears "a matter of fact world, where life will be reduced to a mathematical calculation of conveniences, and everything will be one by steam" and how this convenience-oriented ethos will impact hunting (202). He characterizes hunting as an adventure that results from a not necessarily predictable array of factors involving humans preparing themselves for hunting, humans going hunting, and animals having a reasonable chance for escape. From this viewpoint, the squire believes that the invention of gunpowder weakened the human-animal relationship. Crayon notes that no other single societal advancement "causes him [the squire] more frequent regret," precisely because of the declining interest among English hunters in using the cross-bow and long bow (92). Gunpowder prompted the decline in the archery, thereby lessening the need for practice and competition among hunters with access to gunpowder.

Though Squire Bracebridge espouses the anti-gunpowder sentiment, it has affected his own hunting pursuits and abilities. Crayon notices this gap between what the squire says and how closely he acts upon what he says in "Falconry," when he documents Squire Bracebridge and Master Simon's attempt to revive the ancient sport of falconry. The squire pays anyone in the community who brings him living hawks and, with the help of Simon and Christy the huntsman, attempts to train them to hunt in an effort to revive what he perceives to be a waning 
hunting tradition. This endeavor fails miserably because neither the squire-Simon duo nor Christy can come to terms with how to become successful falconers. Each holds a different mentality and opinion about how to approach the sport. The squire and Master Simon assume that classic English falconry texts will ensure success, but this does not work, as an amused Crayon notes in describing the situation: "Their feathered school has turned out the most untractable and graceless scholars; nor is it the least of their trouble to drill the retainers who were to act as ushers under them, and to take immediate charge of these refractory birds" (93). Meanwhile, and compounding the problem, Christy ignores their methods because of his "sovereign contempt for all book-knowledge" and attempts his own—all of which derive from his experience cockfighting during his younger days (94). Though Crayon finds much humor in this situation, it results from a lack of immediate knowledge of falconry; it shows the many hunters had lost their connection with hunting alongside falcons because of a decline in tradition enabled by easier forms of weaponry.

Through his depiction of Christy, Irving also explores the figure of the storyteller, amateur archivist, and hunting historian. Hunting is so important to Squire Bracebridge's conception of history and family lore that its remnants serve as centerpieces of the house-for example, Crayon marvels at "a pair of antlers in the great hall ... one of the trophies of a hard-riding squire of former times" (35). However, the most important element of hunting culture is what the squire is able to share to others through storytelling. Squire Bracebridge delights in hunting stories from prior generations, and they define dinner discussions with all visitors. As Crayon's account of his visit reveals, the squire's most trusted curator of hunting lore is Christy, his huntsman. The "most ancient servant" of the manor, Christy began working for Squire Bracebridge's father (18). He spends the majority of his time safeguarding family hunting treasures and archiving and then 
recalling hunting stories for others. Crayon notes his extraordinary memory: "He can give a circumstantial detail of every fox-hunt for the last sixty or seventy years, and has a history for every stag's head about the house, and every hunting trophy nailed to the door of the dogkennel" (18). Christy's primary role is to bring the lives of game animals, passed hunters, and past hunting adventures back to life.

In a sense, Christy the English huntsman occupies a storytelling and archiving position unavailable to Rip Van Winkle in America. Unlike the latter character, Christy lives in an environment that nourishes his interests and allows him to use his knowledge without banishment from his social sphere. Christy is one of the more memorable characters in Bracebridge Hall precisely because of how different his social role is from the others and because of his interest to Irving, who does not hesitate in likening Christy's knowledge and dedication to his job with England's best scholars. Crayon recalls stories about when a younger Christy accompanied the college-age squire to school at Oxford, where "he enlightened the whole university with his hunting lore"(18). Christy also trained a young Master Simon how to hunt, thereby serving as manor's hunting instructor as well. In the social role of huntsman, Irving found a living relic - a person who served in a position that would cease to exist with the continued industrialization of England. And though Crayon enabled Irving the narrative distance to both commend and criticize aristocratic culture, he noticed that the relationships that Christy had with his employers, Christy's sensitivity to game animals and, his level of hunting knowledge were different than what the wilds of America afforded. Experiencing aristocratic hunting culture in England would not only, as Jeffrey Dorsky-Rubin points out, enable him to better understand America, but also better grasp hunting culture in America (141).

\section{Hunting for Sustenance: A Tour on the Prairies (1834)}


When Irving finally returned to America in 1832 after a seventeen-year absence and sought to remake himself as an American writer, he seized the opportunity to go adventuring out west. As Anthony Brandt notes, this decision initially seemed odd given that Irving was nearly fifty, "a bit stout, somewhat fussy, and utterly Europeanized" (x). Yet, the author pursued it partly as a means to experience the evolving America of the Jacksonian era, and his initial journey would lead to three western books: one personal account that focuses extensively on hunting and two additional works that include hunting and trapping as central to their purpose. The first, A Tour on the Prairies (1834), is Irving's most profound and pinnacle work of hunting literature, while the remaining two, Astoria (1836) and The Adventures of Captain Bonneville (1837), exhibit a marked change in purpose and demeanor as they rely on the written materials and correspondence of two other people, John Jacob Astor and Benjamin Louis Eulalie de Bonneville. Together, the three would comprise what would become known as Irving's western phase and "the first body of writing in English about the American West to capture a wide audience" (Ronda 546). Moreover, in the process of traveling, hunting, reflecting, and writing, his experiences in the American West greatly impacted his life and changed his perspective about hunting.

Washington Irving documents the most personal, important, and transformative hunting experience of his lifetime in A Tour on the Prairies, one that includes the tracking, trailing, and killing of a buffalo. His intense human-animal encounter after years abroad forced him to reconsider the killing of animals in a different light than his boyhood hunting memories or as a distanced admirer of a foreign aristocratic hunting culture. The ugly and tiring reality of hunting buffalo was enough to revise some of his thoughts about hunting, and after an arduous monthlong journey, documented with the ferocity and intensity in A Tour on the Prairies, Irving 
eventually retreated to a safer (and more admiring and congratulatory) distance in the two subsequent books about the American West. The intensity of the first-person account of $A$ Tour on the Prairies also surpasses Irving's earlier hunting works in scope and importance because it offers a nonfiction account that portrays hunting in a vastly changing America transitioning from post-Revolutionary War, Jeffersonian agrarianism toward laissez-faire attitudes emerging from Jacksonian democracy.

Though he downplayed the assumption and maintained that it happened by chance, Washington Irving's tour through what is now eastern Oklahoma occurred in part because he felt like he had something to prove to American readers after his extended absence in Europe. His idea for regaining the interest of American readers was to write a travelogue about his experiences in the country's remotest regions among hunters and travellers. Irving's introduction to A Tour on the Prairies portrays his unease in returning from Europe back to America. In trying to reacquaint himself with Americans, Irving began by relying heavily on his success with "Rip Van Winkle." He positions himself as a Van Winkle-like figure, noting how upon his return he found a different America from the one he left many years before: "I passed through places that ought to be familiar to me, but all were changed ... I read the names over all of the door: all were new.... The saddening conviction stole over my heart that I was a stranger in my own house! Alas! thought I, what had I to suspect after such an absence! (10). Rhetorically, this move enables Irving space to situate himself within the context of American mythology and to view the country with as new of a cultural vision as he would ever be ever be able to muster. This approach is risky because it can be misread as relying too heavily on past fictional success, and Irving's own apprehensiveness appears throughout the majority of the introduction to A Tour on 
the Prairies in the form of a shaky, nervous tone that suggests more anxiety than his typical jovial disposition.

By the end of the introduction, Irving conveys the idea that the western sojourn will allow him a reintroduction to American readers without attracting much immediate attention. Irving writes, "I have always had a repugnance, amounting almost to disability, to write in the face of expectation" (11). The exotic nature of the trip provides an occasion for reinvention and minimizes the pressure of immediate contact with the New York literary scene. He concludes the introduction by attempting to minimize the grandiosity of one of America's most well-known writer's venture into the wilderness: "As such, I offer it to the public, with great diffidence. It is a simple narrative of everyday occurrences; such as happen to everyone who travels the prairies" (12). By claiming he has no special story to share, Irving preemptively lowers reader expectations since he cannot know how they will respond, especially in light of the fact that $A$ Tour on the Prairies differs in form and content from much of his most popular work.

To a certain extent, the fact that he downplays this episodic account, coupled with the general oddness of A Tour on the Prairies within Irving's oeuvre, shapes the ways that scholars situate the account within the context of his work and the ways his fellow adventurers interpreted Irving. John McDermott, for example, writes that Irving ventured on a brief tour "over the Oklahoma prairies, on a military mission of no importance, during which the party saw not one hostile Indian, nor gathered any significant information about terrain, nor marked a road, nor accomplished anything except to wear out a few horses and to run short of food" (164). Another adds that Irving's "neat freak" habits puzzled his companions throughout what seemed like an ordinary journey to them; and that Irving's desire for so much personal space in order to write and devotion to cleanliness seemed extraordinary from their vantage points (Burnstein 272). 
In other words, for both Irving's companions and scholars, the trip appears relatively uneventful. Nonetheless, while Irving, too, minimized its relevance in his introduction, the trip forced him to reconsider hunting, something ordinary for his companions and of less importance to subsequent scholars.

One principal difference is that for the first time Irving had to hunt in order to eat, which made the experience unique and hunting more personal than ever before. Unlike his boyhood experiences, hunting was not simply for leisure; no matter whether Irving consumed game animals in England or not, he never lacked food hunted, grown, or prepared by someone else there. Out on the prairies, hunting would not serve merely as an escape or leisurely pursuit, as it did for Rip Van Winkle, nor would it function as a habitual unifying event that enveloped otherwise well-provisioned households, as in Bracebridge Hall. On the prairies, Irving would be hunting in part for adventure, but he would also need to help the others hunt for sustenance and prepare their own food. Surprised at the reduction in supplies before leaving for the trip, he realizes that most of his food would derive from game animals along the way. During the best moments of the trip, when there was ample game and when he had enough to eat, Irving relishes the camaraderie amongst his group. During his most content time, he writes, Indeed, I can scarcely conceive a kind of life more calculated to put both mind and body in a healthful tone. A morning's ride of several hours diversified by hunting incidents; an encampment in the afternoon under some noble grove on the borders of a stream; an evening banquet of venison, fresh killed, roasted, or broiled on the coals; turkeys just from the thickets and wild honey from the trees; and all relished with an appetite unknown to the gourmets of the cities (65). 
Yet, there were also tougher moments throughout the journey when game did not appear. These instances instructed Irving as much as moments of abundance. Unaccustomed to this sort of experience, Irving noticed that the prairie lifestyle began to challenge his prior thoughts about humans hunting animals, particularly in relation to his understanding of the function of guns. Irving realized that guns became necessary for survival and safety on the prairies. Early in the account, while describing an angry settler they encounter along the way, Irving describes the man's gun as the "invariable enforcer of right or wrong upon the frontiers," a phrase that could easily have appeared within any of the first major western novels from a little less than a century later (27). Here, Irving still intuited the gun more as an instrument of force that enabled settlers a way to exert power amidst lawless terrain, where some people sensed their safety at risk without firearms for protection. However, within his own party, Irving soon came to believe that the necessity of hunting also reframed the meaning of guns to his companions.

Whereas he had previously viewed them as a hunting tool as a boy or as a contentious technology as part of hunting for leisure in England, guns were highly valuable among his party, and perhaps to the great degree that Irving prized his privacy and his horse. For Irving's fellow travellers, guns became lifelike companions. In one situation, Irving finds himself amidst a heated debate among large game western hunters, who proclaim deeply and personally that a rifle is the only worthy weapon for personal protection and hunting, and who shun easterners who carry shotguns for small game (52). The concern for guns is so serious, Irving finds, that the weapons seem at times to cross the nonhuman-human boundary in becoming human. In the midst of a debate, when the captain considers taking away the guns from some of the accompany rangers so that they might not accidentally attract the threats of rumored-to-be-nearby Pawnees, Irving witnesses a ranger cry, "It's like a part of myself. There's no one will take such care of it 
as I, and there's nothing will take such care of me as my rifle" (59). The captain, "touched by a true hunter's sympathy," takes this retort seriously, replying that he and his gun have been together nearly as long as he and his wife (59). Another hunter nearby steers the serious conversation to a close, adding, "A neighbor of mine says, next to my rifle I'd as leave lend you my wife" (59). This bit of humor helps deflate the conflict, as the captain backs away from taking possession of the rangers, but it also exposes the seriousness of the relationships amongst settlers and rangers and their guns on the prairie.

Toward the end of his journey, just before embarking on his own to kill a buffalo, Irving falls behind the crew. His stated goal for following from a distance is the plan to "behold the wilderness relapsing into silence and solitude," yet the remnants of unrestricted hunting thwart Irving's desire for solitude: "great morsels of roasted venison and Buffalo meat, standing on wooden spits ... while around were strewn the hides, the horns, the antlers, and the bones of buffalo and deer, with uncooked joints and unplucked turkeys, left behind with that reckless providence and wastefulness which young hunters are apt to indulge when in a neighborhood where game abound" (130). Here, Irving's writing would in spirit precede later criticism of wasteful hunters by Henry David Thoreau and John Muir, and it would also foreshadow his much greater distancing from the hunters during the next chapter, where he documents the crucial buffalo hunt that altered his opinion about hunting.

Up until this point, if hunting had not been central to Irving's life, it had been a formative part of his experience and an activity that he imagined as formative to boyhood and a reasonable part of adult life. In the chapter ten of A Tour on the Prairies, he expresses how the prairies enhanced this understanding, writing, "We send our youth abroad to grow luxurious and effeminate in Europe; it appear to me that a previous tour on the prairies would be more likely to 
produce that manliness, simplicity, and self dependence most in unison with our political institutions" (44). As with many others who were caught up the spirited fervor of Jacksonian Democracy, Irving appears at this instance to buy into the idea of the American West as a training ground for producing ideal American men. This particular passage is one of the two most cited pieces of A Tour on the Prairies, and what remains fascinating is how it starkly contrast with the second most-mentioned passage, which appears in chapter twenty-eight. There, Irving writes of his frustration with the consequences of unfettered hunting in general and his own buffalo hunting experience in particular. This latter situation would influence Irving to resituate himself at a comfortable distance from hunting culture, and to eventually announce his resignation from it.

The twenty-eighth chapter of A Tour on the Prairies, which documents Irving tracking and killing a buffalo, attracts the most scholarly interest and offers a direct rebuttal of the Jacksonian sentiment expressed earlier in the book. William Kelly writes that this episode is where Irving proves that he is "actively engaged" in the American culture he had abandoned for Europe, and that the hunt is so important to the text that it structurally reframes the book from a collection of sketches and scenes on the prairies to a "rite of passage" text (xxxvi; xxxviii). Though neither prior scholars nor Kelly articulate it this way, it is as if Irving attempted to enact what he theorized earlier about experience on the prairie as a means of nurturing the growth of young American men. While Kelly's analysis focuses on the psychological component of the hunting ritual in American culture, it also focuses heavily on the actual killing of the animal and deemphasizes what the process teaches Irving, and what he attempted to communicate to readers.

Irving shows that pursuing buffalo on the open prairies is not as easily as might be imagined. First, the terrain, comprised of rolling hills, soil rifts, and obscured holes created by 
burrowing animals, is forbidding. Consequently, it is easy for horses to tumble unpredictably. In his initial attempt, Irving fails when he breaks from his companions and chases a buffalo on his own. When it escapes, Irving realizes that another danger of the prairie is its monotonous uniformity. Irving complains of the "deficiency of land marks and distinct features" that makes the prairie as disorienting as the sea, an idea possibly implanted in his mind by James Fenimore Cooper's The Prairie (1827) (134). The visual sense of isolation is overwhelming-Irving notes that in the forest, the abundance of trees allows the human imagination to better hope for something or someone just out of view of the closest trees. By contrast, the openness coupled with the occasional sounds of ravens and howling wolves reinforce the vast emptiness. Living things longing for something absent (food or companionship or shelter) dominate Irving's emerging understanding of the prairie amidst the hunt. During his first botched attempt to kill a buffalo, the always sociable Irving momentarily realizes that without support, he becomes prey to his environment. If he becomes lost and is incapable of locating food or water, he too, is at risk of become the hunted rather than a hunter. This disarming idea shakes him temporarily before he is able to regain his composure and relocate the hunting party.

When Irving later succeeds and kills another buffalo, his perspective about hunting undergoes a major change. Irving regroups with his companions and they decide to pursue a herd of buffalo a couple miles away. When they succeed at sneaking upon the herd, Irving finally gets his chance and shoots a buffalo from a far distance. As he approaches the animal just after shooting, he realizes that it is still very much alive and he feels a strong sense of regret. What horrifies Irving the most is, again, the different scale of experience on the prairie. He writes, "It seemed as if I had inflicted pain in proportion to the bulk of my victim, and as if there were a hundred fold greater waste of life than there would have been in the destruction of an animal of 
inferior size" (136-37). As the buffalo lies in pain, Irving again becomes hypersensitive to the sounds and movements of the "skulking and howling" wolves and "flapping ... and croaking" ravens, both waiting nearby for him to leave. (137). Moments before, Irving writes, "I had been prompted to this unwonted exploit by the magnitude of the game and the excitement of an adventurous chase;" now, Irving reflects, "To inflict a wound thus in cold blood I found a totally different thing from firing in the heat of the chase" (137-8). The memories of boyhood hunting exploits and the jovial spirit of English hunting party fade away, as killing something as large and defenseless as a buffalo shatters his prior conception of what hunting meant to him. Later, he would return to the spot of buffalo's carcass to find a "legion of ravenous wolves" eating its remains, and contemplate his role in the process of death and renewal (141). Notably, too, Irving distanced himself from hunting for the remainder of the trip, devoting one chapter to his observations about prairie dogs and others to the trip returning home.

\section{Hunting as Extractive Economic Activity}

After buffalo hunting, Irving came back to the east and kept personal distance away from hunting (or trapping) in his subsequent two works, Astoria and The Adventures of Captain Bonneville. These works comprise the fourth phrase of Irving's hunting writing in their portrayal of the sport as an extractive resource associated with industry and profiteering. Following some of his observations of wastefulness from A Tour on the Prairies, this career moment could easily have presented a chance for Irving to expand his concern about hunting's potential impact upon American wildlife. After engaging in childhood hunting adventures, writing about hunting in a small New York town, documenting aristocratic hunting traditions in England, and then experiencing first-hand subsistence hunting in the American West, Irving seemed primed to imagine or anticipate how extractive hunting might correspond with the decline of large animal 
populations throughout the nineteenth century. Arguably, his breadth of experience in various hunting cultures positioned him to be both a spokesperson for the value of hunting and a critic of its excesses. Unfortunately, he largely ignores this opportunity. Instead, the richness in detail about human adventure and camaraderie within Astoria and The Captain Bonneville triumphantly appear at the forefront while serious concern about the potentially damaging nature of overhunting is virtually nowhere to be found. Worse, the sense of reverence for hunting traditions that characterize much of Irving's earlier writing is absent, a great disappointment considering the clarity of A Tour on the Prairies. Instead of an exposé or even a partial critique of hunting's potential costs when coordinated on a grand scale by people more invested in natural resource extraction than ideas of hunting for leisure, tradition, or subsistence, Irving wrote two adventurous, fact-based books about a wealthy investor in fur, John Jacob Astor, and an explorer, Benjamin Louis Eulalie de Bonneville, that focus on human ingenuity and business practices and that minimize the human-animal conflict he had so profoundly presented in his first western work.

After returning to New York after his tour, Irving's interest in writing about the American West remained, yet social circumstances would alter his point of view as a writer. The western experience "fired his enthusiasm for the frontier," even as he never made plans for a return trip (Rust 159). If Irving would no longer yearn to travel there again, the lives and work experiences of its inhabitants still occupied his mind. During 1834, months before robust sales and rave reviews of $A$ Tour on the Prairies catapulted him back to celebrity status and inaugurated him as the premier writer of the West, one of Irving's friends, a wealthy American capitalist named John Jacob Astor, approached Irving looking for a writer to recreate his disastrously failed mission to establish a major fur trade company in the Pacific Northwest 
between 1810 and 1812. Inconvenienced to a great extent by the War of 1812, Astor's endeavor remained, at least to him, important and deserving of literary presentation. At this point, not knowing how successful A Tour the Prairies might be, Irving may have fallen victim to the lure of wealth and fame. He was looking for a place to settle outside of New York City and to earn enough money to support his desired lifestyle, so he accepted Astor's proposal and enlisted the help of his nephew Pierre M. Irving to help sort through a large trove of journals and written documents about the expedition. The process from start to finish was relatively swift, and the final result, Astoria, appeared in 1835, just one year after A Tour on the Prairies.

Astoria's preface contrasts sharply with A Tour on the Prairies and sets the tone for a wildly different book in terms of its purpose, execution, and relationship to hunting. First, there is no sense of hesitation or insecurity. Irving describes how he became acquainted with trappers and fur traders at a young and impressionable age. He expresses that tales of these "Sinbads of the wilderness" who trapped for furs were "a perfect romance to me" as a child (179). With these childhood memories as well as those from his own tour in mind, Irving seems far more confident about drafting Astor's collection of journals and writings into a cohesive story than he did at the beginning of his prior work. However, if confident and thrilled by the opportunity, Irving also admits to the challenges of the primary materials he relied on to create the story:

As the journals, on which I chiefly depended, had been kept by men of business, intent upon the main object of the enterprize [sic], and but little versed in science, or curious about matters not immediately bearing upon their interests, and as they were written often in moments of fatigue or hurry, amid the inconveniences of wild encampments, they were often meager in their details, furnishing hints to provoke rather than to satisfy inquiry. (180) 
Consequently, Irving experienced a new form of pressure as writer since he wrote from primary resources that demanded that he creatively reimagine and embellish tersely composed business accounts to an attractive, marketable narrative. Too, Irving also wrote about Northwest areas of the country far beyond the geographical scope of his own expedition. As a result, to a certain degree, Irving appears out of his element writing about Astoria. Drawing from a great store of sources with limited anecdotes or stories, Irving had to rely on personal impressions in creating a mash-up work about adventure and business, which he described as "banded together by one grand scheme [Astor's]" (181). Therefore, Astoria often reads as a business-friendly account of John Jacob Astor's ventures, enlivened by Irving's long-heralded sense of romance and adventure more in the spirit of The Sketchbook and Bracebridge Hall than A Tour on the Prairies.

Rushed and writing to benefit Astor, Washington Irving emphasizes business schemes and moments of human ingenuity to a greater degree than individual hunting anecdotes or extended descriptions of the trapping process. He also avoids any of Astor's questionable motives or flaws. For example, Irving credits Astor for imagining such a bold plan to finance an American fur trade company, but historian Eric Jay Dolin notes that Astor sought Thomas Jefferson's approval in an effort to gain advantage against any future competitors (Fur 195). In the process, Astor attempted to deceive Jefferson about his personal ambition to accrue wealth under the guise of expanding the American empire further to the west (Terrell 138-145). Irving deemphasizes Astor's questionable dealings by stressing other possible motivations: "Indeed it is due to him to say that he was not actuated by ... individual profit. He was already wealthy beyond the ordinary desire of man ... [and therefore presumably motivated by] enrich[ing the] nation, peopl[ing] the wilderness, and extend[ing] the bounds of empire" (205). 
As a result, hunters in Astoria most readily appear as adjuncts of a great extractive mission that Irving avoids interrogating. Astor's expedition featured two groups, one land-based and one sea-based, that would travel to the mouth of the Columbia River to what is now the upper northwest corner of Oregon to establish a fur trading post. Irving strenuously attempts to present Astor's employed hunters along the land-based route within the context of America's rough-and-tough, hunter-outsider tradition. He notes that Astor hired bands of American hunters to help keep the land-based group fed with deer and turkey throughout the tougher stretches of the mission, but "also as protection and defence [sic] against Indian hostilities" (292). Writing from a comfortable position in New York, Irving envisions them as “...American hunters, experienced in savage life and savage warfare and possessed of the true game spirit of the West," but it is impossible not envision these men as brute contractors paving the way for later and greater atrocities against Native Americans (292). Irving even goes so far as to contextualize the hunters alongside an octogenarian Daniel Boone, who makes a surprise appearance at Fort Charette along the Missouri River, and celebrates them as perennial American outsiders, "yearly ejected from the bosom of society into the wilderness" (359). Even if there are a few hunting descriptions sprinkled throughout the narrative, the great length of the journey and Irving's need to account for all of it results in the portrayal of hunters as indiscriminating path breakers for future fur traders, settlers, and farmers. In avoiding vivid descriptions of slaughter as he did in $A$ Tour on the Prairies, Irving positions hunters in Astoria as business partners in a path-clearing tradition before the expansion of railroads and subsequent waves of Americans immigrants journeying to the American West.

As Astoria concludes, it presents a critique of the inefficiency of the federal government rather than reflection about what the failure of Astoria meant for hunters, trappers, animal 
populations, or even Astor. Four paragraphs from the end, Irving bemoans the fact that the federal government did not intervene to assist Astor, hence dooming the enterprise. Championing the wisdom of Astor and presumably other businessmen, Irving writes, "In our hands, beside the roving bands of trappers and traders, the country would have been explored and settled by industrious husbandmen; the fertile valleys bordering its rivers, and shut up among its mountains, would have been made to pour forth their agricultural treasures to contribute to the general wealth" (596). Irving ends, as he started, with Astor's point of view. He surmises that all of the effort and industry Astor inaugurated was wasted, and he neglects to reflect both about how much richer Astor would have been with governmental support for his enterprise and about the fact that Astor would recoup much of wealth during the subsequent years.

While writing Astoria, Irving met Captain Benjamin Louis Eulalie de Bonneville, a fur trapper that Astor financially supported, and the author purchased his writings about an 18321835 expedition with the intention of developing them into a follow-up work to Astoria. Irving realized that the more recent events plus Bonneville's personal account and more thoroughly composed journal, in addition to his greater freedom as writer not nearly as indebted to his subject, would allow him more freedom to focus a fur trapping-oriented story. In short, there was an abundance of material with much less at stake. He found, too, that unlike Astor, a "curiosity and his love of adventure" motivated Bonneville's adventures and energized his journals.

However, as in the case of Astoria, Irving chooses to ignore the potential for overhunting or the effects on animal populations for the bulk of the narrative. In the opening chapter, while detailing escalating competitions among fur companies to enclose and claim certain areas of the American West as their own, Irving shows how fur trade business strategy changed from Astor's 1810-1812 time frame by the early 1830s. Instead of relying of heralded American backwoods 
hunters to protect them from Native American violence, rival companies now depended upon Native Americans to help them increase their profits. Irving writes, “The company that can first open the tempting supplies of coffee, tobacco, ammunition, scarlet cloth, blankets, bright shawls and glittering trinkets, has the greatest chance to get all the peltries and furs of the Indians and free trappers, and to engage their services for the next season" (639). The increase in competition and weaponry, though, also made the trapper's lifestyle more prone to violence and danger and necessitated the ability to learn quickly.

Too, as he tells a story of Bonneville's involvement the fur trade without adding many technical details about the process of hunting and trapping and without providing much authorial reflection, Irving seems further and further away from his own experience on the prairies, which arguably prompts the narrative's weaknesses. First, with increased distance, Irving struggles to imagine the tensions between extractive hunting and the realities of overhunting in some areas until the very end of the story. Second, to a greater extent than he did in A Tour on the Prairies and Astoria, Irving resorts to the humor associated with his less serious works. For example, he relates a tale about an Irish man cured of "hunting mania" when he accidentally frightens his own horse away with all of his ammunition (663). Worse, though, Irving appears to mischaracterize the region. Richard Cracroft notes that because of his geographical and experiential distances from the American West at this point, Irving replaces coarse humor associated with West with his own perspective as an "aristocratic gentleman" to an extent that it "...distort[s] the voices of the participants ... [to the degree that] the effect is similar to viewing a foreign film with dubbed-in sound" (37). To a greater degree than the prior two western works, The Adventures of Captain Bonneville suggests a very distanced attempt at sociologically 
unpacking various groups of people trapping in the West, punctuated by picaresque-like tales told with the imprint of Irving's voice from an earlier phase of his career.

There is one great exception, however, in the final chapter, where Irving elucidates his view of the future of trapping and provides his most striking commentary about the dark side of extractive hunting in the nineteenth century for both Native Americans and animals. Here, Irving sets aside humor, adventure, and business-minded rhetoric to present what sounds like an epitaph for the fur trade. Describing the industry that gave "life to all of this portraiture" as "essentially evanescent," Irving adds,

Rival parties of trappers soon exhaust the streams, especially when competition renders them heedless and wasteful of the beaver. The fur-bearing animals extinct, a complete change will come over the scene ... all this romance of savage life, which yet exists among the mountains, will then exist but in frontier story, and seem like fictions of chivalry or fairy tale. (949)

Here, imagining the great changes taking place in the American West and drawing from his knowledge of stories and storytelling, Irving frightfully conveys the reality that the real hunting and trapping in the American West might soon vanish and only reappear in stories of the past. Because of extractive hunting and trapping, Native American lifestyles and animal populations may vanish. Unfortunately, Irving stops far short of condemning the ongoing effects related to full-scale, self-destructive enterprises that accompanied American expansionism. For example, the United States Government's establishment of "Indian Territory" only a few years before in 1830 pioneered the removal and deaths of thousands of Native Americans en route to western areas that would later be redefined for "unhindered expansion" (Maddox 7). Too, it seems inevitable that the American West must change. In the final paragraph, Irving suggests that 
without animals to hunt or trap, the entire region could become more desolate and dangerous than before, and he proclaims a need for a more militarized force to protect traders travelling toward the West Coast. By rendering Native American life and hunting and trapping in the west as archaic, Irving regrettably avoids reflecting too deeply about the environmental costs or potential measures to reestablish and support animal populations following the damages of extractive hunting and trapping. In short, he either avoids or else misses an opportunity to critique the sometime damaging nature of unchecked, venture capitalism that would decimate animal and Native American populations, and in a short amount of time, would relocate its focus to American slavery and land (Hyde 20).

\section{Conclusion}

Given the way that Washington Irving wrote about hunting earlier in his career, his final two western works are disappointing in the way that they fail to address the costs of hunting as an extractive industry. In his earlier journals and in The Sketchbook, Irving demonstrated how hunting for leisure impacted the lives of his rural New York characters, and with Bracebridge Hall he charted how aristocratic hunting culture in England contrasted from American hunter's lives. With A Tour on the Prairies, Irving reached his pinnacle of outdoor writing by detailing via participation within a culture of hunting for sustenance. He came face-to-face with realities of big game hunting, and perhaps due to his maturation, life experiences, and/or his final buffalo hunt, lost interest in envisioning hunting as a sustainable practice. If he had hunted small game and deer and theorized hunting as a legitimate leisure activity before his western journey, his tour and later writing about the West altered his perspective. Personally, he became distanced from hunting and more interested in settling back into American and fostering and maintaining 
personal allegiances with figures such Astor and Bonneville whose exploitative fields of work in time produced grave side effects.

In losing his own connection to hunting, Irving lost much of his interest in questioning the role of the individual hunter's relationship and responsibility to the land, a theme more consistently considered by his occasional rival James Fenimore Cooper in The Leatherstocking Series (1823-1841). Yet, in the great breadth of his hunting writings, Irving laid the groundwork for recurrent human-animal conflicts that would occur throughout the next two centuries. Too, although he seems to have walked away from hunting, his interest may not have completely vanished because during the late 1840s Irving added the aforementioned postscript to "Rip Van Winkle" that helped emphasize Native American hunting beliefs as important to the story. Also, during the 1850s, Irving would again explore the importance of Native American legends in certain landscapes in upstate New York; as Aaron Sachs notices, he was still "particularly optimistic" about the potential impact of landscapes and outdoor experiences on the human imagination (105-6). These later thoughts would stem from Irving's return to both the landscape and stories of his youth. However, there would be virtually no more explication about hunting. Irving's sojourn revised his interest and perspective, as he lost something out on the American prairies, coincidentally the final resting place of the nineteenth century's most famous fictional hunter, Natty Bumppo. 


\section{Chapter Two:}

\section{'Longing for Motion and Chase': Human-Canine Relationships in James Fenimore Cooper's The Leather-stocking Series}

During a reflective moment in The Last of the Mohicans, a novel celebrated for its actionpacked plot structured around several chase sequences, James Fenimore Cooper's Hawkeye, around a fire, in the midst of other men, and following a meal of dried bear's meat, expresses his idea of what an afterlife might look like: "I have heard preachers say, in the settlements, that heaven is a place of rest. For myself, and I say it with reverence to the ordering of Providence, it would be no great indulgence to be kept shut up in those mansions of which they preach, having a natural longing for motion and the chase" (692). If Hawkeye's statement asks readers to consider what their ideal afterlife might look like, it also advances the idea that motion and movement are central to human life.

For James Fenimore Cooper's Natty Bumppo, the ideal form of motion and chase meant going hunting alongside a canine companion. Cooper's hero defined his persona in part on his love of the sport, and his prowess inspired a host of admirers within The Leather-stocking Series, as well subsequent generations of real-life hunters. Indeed, many present day American hunters celebrate movement and motion in open fields or scarcely traversed woodlands, and some of them still define the hunt as an outdoor event that depends on the presence of a hunting dog. Within the American literature canon, no literary character made hunting more popular, although stories associated with the accounts of historical figures such as Daniel Boone and David ("Davy") Crockett may exceed The Leather-stocking Series in terms of their lasting influence in popular culture. Nowadays, hunting may be more likely to garner Cooper's hero an extra layer of 
criticism in college literature discussions. Yet to bypass or dismiss the importance of hunting in regards to Bumppo is a mistake, especially since the way he hunts alongside cherished companion animals provides a window into understanding the enrichment of his life, the formation of his personality, and the basis for some of the subsequent and enduring humancanine stories.

This chapter explores the roles of companion hunting dogs in Natty Bumppo's life throughout The Leather-stocking Series, and it charts the complicated nature of the humancanine bond within the context of hunting. Writing amidst great cultural changes during the first half of the nineteenth century, Cooper adopted a romanticized sentimentalism that still appeals to us today - if not so much in fiction then certainly in the forms of photographs or short videos that try to capture what animals are in thinking in response to our world rather than a shared world. Yet, couched within Cooper's broader sentimentalism, some of his writing about Bumppo's relationship with his hunting companions bears stronger traces of poignant realism. Bumppo's companions are steady throughout his lifetime and they support him until the moment of his death. Throughout a series of five novels, Cooper captures the complex ways that hunting dogs impact Bumppo's social and emotional life, honors how canines enhance the hunting experience for generations of rural men and women, and inspires the writings of twentiethcentury authors such as William Faulkner ("The Bear"), Fred Gipson (Old Yeller) and Wilson Rawls (Where the Red Fern Grows).

I argue that Cooper was especially attuned to the human-canine interaction throughout the majority of The Leather-stocking Series (1823-1841). During two of the first three novels, The Pioneers and The Prairie, he depicts the roles of companion animals during Natty Bumppo's later years. Although this focus appears largely set aside in The Last of the Mohicans, Cooper 
continues to write about how Bumppo's understanding of animals and thoughtful interaction with the animal world enables smarter, safer decisions in treacherous frontier areas. Dogs also factor in the final novels in the series, The Pathfinder and The Deerslayer, where Cooper becomes more fascinated with how anthropocentric romance, greed, and self-interest threaten to sever human ties with the animal world. In these two books, Natty Bumppo's experiences with his dogs help him to define himself amidst one major instance of emotional turmoil (The Pathfinder) and several encounters with the self- and environmentally-destructive presences of others (The Deerslayer). Altogether, The Leather-stocking Series demonstrates how Natty Bumppo’s hunting companions help co-shape his experiences and impressions, which-in addition to Native American lore and his faith—help him develop a deeper sensitivity to animals within the frontier forests and prairies, formulate a more intimate understanding of the natural world, and strengthen and espouse his viewpoint as an environmental steward.

\section{Animal Studies: Donna Haraway}

In developing this chapter, I rely upon the animal studies theory of Donna Haraway, who became famous in scientific, philosophical, feminist and literary circles for her essay " A Cyborg Manifesto." One of Haraway's major ideas is the illusoriness of the concept of an autonomous, human self. She cites the "self/other" dualism as first among a list of other dualisms that perpetuates domination of "all [other living things] constituted as others," including "people of color, nature, workers, and animals" (177). To Haraway, the idea of that individual freedom can be untangled from other living things is merely a façade. This assertion is valuable to discussions about hunting literature because scholars often position the hunter figure within American literature as symbolic of a human-centered conquest over nature, or as an extreme emblem grounding human-animal or human-nonhuman dichotomies. Haraway does not directly address 
hunters or animals extensively in her early criticism, but she calls attention to the faultiness of a human self versus others paradigm in regards to animals, an idea she would explore in some of her later works such as The Companion Species Manifesto: Dogs, People, and Significant Otherness (2003) and When Species Meet (2008).

In The Companion Species Manifesto, Haraway refines the focus of her work to humans and companion animals, and she argues that humans throughout the past centuries have coevolved with them. Specifically, she argues that people should think about animal others in terms of relationships. Pointedly, she writes, "subject, objects, kids, races, species, genres, and genders are the product of their relating" (The Companion 7). Here, Haraway destabilizes our feigned hierarchical position by suggesting that as we develop alongside companion animals, they "coshape" the rhythms and experiences of our lives. In theorizing interactions rather than conflicts, Haraway carefully advances the plight of animals without evoking or engaging directly with polarizing animal rights discussions popularized in the 1970s and 1980s by Peter Singer and Tom Regan. She bypasses debates often characterized by sharp back-and-forth rhetoric in The Companion Species Manifesto and in her follow-up work, When Species Meet. Haraway implores scholars to reconceptualize how they view companion animals throughout the arts and within human lives. She also extends an invitation to look closer at the ways that they have coshaped the lives of people in prior eras, even those that may seem less sensitive to the plights of animals. The interaction among hunters and their dogs is the paramount example of humananimal co-shaping in American hunting literature, and its literary significance begins with the life of Natty Bumppo.

James Fenimore Cooper's The Leather-stocking Series (1823-1841) 
Nineteenth-century readers flocked to The Leather-stocking Series for James Fenimore Cooper's memorable character Natty Bumppo and for the author's adventure-filled, semihistorical recreation of early American life, often along the borders between undeveloped woodlands and encroaching settlements. Yet toward the latter half of the nineteenth century, Cooper's work began to lose favor among successive generations of writers. Following the Civil War, for instance, American writers such as James Russell Lowell, Bret Harte, and most famously Mark Twain ridiculed Cooper for wooden prose, flat characters, repeated lines or phrases, and lapses in logic and plotting (Tomc 142). Later during the next century, modernist and postmodernist literary movements deemed some traditional forms including the sentimental and the historical novel, with their formulaic echoes of one grand narrative, as problematic, and in some cases, obsolete. As a result, Cooper's work waned in popularity among literary scholars and his readership decreased. However, a couple of his novels, The Last of the Mohicans (1826) or The Deerslayer (1841), remained in American high school literature curriculums in some parts of the country through the 1970s. While Cooper sometimes romanticized portrayal of social changes occurring in the United States mars his work, his emphasis on the ways that successive phrases of people living near civilization's borders contributed to the evolution of the United States remains culturally relevant, especially since borders (and, in particular, what transpires within and around them in regards to immigration) continue to generate fiery debates. If they still remain far less popular than they once were for a general readership, The Leather-stocking Series still provides much fodder for environmental and human-animal studies.

The Leather-stocking Series perches precisely at the intersection of scholarly interest in both ecocriticism and human-animal studies. Cooper's foremost biographer and scholar Wayne Franklin, for example, describes The Pioneers (1823), the first novel of the series, as "a 
beginning point of environmental consciousness" (James xxviii). Indeed, throughout The

Pioneers as well as the remaining four novels, Cooper interrogates land and natural resource use and their impacts on people's lifestyles similar to how politicians and scientists now debate the effects of natural resource development and global warming. For this reason, the passages from The Pioneers that most directly express environmentalist-oriented themes are currently the bits of Cooper's work most likely to be anthologized. Additionally, though, some of Cooper's ideas regarding animals are also worthy of consideration, and his extended portrayal of human-animal relationships in relation to hunting remains absent in the fields of ecocriticism and human-animal studies. Interdisciplinary work between the two scholarly fields remains underdeveloped, but scholar Catriona Sandilands notes that one mutual area of concern is interaction among humans and animals in direction relation to interspecies violence. She describes closer analyses of these moments as promising "of renewed ontological connection in a multispecies, multiagential universe" (90). In other words, situations of human-animal violence merit discussion from a range of critical discourses, including ecocritics and animal studies scholars, as well as scientists and post-humanists. Texts such as The Leather-stocking Series that reveal complex portrayals of human-animal interactions as well as violence provide a great starting place for considering human-animal relationships in conjunction with environmental studies in American literature.

\section{The Pioneers (1823)}

In The Pioneers, Cooper depicts Natty Bumppo's emotional development as deeply entangled with conflicts about hunting and his dogs. In the opening scene, Judge Templeton and several others are returning to the Templeton settlement late in the day on Christmas Eve, 1793. They are about a mile from the settlement when suddenly, the Judge hears a familiar voice: "Hold up, Aggy there is old Hector; I should know his bay among ten thousand. The Leather- 
stocking has put his hounds in this hills this clear day, and they have started their game" (18).

With the intention of profiting from Bumppo's hunt, Templeton asks his servant to stop while he attempts to shoot a deer crossing their path. The resulting scene features a deer carcass, a wounded human (Oliver Edwards, Natty Bumppo's companion), and a lengthy argument about who actually shot the deer. For modern readers and hunters, it sparks a debate about the ethics of seeing and shooting animals from a road, and it also encourages discussions about proper hunting etiquette, weaponry, land ownership, and hunting rights.

An important part of the scene that gets lost in the midst of the dramatic chase, injuries, and arguments is the way Natty Bumppo appears and how he understands his dogs, referred to as Hector and the slut. Elizabeth notices that Natty is "lank" with a "skinny face ... thin almost to emaciation ... [yet] of the most robust and enduring health" (21). Cooper announces here at the beginning of the novel that Bumppo is older, roughly in his seventies. When Judge Templeton wishes to claim the buck's tail, eager to one-up his cousin Richard "Dickon" Jones (who has returned disappointed during his prior seven hunting attempts), Bumppo complains about how the clearing of woods for housing and farms has contributed to the decline in game in the areas surrounding Templeton. Bumppo implies_-via a contrast imagined through his dog Hector's perspective - that Templeton and his adherents do not understand the balance of nature. Bumppo states, "There's old Hector...the dog is to be more trusted than many a Christian man; for he never forgets a friend, and loves the hand that gives him bread" (20). On the surface, this comment characterizes Bumppo's close relationship with Hector, whom he positions as nearer to him than other humans, but this human-canine understanding also conveys Bumppo’s increasingly resigned countenance toward his New York home. He implies that Hector comprehends something that Judge Templeton does not— that the abundance of Bumppo's 
preferred food (wild game) that the hinterlands afford depends on a perceptive understanding and interaction with both land and animal. Of course, Judge Templeton, though he does not counter this particular comment, holds his own notions of food production in the form of agriculture, and so Bumppo's point seems lost as a cantankerous aside. However, the way Bumppo conveys his idea shows even from the beginning of the novel how his conception of a human-animal relationship, developed throughout his years, helps him better understand both companion animals and land use.

For Donna Haraway, these small moments of communication between humans and nonhuman species are integral for people to better understand their relationships with nonhuman others. She writes, "response and respect are possible only in ... knots" formed through interactions that affect future understandings of both the human and the companion (When 43). By extension, as well, they have the potential to inspire greater appreciation for the natural environment, since the human degree of consideration for it depends upon deeper conceptions of where and how we fit. Judge Templeton is so enmeshed in the human-designated material emblems of success and the charming appearance of an expanding village that he holds a severed relationship with the natural world. Materialistic visions cloud his ability to comprehend not only the interests of other humans living at the edge of society, but also the animals that support those people. Instead of responding Bumppo's opinions, he proposes a wager before they determine who killed the deer and, in the event that he loses, he offers to pay three dollars for it. A bit later, the only thing that deters Judge Templeton's sense of urgency to claim the deer is the embarrassment he feels upon realizing that he shot Oliver Edwards instead. Though few people revere Bumppo, many others view Templeton as a person of authority because of his material prosperity and community influence. However, despite his leadership position, Templeton lacks 
the capacity to form a relationship like the one that Bumppo shares with his dogs. His life experiences prevent him from conceiving of the natural world beyond its use in helping to building a human community, and because he does not think about other nonhuman species beyond their worth in reaffirming his authoritative position, Templeton's influence in shaping the community is potentially ecologically destructive.

Bumppo's and Templeton's understandings also clash later in the novel when an out-ofseason hunting incident sparks a string of events that lands Bumppo in jail. As Bumppo, Oliver Edwards, and their companion John Mohegan are fishing, they see Hector and the slut chasing a deer that jumps into the water. At first, Bumppo attempts to end the chase, muttering, "the buck has gone by them with the wind, and it has been too much for the poor rogues; but I must break them of these tricks or they'll give me a great deal of trouble" (299). Natty gets the dogs to stay ashore, but as the buck approaches the fishermen in water, he, like his dogs, falls into the temptation of chasing the buck, thinking "Let me see-July is the last month, and the flesh must be getting good" (299). Then, Cooper writes that Bumppo "instinctively" prepares the canoe for a chase (299). As he and Mohegan move toward the deer, Bumppo again briefly considers whether or not to participate in the hunt begun by his dogs. He thinks aloud, "Shall I, John, or no?" before John laughs and hastily moves the canoe in the deer's direction (300). Cooper shows that at this moment in his life, Bumppo and Mohegan hunt alongside the dogs, and that on occasions such as this one, their feelings are remarkably similar to the dogs.

Later events - a warrant granted by Templeton to search Bumppo's cabin for deer remains and Bumppo's violent resistance_-place Bumppo in jail after a deep disagreement between Bumppo's and Templeton's diverging conceptions of law. This string of consequences that develop over multiple chapters from the original incident downplays the initial empathy that 
Bumppo feels for Hector and the slut as they chase the buck and his own similar, instinctual reaction to become a part of the chase. Although there are other moments in the series where Bumppo remains more prudent about observing the balance of nature and not taking what he perceives to be an unfair advantage, Bumppo here cannot resist continuing the hunt begun by his dogs. Seeing their chase ignites his desire to continue the hunt as much as the eager John Mohegan, who pushes the canoe in the direction of the deer.

Cooper implores readers to consider how hunting may include its own small community of hunters, dogs, and wild game, and how this community ethos may be different from that of a pioneer settlement. Donna Haraway notes that looking at the fine details within social, cultural, and animal contexts help to comprehend the relationship of "actual beings to actual responseabilities," or how what people believe and are capable of doing influences their response (“Awash" 312). On the one hand, Cooper asks readers to consider the potential wrongs of hunting out of a government-established season or hunting without ecological balance in mind. However, he also shows the way that human emotions sometimes intertwine with animal instincts to the point of overcoming the rationality of a human community. In short, animal instinct and adherence to a soon-to-be-passing way of living govern Bumppo in this scene. Bumppo's initial response to the baying of his hounds is to discourage their chase, yet his wavering and brisk retreat from this position stems from empathizing with his dogs more than other humans, excepting John Mohegan, who feels the same way. When Oliver Edwards yells to Bumppo, "Hold! ... Remember the law, my old friends. You are in plain sight of the village, and I know Judge Temple is determined to prosecute all, indiscriminately, who kill deer out of season," it remains unheard, because Bumppo is more mentally and physically in tune with his dogs (300). Pointedly, as they ignore Edwards's words, Cooper notes that Mohegan and Cooper 
move toward the deer speaking an entirely different language (Delaware). If all of the conflict that follows obscures this scene and kick-starts the novel's late plot, this scene at Otsego Lake is the crucial moment when Bumppo aligns himself with his dogs and Mohegan rather than the lawful policies of the community that approaches him.

The greatest realization for Bumppo following the consequences of the illegal hunting incident is that he, Hector, and the slut no longer belong near Templeton once John Mohegan passes. The future of the town depends upon notions that Bumppo finds too troubling so long as he and the dogs are able travel to other more amenable areas; he voices this perspective to Oliver Edwards and Elizabeth Templeton just before leaving: "I love the woods, and ye relish the face of man; I eat when hungry and drink when a-dry, and ye keep stated hours and rules; nay, nay, you even overfeed the dogs, lad, from pure kindness; and hounds should be gaunty to run well" (463). Despite his age, Bumppo perceives that he, Hector, and the slut have many remaining hunts, and as he disappears with his dog at the end of the novel, we are left to the ponder the strong desire for the chase that would inspire someone Bumppo's age to head much further west from his lifelong home in New York. By considering the hunting incident from Bumppo's perspective and with his animal companions also in mind, one can imagine that his departure is more complex than simply the action of mythic American individualist absconding further away from civilization. Bumppo's decision suggests that the quality of the lives of Hector and the slut matter as well.

\section{The Last of the Mohicans (1826) and The Prairie (1827)}

In The Last of the Mohicans, Cooper's second novel in the series, Natty Bumppo is thirty years younger and spending much less time hunting in a story associated with the French and Indian War in 1757. Cooper published the novel in two halves, with each part detailing one 
lengthy chase sequence within the war (Barker and Sabin 17). This was a marked departure in terms of offering a much faster and more immediate plot than The Pioneers, and the nature and intensity of the story influence Bumppo's thoughts and actions throughout the novel. For example, Cooper focuses less on hunting adventures or community formation than on the recovery of captured people in danger, thereby creating a more action-packed novel.

Importantly though, Cooper introduces a dominant theme of reading wilderness areas, and how this necessitates interaction with animals and eventually a deeper understanding animal behavior. Here, Hawkeye acts more overtly as a teacher of Native American knowledge in his actions rather than as older sage providing instruction through reflection. Some of the novel's excitement stems from the potential dangers lurking in the woods as Hawkeye attempts to guide a group through the wilderness. Although there is an absence of hunting scenes alongside dogs in this novel, Hawkeye and Chingachgook both employ their knowledge of animal behavior and embody animals to assist their mission to rescue two women and to track and elude their captors. Through Hawkeye's instruction, Cooper shows readers the usefulness of woodcraft and animal knowledge when lives are at stake. To strengthen this theme, Cooper introduces David Gamut, a music teacher who must learn from Hawkeye in hopes of navigating the wilderness and helping the rescue party.

Three scenes from The Last of the Mohicans display the way Cooper envisions how understanding and interacting with animal behavior facilitates safety. The first situation involves the murder of David Gamut's foal as Hawkeye, Chingachgook, and Chingachgook's son Uncas attempt to lead four travellers to safe location. As the first abrupt killing in the novel, the scene seems like an extraneous act of savagery, but it sets the tone greater threats in the novel, and it also shows how a domesticated animal could become dangerous in a wilderness area. Hawkeye 
fears that the foal's loud or abrupt noises might make the group's presence known to their pursuers, so his party kills it. In the second situation, Hawkeye dons the skin of a bear to get closer to the captured members of the party. After it is safe for him to fully reveal himself as human, Hawkeye remarks, "I should be but a poor scholar, for one who has studied so long in the wilderness, did I not know how to set forth the moves and natur of such a beast!” (769). Finally, in a separate scenario, Chingachgook disguises himself as a beaver within a "little artificial lake of the beavers" near the pathway that their nemesis Magua and his warriors take en route to a Delaware camp to retrieve their lost prisoners (799). As Magua, dressed as a fox, and his men pass by, one of them who identifies with the beaver, pauses and makes a speech of thanks to beavers. When Chingachgook responds to the warrior, the latter interprets it a “favourable omen" and the group proceeds (800). Shirley Samuels explains that both Hawkeye and Chingachgook transform themselves by adopting the "skin of another species in a manner that challenges species distinctions" (98). Too, though, these transformations also suggest that Cooper envisioned the blurring of the human-animal boundary as a means of not only survival, but also as a form of human thinking, living, and expression. As the two heroic characters with a great amount of knowledge of the wilderness, Bumppo and Chingachgook understand and convey to readers how animal behavior both threatens their safety and enables their survival in treacherous situations.

In The Prairie, Cooper picks up where his first novel left off with the elderly Bumppo and he again writes more about human-canine interaction. For a variety of reasons, including Bumppo's age (80s), his priorities, and the novel's setting, dogs are more centrally involved in the story than in any of the other novels in the series. Though they serve multiple purposes, Bumppo's dogs help solidify an idea that would become prominent throughout children's 
hunting literature in the twentieth century: the seemingly extrasensory ability of canines to help humans ensure their own safety amidst the dangers that accompany an active hunting life. In a sense, The Prairie is Cooper's ode to Bumppo's relationship with his dog Hector. In this novel, he characterizes Bumppo and the dog as equals, and Hector as more intelligent and capable than other humans within the vast, open prairies. As Bumppo ages, safety and sound sense are the most important things that he holds onto, and he depends more than ever upon the aging Hector for support and companionship. Hector's dependability, after years spent alongside Bumppo, is so strong that Cooper argues he is a more qualified and helpful living thing to Bumppo than any other character in the novel, including the scholar and naturalist Dr. Obed Battius.

In writing about the relationship between Hector and Bumppo, Cooper suggests that the human-animal hierarchy easily collapses in situations where companion animals are more knowledgeable and trustworthy than other humans. In other words, there are moments when humans thrive (or survive) because the mutual love and devotion of companion animal fosters an extraordinary sense of protection when other forms of human companionship will not suffice. Nowadays, videos of companion animals protecting other companion animals, children, and adults from harm attempted by other animals are easily found online; in Cooper's world, the same general intent appears. With his portrayals of Hector and Dr. Obed Battius, Cooper depicts this tension acutely, and so much that Bumppo's companion Hector is actually an integral part of Cooper's collective narrative foil for the human Dr. Obed Battius.

Scholars typically characterize Battius as a foil for Bumppo or as comic relief. Donald Ringe points out that Battius's name suggests his "intellectual blindness," even though the greater class of formally educated naturalists he represents step into the natural world with a "new attitude toward nature" that, with an emphasis on the power of the human scientific reason 
and its associated cataloging and documentation of the natural world, abrasively squelches the form of human-environment relationship that Bumppo espouses - rooted in faith, observation, reverence, memory, and storytelling (28-29). Separately, in a critical introduction to the novel, Domhnall Mitchell identifies Battius as "comic relief and a satirical target" saddled with a form of dogmatism that separates him from "physical harm and perhaps relevance" (xi). Mitchell's greater point is to liken Battius with a similar comic character from the series, David Gamut from The Last of the Mohicans. However, while their befuddled or clumsy natures are noticeably alike, the way that Battius functions in conjunction with Bumppo and Hector gets lost by focusing too much on parallels to David Gamut.

When Bumppo disappears into the forest, bent upon heading west at the conclusion of The Pioneers, he leaves behind friends concerned about his age. When Judge Temple's daughter Elizabeth Effingham's parting plea to him is, "For my sake, if not your own, stay. I shall see you, in those frightful dreams that still haunt my nights, dying in poverty and age, by the side of those terrific beasts you slew. There will be no evil that sickness, want, and solitude can inflict, that my fancy will not conjure as your fate. Stay with us, old man; if not for your own sake, at least for ours" (463). When he resurfaces to readers in The Prairie, his health is already waning. Making it to the prairies from New York state would have been no easy feat for Bumppo, and the novel's extensive and continuous meditations about his age convey Cooper's idea that Bumppo's greatest foe — now that he has triumphed over an amazing multitude of life-threatening challenges - is finally the deterioration of his own body.

This decline in Bumppo's body and mind is somewhat matched by a decline of Hector's as well, although Bumppo is more reliant on his companion than ever before. Donna Haraway describes the difficult necessity of two aging companions (herself and her dog Cayenne) 
supporting one another in an essay. She describes the consequences of cross-species kinships by observing that the stress she felt upon realizing the complicated history of a drug she was administering to her dog for its urinary issues was causing her own health to suffer ("Awash" 303). If Haraway's essay frankly depicts the emotional worries that accompany an aging humancanine relationship within a society that too-readily peddles drugs as health solutions, Cooper's novel captures a similar emotional tension within an unfamiliar and bleak setting that offers little future promise for either Bumppo or Hector.

Both Haraway and Cooper probe at how cross-species companions react in the face of the frailty of the flesh. Near the beginning of the novel, when bee hunter Paul Hover first comes into contact with Bumppo and Hector, he realizes that the latter is creeping towards him. When he asks Bumppo to call his dog back, Bumppo replies, "Come hither fool. His growl and his bark are all that is left him now; you may come on, friend; the hound is toothless" (910). Like Haraway, Cooper articulates the rhythms of passing lives between companions, and the possibility of Hector's death before his own weighs heavily upon Bumppo. In one of the more surprising moments in the novel, Bumppo meets Captain Duncan Uncas Middleton, the grandson of Duncan and Alice Heyward from The Last of the Mohicans. Middleton's appearance surprises Bumppo, who is equally as happy to realize that the dog alongside Middleton is Hector's descendant. Bumppo exclaims, "do you hear that, Pup? Your kin and blood, are on the Prairies!" (1007-8). A portion of his excitement stems from the fact that Hector's lineage continues even though Bumppo's own does not. As Hector befriends Middleton's dog, this thought gives the aging trapper a small bit of relief from the prospect of passing before his companion.

While alive, though, Bumppo depends upon Hector for the dog's senses to the dangers of the territory, and these uncanny abilities lead Bumppo to the conclusion that Hector is more 
alert, sensitive, and in tune with the environment than naturalist Obed Battius, his counterpart. Commenting upon his declining sense of smell and hearing loss, Bumppo says, "There are both scents and sounds in the air, though my miserable senses are not good enough to hear the one or to catch the taint of the other." (1101). Hector helps Bumppo's declining senses by warning of him of danger, yet Dr. Obed Battius downplays the power of a human-canine bond. Battius's frequent errors are a source of humor in the novel, but Cooper also suggests that close companion animal sense may provide something more immediately helpful than the scientific method. The pinnacle debate regarding this issue occurs in the ninth chapter when Bumppo directly challenges Battius to a test against Hector to figure out what living thing is approaching them. Battius is indignant: "Do you pretend to oppose a dog to man! brutality to learning! instinct to reason! ... In what manner, pray, can a hound distinguish the habits, species, or even the genus of an animal, like reasoning, learned, scientific, triumphant man!" (996). Bumppo then refers to a crackling of twigs and asks Battius to name the animal, which he is unable to do. He then turns to Hector and the dog listens and then signals back to him that it is a human. Here, Cooper shows that the relationship between Hector and Bumppo enable them to generate knowledge beyond the scope what Battius's can learn through science. Though Cooper depicts this tension most vividly in this scene, there are other moments throughout the novel where Cooper portrays Hector and Bumppo's collective interpretation as a much more reliable barometer for taking appropriate safety measures than Battius's observations. Unlike the psalmodist David Gamut in The Last of the Mohicans, to whom Battius is sometimes compared, Battius represents a more direct threat to Bumppo's way of life and interpretation of the natural world, which at this point in his life, is more contingent upon Hector's observations and communications than ever before. 
There is evidence, too, that suggests Bumppo's greater philosophy about the environment derives in part from his interactions with Hector. When squatter Ismael Bush suggests that Hector is old and that Bumppo should kill him out of mercy, Bumppo expresses that the collected accumulation of his and Hector's wisdom is far more valuable at the current moment than their lack of good health, speed, and efficiency. Offering a counterexample to illustrate this point, Bumppo cites the fury of "Yankee woodchoppers," whose pace and destruction, if not tempered, will lead to environmental collapse (963). Here, Bumppo implies that his environmental views are based on how his relationship with Hector helps him realize that a greater appreciation of living things outside of himself. From living and hunting with Hector, Bumppo hones his ideas of a long-term commitment toward observing and conserving the natural world. As a byproduct of this realization, Bumppo values animals to a greater degree in The Prairie than other novels in the series.

Cooper also reveals that Hector affects Bumppo's viewpoint by juxtaposing the ways that Bumppo and Battius conceive their experiences with animals. Simply put, Battius remains more interested and successful at interacting with the remains of dead animals. For example, at one point in the novel he fails to recognize his donkey, the closest living animal that assists him during the journey; and he remains on the prowl for new specimens to identify throughout the story, even in the midst of great danger. Conversely, to capture and attempt to preserve a deceased specimen of an animal without using it for food is, from Bumppo's perspective, a great travesty. In response to a conversation where Paul Hover recalls his first meeting with Battius, when the latter possessed a "crawling museum," or a bag of specimens, Bumppo rails vehemently against the misuse of the nonhuman animal world: "They slay the buck, and the moose, and the wild cat, and all the beasts that range the woods, and stuffing them with 
worthless rags, and placing eyes of glass into their heads, they set them up to be stared at, and call them creatur's of the Lord; as if any mortal effigy could equal the works of his hand!" (9912). In criticizing taxidermy, which some modern hunting enthusiasts consider a noble art, Bumppo invokes his Christian beliefs, but he simultaneously casts a vote for the idea that the mutual benefits of interacting with animals are greater than what might be gleaned from the scientific gaze. Perhaps the greatest critique of figures like Battius occurs when the Sioux capture him later in the novel and ridicule his habit by attaching "sundry toads, frogs, lizards, butterflies, etc." to his hair (1224).

Bumppo's position against the idolatry of animal carcasses and his emphasis on living, breathing, and moving interactions with the animal world are important when considering his final requests and death. The first thing that Natty asks before Captain Middleton leaves him toward the end of the novel is that he let Hector's companion pup remain with them throughout the winter, when he expects that Hector will pass. In contrast to the ending of The Pioneers, this time Bumppo stays behind as others leave him, but Hector and the pup move around him offering companionship. Later, when Bumppo approaches death and cannot see anymore, he does not realize that Hector passes before him. As he sits in his final resting chair, the Pawnees place a stuffed Hector at his feet, but he soon realizes that it is merely an imitation of his companion. When he tells Middleton that he realizes Hector is dead, Bumppo also expresses his final request, that Hector be buried beside him: "A hunter need never be ashamed to be found in the company of his dog!" (1314). This line captures the way that Bumppo imagines Hector as integral to development of his life, and he calmly approaches death imbued and comforted by his memories and love for his companion. As Cooper poignantly concludes Bumppo’s life by 
aligning it with the passing of his cherished companion, he articulates his clearest exhortation of the power of the human-canine bond in The Leather-stocking Series.

\section{The Pathfinder (1840) and The Deerslayer (1841)}

Thirteen years passed before Cooper wrote his final two Leather-stocking novels, and he returned to the series a more mature author, having composed nine additional novels and various political and travel writings inspired by years of living as an expatriate. The first of the two new Leather-stocking stories depicts Bumppo during his middle years in his thirties (The Pathfinder) while the other (The Deerslayer) shows him at his youngest moment in the series, roughly during his twenties. Bumppo's hunting dogs also appear in both novels, functioning in a larger capacity than in The Last of the Mohicans, but in more diminished roles than in The Pioneers or The Prairie. Here, they help shape Bumppo's life and help explain why Bumppo forms deeper bonds with them as he ages. Moreover, despite brief appearances, they assist Cooper as he wrestles with exploring the limitations of human self-interest, a dominant idea in both novels. In bringing human desires and potential romantic entanglements to the forefront, Cooper takes a harsher stance on individual self-interest, positing that human-canine companionship can substitute for human romance in The Pathfinder and that hurried chase of romance and wealth devoid of concern for the natural world is an empty pursuit in The Deerslayer. .

Along with The Prairie, The Pathfinder is generally the least discussed novel in the series, partially because Cooper devotes so much of it to the idea of Natty Bumppo falling in love, a narrative move that seems odd, especially since Bumppo appears resolutely single throughout much of the series. Yet, it is precisely because Cooper shows Bumppo's attraction to another person that this novel blurs the line between human and animal more than any of the others, as we see his hero fumbling about with the idea of being in love and implicitly coming to 
a conclusion — and one that will guide the remainder of his life — that dogs are and will remain his closest living companions.

The novel is akin to other nineteenth-century novels that display potential partnerships that fail because the pair is too poorly suited to overcome individual circumstances and dispositions. Near the beginning of the novel, Sergeant Dunham talks with Natty Bumppo about inviting his daughter Mabel to the frontier outpost with the hope that she and Bumppo might marry. At this point, Bumppo is resistant, seeing himself as nearer to an animal than a civilized human upon reflection about his lifestyle. He responds to Sergeant Dunham's reasoning for the marriage: "We did agree that if Mabel should prove what you told me she was, and if the girl could fancy a rude hunter and guide, that I would quit some of my wandering ways, and try to humanize my mind down to a wife and children" (134). Here, Bumppo insinuates that he must become more human in mind in order to ever accept the social arrangement of marriage and all of its responsibilities. He views himself as wild and animal-like in his predilection to roam and subsist when contrasted with the expectations of modern American society. Cooper positions the clash between the benefits of domesticity and a family life with the freedom of the roving the woods unencumbered by possessions as a means to delineate the difference between becoming "humanized" versus aligning part of one's self with the animal world to attempt to live physically and emotionally in tune with the nonhuman world.

Cooper elaborates more upon stakes of the human-animal divide as Bumppo's romantic feelings for Mabel Dunham appear, and he begins to rethink his initial reluctance to marry. As Bumppo considers himself as separate from Mabel Dunham's society, the narrator notes while observing his endearing qualities that others notice that "the most surprising peculiarity" about Bumppo is "the entire indifference with which he regarded all distinctions that did not depend on 
personal merit" (139). In his rustic form, Bumppo appears to eschew all forms of social contrivances that differentiate social classes within a modern America. While he temporarily imagines marriage to Mabel as a step toward humanizing himself, others see that Bumppo's sense of personal merit stems directly from his engagement with the nonhuman world. What defines Bumppo, in other words, is what he must forsake to marry Mabel. Consequently, the marriage cannot work unless Bumppo changes in a way that would alter his identity and the series, and so Cooper depicts what happens to Bumppo as he falls deeper in love with a woman destined to become a merchant's wife. The conversation with Sergeant Dunham plants a seed of potentially marrying within Bumppo, and over the course of time he becomes smitten with the idea and Mabel. At one point, he utters the possibility of changing his lifestyle as a means of inviting her own affection: “...though it is time that I did begin to think of a house, and furniture, and a home" (186). This moment is one of a few near chances where it seems that Bumppo could alter his lifestyle, but he equates it with materialism. Bumppo awkwardly looks and speaks out of character with keen interest in "know[ing] whether she were listening, and what was the expression of her countenance" (186). Unsurprisingly, Mabel is oblivious, with no thought of ever becoming Bumppo’s love interest, much less his wife. Cooper shows his hero moving outside of his comfort zone into a social realm that he does not understand well. The dynamic reader and interpreter of the woods in The Last of the Mohicans appears functionally illiterate in the art of proposing love to a woman with modern values in The Pathfinder.

Read beyond the failed romance, and with more consideration given to animals, The Pathfinder demonstrates how human self-interest can blind us to the natural world around us. Bumppo continues in an agonizing pursuit of Mabel Dunham throughout the course of the novel despite what reason reminds him and against other odds, including age differences and the 
presence of a better suitor. Pointedly, his thoughts of Mabel redirect Bumppo's mind during the day and dreams of Mabel at night encroach upon his personality. Upset, he exclaims, "Ah's! me, Mabel; I wish never to dream again! Before we met, I had a sort of pleasure, in following the hounds, in fancy as it might be; and even in striking a trail of the Iroquois ... but all those things have lost their charms since I've made acquaintance with you" (284). In this moment, Cooper highlights how human infatuation minimizes Bumppo's capacity to perceive the natural world around him. It reminds readers that among other passions, hunting and his hunting dogs seem to be set aside, and it also recalls an earlier incident when Bumppo shoots and kills two birds wantonly in an effort to impress Mabel. Albeit temporarily, Bumppo seems more separate from his relationship with the natural world than ever before, and Cooper suggests that his hero struggles with the sometime limited nature of self-interest.

Though his feelings for Mabel Dunham remain strong after the failed proposal, Bumppo realizes that he is not her best suitor and reroutes his attention and affection toward his hunting dogs during the novel's concluding chapters. When pressed to talk about the things that matter the most to him, Bumppo replies, "I do not say, that I love nothing, that belongs to the 'arth [sic]; for I do, though not much, unless it might be Mabel Dunham, that I can't carry with me. I have some pups, at a higher fort, that I valu [sic], considerable..." (444). Bumppo's brief comment about his pups foreshadows a later realization that his hunting dogs will constitute his closest, continual companion relationships. Couched within a philosophical discussion, Bumppo reveals that aside from his gun and a few material tokens given to him by others, he does not want or ask much of the living, with the exception of his dogs.

Through Bumppo's protracted internal struggle with romantic feelings in The Pathfinder, Cooper shows his protagonist becoming more sensitive to how his life intersects and evolves 
through interactions with others humans and animals, and he implies that focusing on one human desire can block one's sensitivities to the ways other living things can enrich human life. In When Species Meet, Donna Haraway asks readers to consider how the histories of companion animals intersect with our own. She surmises that when people consider their companions' stories, they come closer to reconfiguring prior anthropocentric understandings that place humans at the center of the universe. Haraway writes, "Whom and what do I touch when I touch my dog? How is becoming with ${ }^{2}$ a practice of becoming worldly? When species meet, the question of how to inherit histories is pressing, and how to get on together is at stake?" (When 35). Haraway's ideas call for a re-evaluation of The Pathfinder, which is traditionally understood as the novel where Bumppo fails at romance, asserts his maturing individuality, and proclaims his independence. In depicting Bumppo's sense of expanding sense of isolation after failing to woo Mabel, Cooper again suggests a way that self-interest cocoons people and prevents them from acknowledging the animals that shape their lives. At the conclusion of The Pathfinder, just as all hope of pairing with Dunham evaporates, Bumppo feels a deep emotional wound: "Never before had he been conscious of his isolated condition in the world ... all had vanished ... in one moment, and he was equally without companions and without hope. Even Chingachgook had left him ... at the precise instant which might be termed the most critical of our hero's life" (475). Worse, he is without the hunting companions that he loves. Although Bumppo sits alone, "almost overcome with a sense of loneliness," he does not give up (475). Facing the pain associated with Mabel that will accompany him for years, he resolves to help the widowed Dewof-June, and he does this in part by returning to the woods to hunt the birds he brings to her for food. Cooper's solution for his hero's woes - physical movement and hunting for charity to support another isolated character-temporarily serves to reinvigorate Bumppo's sense of self

\footnotetext{
${ }^{2}$ My italicization for emphasis.
} 
before he disappears into the forest. When he reemerges, his greater appreciation and understanding of the natural world around him has fully replaced his disappointment about his failed relationship with Mabel.

The Deerslayer, Cooper's final novel of the series, also corresponds with The Pathfinder in that part of its plot development hinges on a hope for a potential romantic relationship, but it focuses more on what informs Natty Bumppo's viewpoint as he comes of age in his early twenties. In the preface, Cooper writes, "In this book the hero is represented as just arriving at manhood ... As a consequence, he is loved; and, what denotes the real waywardness of humanity, more than it corresponds with theories and moral propositions, perhaps, he is loved by one full of art, vanity, and weakness, and loved principally for his sincerity" (493). Cooper articulates that a central thematic focus concerns how his young hero develops amidst the company of less honorable others and how he deals with advances from a woman who is not an ideal partner. The novel teems with moral contrasts, frontier mystery, and a sense of doom and bodily decay that all serve to sharpen Bumppo's budding sense of character.

Yet, from its beginning, hunting ethics, human-canine relationships, and natural resource use all play a central role in young Bumppo's character development as well, and Cooper reveals this through Bumppo's contrast with the self-centered and physically imposing Henry "Hurry Harry" March. As in The Pioneers, Bumppo's opening conversation shows how hunting shapes his perceptions. When March offers him a slice of venison steak "that would have made an entire meal for a European peasant,” Bumppo replies, "Nay—nay, Hurry, there's little manhood in killing a doe, and that, too, out of season. ... There may not be any cowardyce [sic], in overcoming a deer, but sartain [sic] it is, there's no great valor" (499). March's greedy pursuit of game animals also extends to how he speculates about the use of his time. For example, he 
bemoans to Bumppo the loss of personal profit while he follows Judith Hutter, a woman he courts, in one direction rather than trapping in the other, but he holds onto the hope that wooing her will eventually afford him access to a portion of her father's estate. In the presentation of Harry in this scene, Cooper "critique[s] the increasingly prevalent ideal of masculinity grounded primarily in body and strength," and courage rooted in physicality rather than mindfulness (Person 84).

In contrast, Bumppo deplores the way that abundance prompts a mindset that sanctions the pillaging of the earth, a viewpoint that stems in part from his prior experiences hunting with an unnamed hound. Because of a more measured approach to life, devoid of much haste and devoted to a subsistence lifestyle, he must continually align his deep love of hunting alongside his dog with what he intuits as environmental balance. Later, when Judith Hutter asks him the identity of his "sweet-heart," Bumppo replies, "She's in the forest, Judith" (616). In a subsequent conversation he explains,

“...but to me there's no music so sweet as the sighing of the wind in the tree tops, and rippling of a stream from a full, sparkling, natyve [sic] fountain of pure forest water - unless, indeed,' dropping his head for an instant in a thoughtful manner'unless indeed it be the open mouth of a sartain [sic] hound, when I'm on the track of a fat buck-As for unsartain [sic] dogs, I care little for their cries, seein' they are as likely to speak when the deer is not in sight, as when it is." (636) Here, Cooper shows the depth of the bond between Bumppo and a hound. The experience is rooted in the personal, mutual understanding between a human and canine trailing a buck, and Bumppo declares it to be the epitome of how he appreciates the sounds of the forest. This 
gratitude in turn inspires a principled commitment to avoid killing too many animals and to monitor the impact of his hunting on animal populations.

If The Pathfinder documents what transpires when Natty Bumppo falls in love with another human, The Deerslayer portrays him as deeply in a celebratory love with the forests and hunting alongside his hounds. To a greater extent than the earlier novels, Cooper considers how self-interest and self-centered behavior can circumvent even the best human intentions to become environmental stewards. In the final sentence of The Deerslayer, Cooper writes, "We live in a world of transgressions and selfishness, and no pictures that represent us otherwise can be true," before he proclaims that a "pure spirit in whose likeness man has been fashioned" occasionally emerges to abate our "deformities, and mitigat[e] if not excuse its [our] crimes" (1030). In the context of the entire Leather-stocking Series, the "pure spirit" appears most readily from within Bumppo, whose careful attention and a measured approach to his interaction with the flora and fauna of frontier forests and the western prairies. The Deerslayer hints that the formation of his character stems from Native American lore supported by close observation, a willingness to learn from the nonhuman sights and sounds around him, and sensitivity to animal lives. Cooper's hero's overwhelming love for the forest, illustrated most strongly by his hunts with a companion animal, foreshadows his greater reliance on canines to help him navigate terrains as he ages in The Pioneers and The Prairies. As The Prairie closes and Bumppo and his hound Hector pass nearly simultaneously, Cooper suggests that bettering our spirits within the world we inhabit may begin in paying attention to interactions with the companion animals devoted to us and that enrich our lives.

The Leather-stocking Series contains James Fenimore Cooper's most popular works because of its central character Natty Bumppo, whose life continues to invite critical discussion. 
D.H. Lawrence famously argues that for Cooper, Bumppo is merely "wish-fulfillment," or little more than a mythic form to express frontier desires or lifestyles that he and many other European descendants born into wealth could not easily seek (52). Lawrence stresses that Cooper's societal position shielded the writer from ever having to live in any manner similar to Bumppo. From this perspective, Bumppo differs little from modern superheroes for Cooper and similar men from the early nineteenth century. Daniel Peck also views Natty as a mythical figure who embodies the best of human civilization within the natural world. Peck notes that Cooper's imagery "works to form an aesthetic union" between these two sometimes opposing forces (77). Wayne Franklin grants Cooper's personal life a bit more agency by adding that Natty is more of an "emotional symbol" of an attachment to a frontier childhood and lands that he lost as he matured (The New World 106-7). Like Lawrence, Franklin views Natty as an extension of Cooper in the way that he embodies a wilderness spirit that Cooper gravitated further and further away from as he grew older.

While it is possible to imagine Bumppo's experiences as symbolic, I argue that to a certain extent Cooper sought to infuse his character with realistic elements within a more dominant sentimentalist narrative mode. Consequently, critics should also assess Bumppo's life in the context of his relationships with other humans and his dogs. My analysis continues in the tradition of George Dekker, who asserts that Cooper documents the beginning of a change in America when the "hunting and fishing mode of subsistence was no longer viable or even lawful, and that figures like Leatherstocking were obliged to move on or remain stranded in obsolescence" (87-8). Even as he writes about historical romance, Dekker notes a basis in the realism of those living on the edges of the frontier away from a dominant modern society in Cooper's fiction. Robert Emmet Long adds that because of Bumppo's vast array of 
contradictions — a "childlike quality, yet ... almost unnaturally old"; "physically unsightly, yet a lover of beauty and natural sublimity"; "saint" and "deadly marksman"; "guileless" and "shrewd"; "quick to act in moments of crisis ... [yet] embodying a time-suspended loquaciousness" in spirit — he is a more fully rounded character that many critics surmise (1934). To this, I add that relationships with his dogs also help shape Bumppo's character. Separate from myth, symbolism, or the societal evolution that also appears to approach him, Natty remains human, and defines himself and his attentive relationship to the Earth in part through roving the woods hunting with his dogs. 


\section{Chapter Three:}

\section{The Self and Survival in Nineteenth-Century Frontier and Subsistence Nonfiction}

This chapter peers more deeply into the contrast between nonfiction related to the massive depletion of American wildlife, which Washington Irving alluded to at the end of The Adventures of Captain Bonneville and that James Fenimore Cooper imagined at a local level in The Pioneers, and subsistence hunting accounts within American slave narratives and Appalachian hunting autobiographies. It focuses on how nineteenth-century industrialization hardened the human-animal boundary in America as industries exploited both humans and animals. First, the chapter examines literature that details how the exploding markets for buffalo hides and whaling products helped to depersonalize the predator and prey relationship through the concept of distancing, and how this damaged not only animal populations, but also hunters themselves through rituals that came to be associated with masculinity and that effectively annihilated large populations of certain species. Here, I present a counterexample of how indiscriminate hunting on large scale illustrates the dangers of environmental detachment for future generations. In particularly, this section focuses on the stresses American industrialization placed on land and sea frontiers: market hunting in conjunction with Francis Parkman's The Oregon Trail (1849) and two accounts of the Essex whaling disaster that inspired Herman Melville's Moby-Dick (1851) - first mate Owen Chase's story, which for more than a century served as the principal version of what actually transpired, and cabin boy Thomas Nickerson's recently recovered chronicle, which offers a separate perspective.

Then, as a means of contrast, I focus on writings of subsistence hunters in AfricanAmerican and Appalachian communities who lived far away from pressures of market hunting. 
In slave narratives and Appalachian autobiographies, I explore how a sense of human selfreliance during this time period was inseparable from interdependence with animals and the roles of predator and prey. These works articulate hunting in a completely different light, as an instrument of hope among humans unjustly animalized by other people, as in John Thompson's The Life of John Thompson, a Fugitive Slave (1856) and Solomon Northup's 12 Years a Slave (1853), and as a means of providing food and sustenance as well as advocating a pathway towards conservation, as in Philip Tome's Pioneer Life; or Thirty Years a Hunter (1854) and Meshach Browning's Forty-Four Years in the Life of a Hunter (1859).

\section{The Intensification of Human-Animal Relations: Population and the Ethics of Distancing and Industrialization versus Subsistence Hunting}

As humans have evolved within the confines of the earth, our increasing numbers have created more heightened interactions with animals. Indeed, the "gradual intensification of our involvement with animals" is the most abiding and continually ongoing "trend" in human evolution (Shipman, The Animal 11). This assessment relates to companion animals and domesticated animals, but it also encompasses the pursuit of wild animals as well. As societies modernize and their populations expand and concentrate in cities, humans are still evolving with animals, and predominantly with dogs and cats. Currently, although there are different species that thrive through mutualistic or commensal dependencies, humans comprise the only species that consciously seeks to live with and care for animals (Shipman, The Animal 11-12). Because of this unique relationship, we are occasionally closer to animals than they are with many other species because of our desire for sustained companionship. Since our actions shape both our relationships with animals and their worlds, since we have become more adept at noticing environmental change, and since we have the capability to reflect about the impacts of our 
behaviors, twenty-first century humans living in first world societies feel the burden of helping species thrive and of curbing damages that may affect animal populations or even render them extinct.

Partly as a result of the intensification of our relationships with animals, concern for other species demands that we consider the impact of a rapidly expanding human population. According to rough estimates, the world's population has expanded from nearly one billion in 1800 to a little more than a billion and a half in 1900 to nearly seven and a half billion in 2016 ("World Population"). A sheer increase in hunger and the amount of calories needed to sustain human life worldwide has led theorist J.M. Coetzee to research human relationships with domesticated animals. Although he adheres to the notion that the pinnacle human task ought to be monitoring and effecting positive, ecological actions, Coetzee notes that this task may be compromised by a growing human dependence on current methods for manufacturing massive numbers of animals into consumables. Coetzee notes the reliance on harmful practices to produce meat to nourish human populations and to help lessen hunger, and he critiques industrialized societies that sanction the means for producing food in a way that severs the relationships with the animals we consume. Devoid of respect or honor for animal lives, the industrial meat-producing system finds its roots in Chicago's massive "factories of death" that Upton Sinclair famously depicted in The Jungle (1906) at the turn of the twentieth century, which revealed management practices of dealing with huge quantities of leftover and undesirable animal parts (53). Coetzee pushes his readers, as descendants of the pioneers of "the commodification of animal flesh," to "be at the forefront of trying to atone for it" by imagining new methods for food production that improve the quality of animal lives and appease hunger (61). Currently, we do not have a sufficient answer for Coetzee's call to action as the demand for 
mass produced meat continues to soar, but understanding changes that took place in America in relation to hunting before the rise of mass meat processing provides a good beginning point for rethinking about how we found ourselves in the current ethical dilemma.

Increasing concern for other species and the environment encourages greater emphases on our ethical relationships with animals in a perilous time of global warming and toxic runoff from wastes at concentrated animal feeding operations (CAFOs). Kari Weil expounds upon Coetzee's call for renewed consideration of our ethical relationships to animals within the context of animal studies. Pointing to one dilemma that appears, she writes, "[the] ethical demands produced by these [animal] encounters may be equally unfathomable" (131). The difficulty Weil identifies is the yet unquantifiable understanding of how animals actually interpret our behavior toward them. She articulates how this tension manifests within the ethical strand of animal studies between theorists who plea for policies that encourage humans to provide the best possible lives for domesticated animals within our current social, cultural, and business climates and more radical theorists who identify themselves as "animal abolitionists," who view domesticated animals as no different than slaves, and who insist that the entire meat production system must meet its end (132). Indeed, as Weil implies before stepping away from the discussion, the two differing perspectives among ethicists make compromise difficult. At least in the near future, the more extreme abolitionist position remains convincing only in theory because it underestimates how humans have co-evolved with both wild and domesticated animals; the bearing of co-evolutionary history is not easily undone.

It also prompts two understudied and relatively unexplored questions. First, what of American environmental history? The fervor and immediate demands of the present blinds us to the chance to understand the larger evolution of how modern attitudes about meat production 
developed, in part from highly problematic human behaviors toward animals during the 1900s, America's century of disregard toward what then seemed like limitless animal populations. Secondarily, what do our relationships with wild rather than companion or domesticated animals teach us about alternative cultures or modes of living, as well as our past mistakes? An emphasis on food production and companion animals may be productive, but also, too, is consideration for the measures prior Americans have made to protect wild animal populations from the great decimation of the nineteenth century, when the idea of free ownership and the pursuit of wild animals for the sake of market products rather than subsistence led to near collapses for certain species.

Although there were some early efforts to conserve animal populations in the nineteenth century, the pressure of the psychological distancing between humans and wild animals expanded during this time and enabled an era of environmental disregard that continues today in different forms. Distancing is a social means for an organized society "to displace, but never disrupt, institutions that are problematic" in order to maintain the status quo (Vallely 114). Sociologists routinely use the concept to characterize the ways that Americans agree, sometimes implicitly and sometimes not, to relocate imprisoned, mentally ill, or elderly people under the guise of being helpful to the person or society. Distancing is also applicable to the way we transform domesticated farm animals into meat products within the "industrialized and concealed animal factory" (Vallely 114). More than a century after the closing of the American frontier, animal processing now remains arguably more distant from American consumers than ever, couched and legally shielded in out-of-the-way rural locales far from the eyes of the greater percentage of the population. Distancing also encompasses the barriers that twenty-first century animal processors, as well as nineteenth-century market hunters and whalers, formed in an effort 
to separate human feelings from the necessities of slaughter. As modern distancing comes with human costs, so did nineteenth-century distancing, which blinded many different parties from considering the potential bleak social, psychological, and environmental outcomes of overhunting. Human currency and trade fueled reckless behavior that wrought massive damage on wildlife populations. Goaded by the lure of wealth, by romance, or by necessity, humans engaged in hunting operations that often disabled them from considering wild animals as more than certain body parts they provided to their companies. Consequently, this mindset underscored the increasing divide between human (as market hunter) and wild animal (as product).

A fuller picture of nineteenth-century America, however, reveals pockets of subsistence hunters whose writing does not portray hunting as the impetus for romance or riches, and instead conveys a more personal sense of interdependence between predator and prey rooted in hunger and survival. While nonfiction market-oriented hunting accounts warn of the excesses of the distancing of humans from animals more obliquely than the directness of modern industrialized farming exposés, stories of subsistence hunting remind readers of the benefits of a local and empowering form of hunting that preserved a greater sense of integrity between predator and prey. Having a hand in feeding themselves and their dependents placed subsistence hunters in far tougher situations than modern consumers, but it also fostered relationships with species that transcend the idea that humans fully own, manage, control animal lives. In a modern humandominated world where the most common discussion about domesticated animals is how to better engineer the birth-to-meat process in order to feed the burgeoning world population and maximize profits, the idea of subsistence hunting appears silly unless one lives in proximity to the rhythms of the people's lives who participate in a subsistence or even partial-subsistence 
lifestyle. As in the case of nineteenth-century Americans, present-day hunters who embody this lifestyle rarely make appearances on mainstream news outlets unless they are portrayed as exotic or anachronistic curiosities. Yet, as Claude Evans notes, these hunters live with closer view to the webs of interdependence between animal and plant life because a hunter killing an animal for food does not neatly fit into "hierarchies of any kind," and that "the instrumental use of another organism does not necessarily involve any kind of superiority of the eater over the eaten" (159). Evans's assessment refers to predators and prey within the human-animal, animal-animal, and even plant-animal pursuit of sustenance; he criticizes the notion that hunting is wholly a way that humans display their superiority through domination of other species (159). Though market hunting certainly calls Evans's hunting paradigm into question, as its bounty depended upon the use of human reason and technologies to maximize profit that persisted throughout the nineteenth century, Evans suggests there are benefits of a one-on-one predator and prey relationship rooted in the responsible pursuit of food as opposed to speculation or greed.

One of subsistence hunting's benefits is its impact on the human senses and imagination. Though it may be an inefficient way to feed masses of people in the context of agricultural expansion, hunting for food provides opportunities to witness and participate in the food cycle. It is also a way “to imagine and remember one's self, for a moment as able to live by one's own wits in the woods and wildness" (Carmine 244). Contrary to market hunting enterprises, subsistence hunters often hunt with hunger in mind. The associated personal risks afford a greater sensitivity to the seasons, to game populations, and to game behaviors in a complex process of negotiation among predator, prey, and environment. For many nineteenth-century hunters, close observation and human ingenuity were both vital to successful hunting and what we now know as ecological balance. These demands shaped their perceptions of themselves as 
part of a greater food cycle that also included the sun, precipitation, and the ground beneath their feet. The hunting process required creativity and it honed intergenerational perceptions of local geographies and natural histories.

\section{Hunting Industries: Francis Parkman's The Oregon Trail and the Essex Tragedy}

At the opposite end of the spectrum from nineteenth-century subsistence hunters, American capitalists and the hunters they employed sought to maximize the use of their power and tools to profit from a seemingly endless supply of large game animals on land (buffalo) and at sea (whales). In time, both ventures collapsed because of a combination of new technologies, a decreasing supply and demand for animal products, and more investment in other industries. Literature detailing hunting experiences of the Great Plains, the American West, and parts of the Atlantic and Pacific Oceans reveals the desolation of these environments and the desperation many of the industry's workers felt. Yet, due largely to imagined wealth and a love of the chase, many hunters and whalers worked arduously to maximize their harvest. In the process, they embodied and spread a destructive Western ideology that stemmed from the Christian idea of dominion over animals, and many bands of hunters or whalers, because of circumstances and the earnings at stake, became distanced from the animals they pursued.

Francis Parkman's The Oregon Trail (1849) picks up where Washington Irving's western trilogy left off, and it offers a far more nuanced portrait of buffalo hunting and the changing culture of the American West. Like Irving, Parkman originated from the Eastern States, but he began his two-month western tour at a much younger twenty-two, shortly following his graduation from Harvard University. Consequently, Parkman approached the West eager for new experiences, and his account is free of Irving's anxiety about reestablishing his place in the American literary scene. To a greater extent than his predecessor's works, Parkman's account 
reveals the changing relationships between humans and buffalo. He hunted alongside a variety of people, including his guide Henry Chatillon and members of the Oglala Sioux, and he depicts the spawning of conflicting human ideologies that would ultimately lead to the dramatic collapse of the American buffalo herd. The Oregon Trail is an ideologically uneven mess of a work. It is occasionally romantic like Irving's Astoria and The Adventures of Captain Bonneville in some places, but in other instances, it appears realist, hypercritical, and dismissive of certain hunters and Native Americans. Altogether, it forms a first-step writing experiment serialized in Knickerbocker's Magazine during the course of two years from a writer still learning about himself, his craft, and life far from his eastern home. By not featuring a strong allegiance to any one particular group of people and in its extended accounts of buffalo hunts, The Oregon Trail captures the head-on collision of the desire for human wealth versus the welfare of one species. Enveloped in unfamiliar territory, amidst gigantic herds of buffalo, Parkman sought to capture the experience of hunting from every imaginable perspective, including the buffalo's.

Before considering what The Oregon Trail adds to our understanding of the tragic demise of the American buffalo, it is important to understand its literal and symbolic significance within the context of environmental history. The majority of historians agree that the nearextinction of the buffalo is "one of the grimmest narratives in the history of wildlife" (Krech 126). There are divergences of opinion about the numbers that once roamed the American Plains, with estimates ranging from twenty to sixty million, and whether or not Native American tribes lived in ecological balance with buffalo during the mid-nineteenth century, a key point since their declines and removals are often linked together. Dan Flores, for example, notes that between 1825 and 1850, before hunters drastically reduced their numbers during the third quarter of the century, the buffalo population receded in part because of drought and diseases such as 
anthrax, tuberculosis, and brucellosis spread from contact with feral or stolen cattle from Texas beginning around 1800 (481). He also notes an increase in the ownership of domesticated horses among Native Americans during this time may have contributed to the decline. During the second quarter of the century, Native Americans managed between 250,000 and 500,000 domesticated horses, all of which encroached upon grasses and water formerly consumed almost entirely by buffalo (Flores 481). In time, disease would have continued to reduce the buffalo population, and the gradual increase in horses certainly would have continued a further reduction, although certainly not to the extent or at the same speed as that of the impact of market hunters.

Separate from these factors, the deep cultural impact of overhunting beyond the carrying capacity or range allowance of the land is something environmental historians undervalue amidst other concerns. Shepherd Krech calls into question the assumption that Native American tribes were as ecologically sensitive to their hunting grounds as some historians claim. He suggests that some tribes harvested more cows than bulls in a way that may have been destructive in time (134). Krech also notes that the increasing number of domesticated horses helped spark the notion of private property before the major hunting phase, which also led to overhunting among Native Americans as well (136). Yet, neither of these points fully addresses the cost of the mentality of the voracious hunters in need of money had upon Native American culture. When they advanced West to hunt, and later increased in great numbers with the opening of the Transcontinental Railroad, market hunters brought and spread values incomprehensibly different from those of the Oglala Sioux. Francis Parkman depicts the clashing viewpoints converging on the Western Plains to his primarily eastern readers in his description of a friend and shaman named Mene-Seela. Describing him when praying, Parkman writes, 
To him all nature is instinct with mystic influence. Among those mountains not a wild beast was prowling, a bird singing, or a leaf fluttering, that might not tend to direct his destiny, or give warning of what was in store for him; and he watches the world of nature around him as the astrologer watches the stars. So closely is he linked with it, that his guardian-spirit, no unsubstantial creation of the fancy, is usually embodied in the form of some living thing; a bear, a wolf, an eagle, or a serpent; and Mene-Seela, as he gazed intently on the old pine-tree, might believe it to inshrine the fancied guide and protector of his life. (330)

Parkman is careful to note that he lacks the culture, history, experience, or power to understand or attempt to interpret Mene-Seela's worldview and sensitivity to his surroundings. In wonder, he realizes that his classical education leading up to this moment does not suffice, as he comes face-to-face with a person who experiences the world in an alternative, unimaginable way that empowers the animals around him who help to shape his destiny.

Mene-Seela's and many of the Oglala Sioux's ways of understanding the animals that coexisted in their world is inherently spiritual, but they also informed the use of animal bodies, particularly in regards to the buffalo, among Native Americans throughout the Plains, who approached hunting as a ritual that first and foremost provided them with many of their needs and wants. In contrast to expanding foreign markets that commanded a disproportionate interest in, and therefore sought to extract, a single part of the buffalo (their hides), Parkman writes of the Sioux, "The buffalo supplies them with almost all the necessaries of life" (199). One tribe, for example, used the whole animal for more than one hundred different products (Krech 128$).^{3}$ For

\footnotetext{
${ }^{3}$ Offering an extensive list of uses of the buffalo, Krech notes, "They include robes (hair on) for bedding, gloves, winter clothing, and ceremonial and decoy costumes; hides (hair off) for tipi covers and linings, cups, parfleches, moccasins, leggings, and other clothing, kettles, shields, and maul covers; hair for stuffing yarn, and ropes, and sinew for thread, bowstrings, and snowshoe webbing; ribs for arrow straighteners; the paunch and large intestine as
} 
bands of incoming hunters, this extent of the use of the buffalo was simply unintelligible, and so the Sioux post-hunting rituals that strengthened the social fabric and materiality of their culture appeared silly or archaic, as the hunters' purpose and time frame stripped them of the ability to understand the extent that the Sioux prized pre-hunting, hunting, and post-hunting as a central cultural process. Instead, the newcomers slaughtered buffalo, skinned them, left their carcasses to rot, and sent their hides back toward the east, introducing an economy that destabilized the steadier and more balanced use of the buffalo that already existed. Formerly a "builder's emporium, furniture mart, drugstore, and supermarket rolled into one," the animal that nourished nearly every aspect of Sioux life changed into a commodity product whose principal use became distant from the bodies left behind (McHugh 109).

This transformation severely crippled Sioux culture, and in part facilitated Parkman's prediction that without buffalo, the tribes would "dwindle away" (199). Tasha Hubbard notes the application of a "Euro-western ideology to the Plains ecosystem propped up by the continued hierarchy in which humans occupy an exalted place at the top" helped to decimate Native American lifestyles (305). Gauging the buffalo's worth in currency, market hunters expanded their reach, increased their kills, and played a major part in the "relational genocide" (the undoing of a culture by eliminating something central to its foundation), of the Oglala Sioux (Powell 538). Even though he was young and inexperienced, Parkman foresaw this wave of change, and much to the chagrin of modern historians, he appears complicit in the horrors that accompanied Manifest Destiny. Harboring the racist beliefs of his time, Parkman considered the Sioux culture as destined to fade away. Hence, The Oregon Trail remains a clear-sighted

containers; the gallstones for yellow pigment; hoofs as rattles or for glue; the tibia and other bones for fleshers, brushes, awls, and other tools; horns for arrow points, bow parts, ladles, cups, spoons, and containers for tobacco and medicines; the brains to soften skins; fat as a paint base or to polish stone; the penis for glue; dung as fuel; and teeth as ornaments" (128). 
documentation of the spreading of a toxic ideology. Its vivid impressions reveal how the conflation of inferior humans (the Sioux) with animals (principally buffalo) helped to facilitate Parkman's and many prominent Easterners' disregard toward the side effects of expansionist policies.

From this perspective, Parkman's account more than anything else is merely an objective recounting of the way a problematic value system wreaked havoc on the American plains by positioning itself as the superior culture within a dominant species. The culturally ensconced Parkman is mentally as far from Sioux culture and foreign animals as he is physically distant from his home more than fifteen hundred miles away. Upholding this value system, Parkman's narrative details a process of literal and mental distancing from others as part of a larger movement to seek the values of a group of people that exert control over the lives of those whom they exploit (Vallely 114). It is no surprise, then, that in its more eye-opening moments, The Oregon Trail reads more as a journal of a travel narrative than an arduous hunting narrative. Although, as one scholar notes, Parkman does portray particular Native Americans that he admires in a positive light, he reserves the majority of his praise writing about their proficiency in "fights against the buffalo, king of the prairie beasts" (Van Doren xii). Otherwise, the majority of the narrative espouses a lack of investment in local, everyday life on the Plains, and at times, it seethes with contempt. In a startling moment, for example, Parkman likens an elderly Sioux man, with an "emaciated face and gaunt ribs" to a "turkey-buzzard," and then fantasizes about killing him: "He would have made a capital shot. A rifle bullet, skillfully planted, would have brought him tumbling to the ground. Surely, I thought, there could be no more harm in shooting the detestable vulture which he resembled" (225). As horrifying as this detail—which Parkman removed from the 1892 version late in his life - is, it is made doubly worse by the one sentence 
that immediately follows it and which concludes the paragraph: "We dined, and then Shaw saddled his horse" (225). Parkman's unconcern and lack of any further contextualization or attempted justification of his comment suggests that he viewed Native American life as of equal value to a bird known for its scavenging skill, and of less worth than the next detail he might find to support his story.

The emotional distance that Parkman maintains appears in his hunting descriptions as well, where he captures the beauty and strength of animals only to suggest two methods that he, the travelling hunter, employs to remain superior to them. Having fully imbibed the early sentiment of what would become known as Darwinism a little more than a decade later, Parkman writes at one point, "Soft-hearted philanthropists may sigh long for their peaceful millennium; for from minnows up to men, life is an incessant battle" (341). When he kills an antelope, he writes, "When I stood by his side, the antelope turned his expiring eye upward. It was a beautiful woman's, dark and rich. 'Fortunate that I am in a hurry,' thought I; 'I might be troubled with remorse, if I had time for it"” (187). And about the buffalo, Parkman writes, "At first sight of him every feeling of sympathy vanishes; no man who has not experienced it, can understand with what profound contentment of mind he beholds him fall” (418). In each situation, Parkman details a method of distancing oneself from prairie marvels. Any feelings for human-like quality of the antelope, or any other animal for that matter, must be vanquished by quickly moving ahead post-kill and avoiding reflection, and demonizing the qualities of a majestic animal's resistance makes it easier to slaughter without the pangs of consciousness.

These two strategies that Parkman elucidates mirror the violent behavior patterns many hunters from the Eastern states exhibited toward the Sioux and other tribes, as well as the buffalo that they slaughtered in great numbers throughout the following three decades. Rapidly 
approached by well-armed hunters with profit in mind and who harbored no emotional or social connection to the western prairies or a subsistence lifestyle, the American buffalo and the human population that depended upon it for subsistence declined rapidly. Parkman's account indicts an entire generation who, through their human-centered elitism and pursuit of monetary gain, nearly drove the buffalo to extinction and left a troubling legacy for hunting historians to unpack. There may not be a lower point of human-animal relations in American hunting history, as waves of hunters distanced themselves from wildlife and worked arduously at eradicating an entire species and oppressing large Native American populations in the name of expanding the country and pursuing wealth.

Roughly during the same mid-century time frame that hunters began mass harvests of buffalo on the western prairies, whaling was the fifth largest industry in America and reaching its peak after a period of "unparalleled growth, productivity, and profits" that began in 1812 and stretched through the 1850s (Dolin, Leviathan 205). In 1851, Herman Melville released MobyDick, the towering nineteenth-century novel that defines whaling literature and the one American hunting story that is also a "great national epic" (Bergman 268). From a couple of vantage points, this description remains apt. First, although Melville's novel concerns far more than the pursuit of an elusive and destructive animal, its simple narrative shell, minus the novel's many digressions, extensive nautical detail, and Ishmael's psychological unpacking of his fellow seamen, is the hunt for America's most famous fictional animal. Second, within the context of hunting literature, it makes historical sense that a pinnacle work of American literature grounded in hunting would appear during the 1850s, the time when market hunting amidst immense land and sea frontiers was central to American industry and consciousness. Relying primarily on one account from the disaster of the whaling ship Essex from November 1820 through March 1821, 
Melville shaped what would become his most famous novel, a dense, allusive multi-genre work that, similar to Walt Whitman's Leaves of Grass (1855), sought to capture the entirety of American experience, albeit at sea. There is no denying that the magnificent result, continually a candidate for the mythical Great American Novel since Melville's early twentieth-century recovery, towers above many other nineteenth-century novels and troves of imitators since its publication.

Yet, Melville embellished the one nonfiction account (written by a ghostwriter for first captain Owen Chase) he had significant access to while developing Moby-Dick, and the story that inspired the novel has changed since 1980, as modern readers now have access to another perspective from an additional survivor, fourteen-year-old cabin boy Thomas Nickerson, the youngest member of the Essex's crew. The recovery of Nickerson's account expands the scope of the original story, merits more critical attention for its child's perspective of the whaling industry, and, in conjunction with Owen Chase's account, remains equally as fascinating and instructive within the context of nonfictional hunting stories, as well as nautical history, as Melville's novel. Read together, the two survivor stories from Essex incident depict tense and harrowing life-or-death decisions that show the combative whale quickly disappearing after marooning them at sea; Nickerson's account in particular shows that the whale's aggression pales in comparison to the whaling industry, which presided over practices that exploited the adventure-hungry and often downtrodden lives of its hunters and their children. The industry defined and continually reinforced the distant human-animal relationship between hunters and whales as exhausted humans pushed to extreme limits farther and farther away from their homes hacked at whale pieces and collected their bodily fluids to sell. 
In asserting that Thomas Nickerson's boyhood account merits more attention, I write outside of a tradition that privileges the seafaring stories of Richard Dana, James Fenimore Cooper, Herman Melville, and Jack London often inadvertently to the exclusion of others. Jason Berger, for example, argues in favor of examining the works of canonical writers who "possessed a higher social and class status" and whose works may "best reveal complex issues relating to the symbolic construction of the antebellum maritime world, authorship, and class experience" (30). Placing a strict emphasis on literary art enables Berger to delve into the greater psychological anxieties of more competent literary creators, but his inflexibility inevitably discounts what an outlier account might offer about the workings of trying social and working conditions. Instead, by exploring how a young man quickly came of age during the Essex tragedy, I continue in the tradition of Jennifer Schell, who asserts that the whaling industry "complicated the [prevailing] notion that whale men were national heroes" by sanctioning extreme and unsafe conditions and relying on the conceptions of masculinity to thwart calls for change (137). The industry negatively impacted men, women, boys, whales, and hunting in general, and the conditions as recounted by Thomas Nickerson reveal a boy coming to understand how an industry fostered a particular sort of masculinity to continue its competitive dominance.

Centered in Nantucket Island until the 1850s, the whaling industry distanced hunters from their prey and their homes in literal and psychological ways. Sixty years before the Essex tragedy in 1760, Nantucket's local whale population evaporated due to overhunting, and the competition from Pacific sperm-whale hunting forced Nantucket's whalers to sign on for voyages that extended from a one-time average of nine months in length to a routine two-tothree-year journey (Philbrick, In 6-7). These longer voyages placed tremendous social pressure 
on the Nantucket community. By 1810, nearly one of every four women twenty-three or older were widows due to whaling accidents at sea, and local families were accustomed to the cycle of whalers spending three or four months at home for every two or three years at sea while hunting whales (Philbrick, In 14-5). A strong sense of masculine resolve in the face of increasing hardships and risky situations, along with newcomers searching for adventure, provided the industry a continuous, if sometimes unsteady stream of hunters. Writing about the function of ritualized masculinity in creating distance among hunters and the animals that they massacre for profit, J.M. Coetzee writes, "Kill the beast by all means, but make it a contest, a ritual, and honor your antagonist for his strength and bravery" (52). More pertinent in regards to whale hunting, Coetzee adds, "It is only since victory [against animals] became absolute that we have been able to cultivate compassion" (59). As the number of whales needed to justify whaling expeditions began to be located further and further away within what many seamen imagined as a limitless sea of animals, the industry relied on the idea of a man versus whale war that pitted whaling crews against their increasingly elusive prey. Otherwise, the distances were too far and the stakes too high. The ritualized nature of the quest to hunt whales at greater and greater odds help to preserve the allure of the mission. For industry heads to acknowledge or even consider that they had triumphed over the whale might have invited compassion, consideration for whale populations, or legislation in favor of better working conditions for whalers, and so they relied on a primitive form of masculinity embodied in Nantucket culture and passed down through generations to facilitate the aggressive, ritualistic hunts that defined the island by the time of the Essex tragedy.

Thomas Nickerson's “The Boy’s Story” reveals how the Nantucket whaling culture primed boys as its future warriors based on the community's ceremonial reverence for defining 
itself on whaling. Before receiving the opportunity to join the Essex at fourteen, Nickerson notes that he had been "brought up in that nursery for seamen where children from the time that they can lisp are taught to look toward Cape Horn for a support and to idolize the form of a ship" (86). Upon receiving his chance to join an expedition, he takes part in the tradition of the crew "fitting the ship for sea," which amounts to three weeks of unpaid work for "the privilege of going to sea" and which Nickerson describes as "very convenient for ship owners and [which] probably originated with themselves" (86). Given their immense amount of free labor before departure, the majority of the crew at the bottom of the whaling hierarchy prepared for sea with the hope that their hunt would pay off through a large harvest. Once at sea, the captain and his mates sought to organize the crew within a strictly competitive, capitalist subculture, ostensibly to keep members fixated on their goal of maximizing their success. As soon as the ship leaves Nantucket, Nickerson bemoans feelings of "sudden gloom" at his aloneness within an "unfeeling world" as the captain and others begin to bark orders at him (87).

Nickerson's account of the ship's first encounter with whales around the Falkland Islands and Patagonia just east of South America's southern tip reveals the physical and psychological extremes that Nantucket whalers often had to endure to locate their prey, and it outlines the depersonalization involved during the preliminary steps of the hunting process. As Nickerson and others work to harpoon the first whale, another whale rises to the surface and obliterates their boat, leaving all of them floating at sea. Others crew members rescue Nickerson and they return to work. Nickerson briefly expresses his awe and fear during the incident, but he chooses not to write about the subsequent hunt, noting "I do not design in this work to give a description of catching whales or reducing them to oil" (102). Instead, he explains how the ship's underlings are forced to pay for new clothes routinely after harvesting whales, and speculates that if the 
Essex had made it back to Nantucket safely, he would have had to return seven-eighths of his earnings to pay for replacing his soiled outfits (103). Reflecting upon the first moments of whaling that he had been awaiting for throughout his childhood, Nickerson spends much time criticizing ship owners for encouraging predatory practices on their own workers, at one point voicing a common cry that "often goes forth that the ship is worse than state prison and her captain and officers worse than negro drivers" (104).

However, the novelty of Nickerson's story manifests in how he first strips away the hunting element and then the survival-at-sea component in a first-person account of what would become the most memorable animal foe from the nineteenth century. In eschewing narrative refuge in the stalwart masculinity associated with industry that the incident affords, Nickerson bluntly offers a contrasting vision from first mate's Owen Chase's version, which unsurprisingly seeks to uphold the rituals and culture sanctioned by industry. Embittered with the way the industry transformed already arduous whaling experiences into exploitative sea factories, Nickerson shares the fifteen months before a gigantic sperm whale sinks the Essex just west of South America without the romance one might expect in at least small doses throughout whaling tales. Whereas first mate Owen Chase devotes one-tenth of his narrative to what occurs before the sinking of the Essex and the remainder of it documenting the remaining crew members' efforts to survive, Nickerson allots more than half of his story to what happens before the whale's attack. More memorably, as soon as the Essex is destroyed, he shifts from writing fully formed chapters to scant daily journal entries for the remainder of his story. On a purely narrative level, then, Nickerson's account flounders and mirrors the fragmented pieces of the Essex after the attack rather than providing an extraordinary story and the courageous survival, disaster, or revenge narrative more amenable to the aims of the whaling industry. The 
uncharacteristic and anticlimactic switch in form and Nickerson's plainspoken approach present a stark alternative to Chase's account, which shaped Herman Melville's and subsequent generations of historians' understandings about what actually happened.

Though his principal motives are defending his reputation and upholding the aims of Nantucket's whaling industry, Owen Chase details not only a whale's destruction of a ship, but its psychological shock to a business which was systematic, controlled, technologicallyadvanced, and distanced from the lives of its prey. Chase writes, "After several hours of idle sorrow and repining I began to reflect upon the accident, and endeavoured [sic] to realize by what unaccountable destiny or design ... this sudden and most deadly attack had been made upon us: by an animal, too, never before suspected of premeditated violence, and proverbial for its insensibility and inoffensiveness" (29). For the first time, Chase considers the idea that a whale might deliberately counteract the hunter's violence with its own: "he made two attacks on the ship ... both of which, according to their direction, were calculated to do us the most injury ... His aspect was most horrible, and as such indicated resentment and fury" (29-30). Though Herman Melville would later mine and magnify the religious associations of this attack in MobyDick, Chase here shows just how realistically shocking it seems to the crew members to conceive of a whale premeditating violence against its aggressors (Gatta 73). Although whale attacks occurred in rare instances throughout first half of the nineteenth century, the majority of them appeared accidental, and therefore many of the subsequent accounts denied whales the agency to act upon their anger. In the absence of any elaborate symbolism beyond the attributes of good and evil, Chase's impression of the whale reveals it as inexplicably and furiously undermining humans at work. Notably, too, it is the first time he writes about the specific whale in gendered terms. As the hierarchical line between human hunters and whale dissolves, the only way Chase 
can explain the whale's motive is to imagine it to be more calculating and vengeful than docile. The scene is reminiscent of when Francis Parkman kills an antelope and sees a woman when he looks into its eyes, but it is far worse. Then, Parkman has a means of escape and can move on to another hunt to refocus him on his mission and discourage much reflection, while Chase and the survivors must struggle to survive with the memory of a monstrous whale that still lives beneath them as they attempt to find help and save their own lives. In both situations, one brief and one elongated, each writer — shocked out of his systematic routine - temporarily abandons the group or industry logistics, plans, and hopes of the journey to realize the humanness of the animal, and in Chase's case, the malicious superiority of an animal that seems to have bested the crew.

In contrast, Nickerson's version implies his rejection of a ritualized, creaking system that places whalers at great odds and misfortune by propagating a hunter-versus-whale mentality that led to a depersonalized, militarized manner of hunting. His account of the incident leaves far less to the imagination, remains comparatively subdued, and refuses to consider that the whale could have foreseen the damage or the aftermath of the attack on the crew. Instead of expressing shock and couching the conflict as the crew versus the whale, and hence upholding an attitude nourished by extractive capitalism, Nickerson merely recounts the whale's first and then second attack. He notes when the whale first rammed the ship, it "shock[ed] every man upon his feet" (140). Yet, Nickerson stops far short of Chase's characterization of the whale's “decided, calculating mischief,"(30) and in fact, he acknowledges that Chase passed up a chance to strike and kill the whale with his lance in an effort to preserve the rudder (140). This decision proved costly when the whale swam out and then returned to attack again. However, despite the immense struggles that were to come, Nickerson avoids placing blame on Chase or the others. He cannot see the semblance of a devilish fury that catches Chase and others off guard from his 
lesser position, and his account makes transparent how veterans such as Chase were primed to react when they encountered the unexplainable rupture within a culture that assumed supremacy over all whales. In eschewing a fallback onto masculinity or the trappings of industry, Nickerson exposes the ordeal as an unpredictable scenario that defied human expectations and exposed human weakness. In his account, human hubris — energized by industry-sanctioned mentalities, expectations, and narratives - collapses, exposing the limitations of market hunting at sea in an era of widespread overhunting.

\section{Subsistence Hunting in the South and Appalachian Mountains}

While the two frontier industries dominated market hunting in America, there were also more marginalized groups of people that hunted at the periphery of American culture. These groups attracted less attention because they were not privy to the rights of other Americans or because they subsisted beyond the reach of the hunting markets and aristocratic society. Here in the following section, I discuss hunting as it appears in African-American slave narratives and Appalachian subsistence narratives. By necessity or choice, some enslaved African-Americans living in the southern United States adhered to a partial subsistence lifestyle to supplement their limited and/or unsatisfactory allotted provisions. Unencumbered by slavery, Appalachian subsistence hunters scattered throughout the mountain range from Georgia through Maine relied on hunting to supplement what they could procure from farming. Hunting for these groups of people encompassed something entirely different than market hunting: a means of providing food or to aid in escapes, as in the case of some slave narrators, or as a means of supporting a family and continuing to eke a marginalized living from the wilderness, as in the cases of many Appalachian writers. Also, these writers mostly hunted alone or in small groups and with food or small-scale trade in mind. Consequently, their hunting accounts provide an alternative view of 
hunting during the nineteenth century. In contrast to market hunting, both African American and Appalachian hunting accounts portray hunting as a needs-based activity that fosters creativity, innovation, and deeper connections with land and the lives of animals that fed and in some cases threatened them. Because of differing circumstances, their hunting stories vary in content, but they are unified in how they portray hunting as social or personal form of agency in the face of unjust or harsh circumstances. Considering all that was at stake, their hunting stories interrogate the human-animal boundary as facilitated by a dominant society, and they often depict the interdependencies of humans, animals, and their environments by replacing the central goal of a quick profit with a means to survive day-to-day conditions.

\section{Hunting in American Slave Narratives}

With a combination of large agricultural, woodland, and lowland spaces, the antebellum South provided a variety of different hunting experiences, as social stratification shaped how people hunted and fostered differing viewpoints. Describing hunting in the southern states, Stuart A. Marks writes, "Scratch below the surface of any veteran raccoon, quail, fox, rabbit, or deer hunter and differences of caste, ethnicity, and lifestyle may be revealed," all bearing the influence of southern history (4). A history, it is necessary to add, based on exclusion and the denial of rights of African-Americans, which influenced hunting before the Civil War as well as during the Reconstruction, when the expansion of hunting tourism and the conservation movement limited or discouraged subsistence hunting (Giltner 174). Slave owners provided scant and undesirable food and relied on hunting dogs to locate fugitive slaves and keep them afraid (Derr 154). Consequently, hunting appeared as a double-edged sword in many slave communities. Slaves knew that to attempt an escape meant a guarantee of becoming human prey with the possibility of finding freedom, so the "wilderness evoked both fear and comfort" (Glave 
59). In a more positive light, hunting the edges of plantations sometimes supplemented an inadequate food with "game that slaveholders would not miss or desire — pests like foxes, raccoons, opossum and squirrels" (Glave 64). It also provided benefits beyond procuring additional food. As it did for some white southerners, hunting helped to strengthen social bonds, and slaves shared knowledge gleaned from hunting both as assistants to hunting parties and on their own. In the process of learning what animals to hunt and when to pursue them, some slaves gained skills through wilderness education that would help them support their communities and their potential escapes.

Former slaves John Thompson, Frederick Douglass, and Solomon Northup each offer differing insights into the ways that slaves experienced hunting throughout the southern states. Uniquely among the work of other slave narrators, John Thompson's narrative documents his transition from a runaway slave to a member of a whaling ship as way to increase his chances of remaining free. Thompson's The Life of John Thompson, a Fugitive Slave (1856) links the dark side of the whaling industry with American slavery, and it is the only slave narrative that recounts a former slave's experience aboard a whale hunting expedition (Andrews xxiv). The narrative's central theme is seeking comfort in faith and aspiring for continued spiritual growth in extraordinarily difficult circumstances because Thompson was "under perpetual threat of apprehension and return [to the] south" and remained a hunted fugitive up until the publication of his story (Andrews xxi). In suggesting a whale ship, isolated in the Atlantic, as the safest place to fully escape the reach of slave hunters, his narrative shows that for some African-Americans, nowhere on land in America felt completely safe, that hunting in the southern states included acts of tracking, capturing, and returning fugitive slaves, and that northern states did not always promise a safe haven from their pursuers. 
Thompson's story sheds insight into the extent whites animalized African-Americans. Whites used nineteenth-century anthropological and ethnographical theories to support their feelings of supremacy and to categorize African-Americans as subhuman (Harper 123). Although this sentiment became especially pronounced after emancipation following the Civil War, it also provided whites a way to justify horrible mistreatment before the end of slavery. In likening African-Africans to animals, they advanced the prominent beliefs of ownership and strengthened the idea of African-American inferiority. Animalization also positioned AfricanAmericans as beyond the protections of law. Jacques Derrida notes that the process of animalization places subjects as "being-outside-of-the-law," where in practical terms "the law does not appear, or is not respected, or gets violated" (The Beast 117). If Thompson's account details the horrors that accompany this social positioning, it also shows how he was forced to embody the role of prey in order to elude his potential tormentors or captors. In preparation for an escape attempt, Thompson practices hiding from neighboring slave owners or their overseers. He writes, "One man ... as soon as he learned that I was sometimes there, tried to catch me to whip me. But I always managed to elude him, and yet to have him know that I had been there and gone away" (48). Under the pressures of constantly being hunted, Thompson develops sharpened ways of thinking that ultimately assist in his escape. In the context of hunting stories and slave narratives, his account is distinct, then, because it recounts the formation of a mindset partially informed by his reaction to his animalized status, his own subsequent escape from packs of slave hunters' dogs, and his participation in multiple whale hunts while serving as a ship steward on a two-year voyage. To this extent, a greater part of Thompson's life involved acting as a part of predator or prey relationship, and his narrative articulates the complicated notion of hunting for African-Americans who felt that they or members of their race were hunted prey. 
Frederick Douglass and Solomon Northup consider hunting within the realm of the individual slave's experience close to the plantations, though each author presents an opposing view. Frederick Douglass, in advancing his argument for emancipation, essentially rejects what Thompson's narrative asserts by disregarding hunting as a worthy endeavor for AfricanAmericans. He decries it as a poor use of slaves' time, aligning it with other futile sports of "semi-civilized people" that slaveholders encouraged slaves to take part of during the holidays as a means of "prospective pleasure" and as a way of diverting their attention from more productive pursuits, such as learning and manufacturing (184-6). Douglass categorizes hunting and other pleasurable sports as activities for slaves to look forward to, experience, and then quickly forget. Sanctioned by slaveholders, these occasional hobbies offered little productive promise toward undermining the system of slavery precisely because they existed as part of its greater scheme. He found no useful sanctuary in the wilderness, arguing that "Baltimore, when most oppressive, was paradise to this [wilderness]" because the city facilitated dense populations of people where "a general sense of decency ... does much to check and prevent those outbreaks of atrocious cruelty" $(110 ; 172)$. Douglass also never found comfort in hunting because its locations often shielded violence and human terrors from view. As a result, he aligned hunting with activities that oppressed rather than uplifted African-American lives.

Although some slave narratives support Douglass's assertions, others complicate it by articulating the virtues of hunting and woodcraft. Many slave narratives describe the advantage of slaveholders keeping slaves illiterate not only in traditional connotations such as reading and writing, but also in regards to nontraditional literacies as well. To most easily control large populations of slaves required developing a program with a foundation based on fear, illiteracy, coercion, and fatigue. Knowledge of any form had the potential to threaten slaveholders, their 
families, social relationships in the South, and profits. Hence, owners generally discouraged slaves from knowing more than the boundaries of their plantation and the extent of their work. However, hunting sometimes existed as an exception to general expectations because it benefitted slaveholders. Slaves worked as servants during hunting trips, and they helped to rid plantations of animals deemed as pests by hunting or trapping at night to bolster their food supplies. Of all the slave narratives, Solomon Northup's story best accounts for the fact that when enabled these hunting opportunities, slaves could and did benefit from hunting and trapping as well.

In Twelve Years a Slave, Northup counters Douglass by positioning hunting literacy as a means of education, hope, and empowerment. He shares the story of a free man captured in Washington, D.C and sold into slavery in Louisiana who eventually escapes after extended devotion to gaining knowledge of his social and local environments. Northup's narrative shows that slaves often had to adapt and to negotiate their place within the human and animal worlds around them while hunting, at times using every means possible to imagine what might assist their escape attempts. Hunting well meant a chance at attaining food, which in turn might provide confidence and the nerve to pursue an escape. In J. Claude Evans's critique of philosophers who reduce hunting to a masculine display of human dominance, he asserts that the recreational sport is part of the "web of interdependence" of among species that is nonhierarchical (159). He theorizes that "the instrumental [and for humans, ethical] use of another organism" demands that one evaluate environmental circumstances and need; he argues that it is both faulty to assume mastery over another living thing and "to model our obligations toward animals on our obligations toward persons" $(159 ; 161)$. Along with other subsistence hunting stories, Northup's narrative articulates the stakes of human negotiation with the animal world to 
a greater degree than other types of hunting stories. He emphasizes primitive hunting methods and the way that hunger fosters creativity; his narrative conveys how a "web of interdependence" facilitated the empowerment of slaves who hunted, and it contrasts with the impersonal mass slaughter that appears within market hunting stories. Solomon first stumbles upon the idea of hunting in response to his objection to a summer's supply of worm-ridden bacon. He writes, "I conceived a plan of providing myself with food, which, though simple, succeeded beyond expectation. It has been followed by many others in my condition, up and down the bayou, and of such benefit has it become that I am almost persuaded to look upon as a benefactor" (131). Using dogs and clubs, Northup and others hunt raccoons and possums around the plantation; their success inspires him to continue to imagine better methods of hunting, including the invention of a fish trap.

In recounting his gravitation to learning how to hunt and fish, Northup notes that his master's unwillingness to imagine slaves as active thinkers granted him access to helping with the hunting dogs, which would eventually give Northup a way to orchestrate his escape. Legally unable to own property easily accessible to other hunters, Northup uses a combination of wit, intuition, and experimentation in forming a greater understanding of the interdependence of animal life. Once Solomon learns how to hunt, he learns to fish; and while becoming proficient at fishing through trial-and-error, he devises a fish trap; then, while hunting, he deduces which dogs would trail him during a future escape attempt and trains them to fear him while in the woods away from his master. In a way that Thompson and Douglass do not, Northup realizes the power found in Derrida's concept of "being-outside-of-the-law." Instead of stressing how his animalized status traps him into only moving on the run, he chooses to accept the role of a predator to sustain himself and potentially assist others during an escape. As he learns how the 
natural world might support him in preparation for the riskiest decision of his life and as he shares his knowledge to other slaves, Northup gains the confidence and wherewithal to attempt his eventual escape.

\section{Appalachian Subsistence Narratives}

Given full consideration of his circumstances, Solomon Northup merits recognition as one of the nineteenth century's most innovative hunters in regards to showing how subsistence hunting benefitted some oppressed or disadvantaged people, and he easily joins the ranks of Philip Tome and Meshach Browning, two well-known Appalachian hunters who composed their autobiographies during the 1850s. Though Tome and Browning hunted with unlimited freedom, they, too, wrote to advance what constitutes the expanding notion of the American hunter and felt compelled to use their talent to provide for family and others. Tome's Pioneer Life; or Thirty Years a Hunter (1854) and Browning's Forty-Four Years of the Life of a Hunter (1859) depict ways that subsistence hunting can improve the environment, human understandings of animals, and communities. In a more modern defense of hunting, James Carmine characterizes hunting as an important way to imagine one's connection to prior generations of Americans who depended upon it to survive (244). Carmine surmises that hunting continues to face opposition because it seems outdated, as humans have "a better chance of survival by spending [their] energies herding, farming, and trading than by expending [their] energy hunting" (241-2). Carmine's concern harkens back to the members of Rip Van Winkle's community, who frown upon Van Winkle for neglecting his farm to go hunting, or Alex De Tocqueville's observation about the clash between hunting and agriculture during his trek through America the 1830s: "Once men have indulged in the lazy and adventurous life of hunting, they feel an almost insurmountable distaste for the constant and regular work demanded by agriculture" (383). As a partial rebuke to 
Tocqueville, Tome and Browning suggest that divide between hunting and farming in American history is too simplistic, especially in regards to hunters who engage in both while living a subsistence or partial subsistence lifestyle. In modeling how localized hunting involves more than killing animals, Tome and Browning suggest that future generations' abilities to hunt depends upon turning away from market hunting and emphasizing individual connections with local landscapes and animal communities, and they foreshadow the implementation of game laws, national parks, and public lands that help facilitate hunting today.

Like Solomon Northup, Philip Tome displays a knack for creating fish traps in his autobiography Pioneer Life or Thirty Years a Hunter, and he also implies that acquiring a hunting education through trial-and-error experimentation helps people achieve a sense of independence. Tome, who lived a partial subsistence and farming lifestyle in Lycoming County in central Pennsylvania, believed that challenging oneself to learn how to become aware of one's environment and how to capture and kill animals were necessary parts of both subsisting and expressing one's self in the rural Appalachian Mountains. While his autobiography contains thrilling accounts of his hunts, they are largely cast aside as transitions among informative chapters educating readers about innovative hunting practices and observations from Tome's years spent observing animal behavior. Readers learn, for example, how to track bears and the importance of training a hunting dog well.

Over the course of three chapters, Tome also breaks away from the traditional shape of a hunting memoir in recounting his attempts to domesticate subsistence prey. Tome tries and fails to tame deer and four bears before giving up and letting all of them go. Rather than portraying these occasions as futile experiences or minimizing their importance, Tome writes of them as part of a woodcraft education that enables him to consider how neither human innovation nor a 
pioneer spirit guarantee a desired change in the animal world. He attempts what J. Claude Evans describes as the problem of humans extending the exact ethics to animals as they display to other humans. Evans claims that this produces a "counterintuitive result ... [because] our obligations to animals ... [become] stricter than our obligations to persons: we are obliged to simply leave them alone, stay out of their lives and their world, in spite of the fact that we, persons and animals, are all interdependent parts of the one biotic world" (176). Defying Tome's wishes, these animals buck the possibility of becoming domesticated, forcing Tome to realize that their species will likely never act as he hopes and the futility of attempting to alter what the natural world will not allow. Through trial and error, Tome internalizes that the living animal world sometimes imposes limitations on how much humans can extend their control, and he learns that what people seek in their relationships with animals should not necessarily remain fixed on one subservient end, because animals also adapt and have inner lives beyond the scope of human understanding. Tome's taming experiments call into question the ability of humans to coerce animals into serving our wishes and what constitutes "nature" and "wild." They make explicit the problem that Carmine notes with a controlled and enclosed definition of "nature": it is problematic and limiting because it derives from one species' vantage point and excludes what animals, plants, or the land might say (245). Tome notes that the animals he attempts to train are uncooperative, but he illustrates empathy towards them and does not merely denigrate their desires. These experiences help him redefine himself as part of the local flora and fauna rather than as ruler over the plant and animal kingdom.

As a hunter with a nuanced understanding of the local ecology, Tome argues in favor of the cautious use of resources and helping others. On the one hand, he notes that the "subsistence or defense of ourselves and those whom we were bound" triumphs as a "stronger motive than 
love of excitement and for seeking out and destroying the denizens of the forest," but on the other, he shows that providing for other dependents requires efforts toward sustainability (100). In modeling ways to be a resourceful subsistence hunter, Tome notes instances of feeding leftover fish to hogs, driving away unneeded elk and bear, and using an old abandoned housing structures to construct hunting areas. Tome also conveys the way that some subsistence families struggle to find enough to eat helped to create networks of volunteers and foster community. During one situation, he assists a woman and family whose husband is lost in a snowstorm trying to procure more provisions (54-55). And Tome was also known to donate venison to free lunch counters in Pittsburgh and Philadelphia as a means to proclaim the value of woodcraft to help feed others (Wegner, Legendary 75). Advocating a wise use and sustainable policy for hunters and consumers, Tome forecasted legislation created to assist animal populations toward the end of the nineteenth century.

Like Tome, Meshach Browning lived in the mountains (in Garrett County of western Maryland) and his autobiography stresses hunting as a way to provide for a family and as a means to help facilitate a rural lifestyle comprised of both hunting and agricultural pursuits. Historians best remember him as a prolific hunter who slayed numerous animals and then recounted his adventures in Forty-Four Years in the Life of a Hunter. However, this assumption, while true, dominates discourse about Browning and reduces an account of a more well-rounded working life in the Appalachian mountains to a man with a dog and a gun on a four-decade-long shooting spree. Browning's memoir contains multiple reflections about how engaging with animal life influenced his own perceptions and behavior.

One central strand of his story is the immense difficulty of learning to subsist in a wilderness area, and how being a proficient hunter alleviates some of the stress. Writing about 
entering the wilderness where he would remain at sixteen, Browning notes that he was "thrown into a strange country, without friends, without money, and worse than all, without education; like a wild colt in the wilderness, to stray where he pleased" (38). He lacks valuable knowledge and knows that he, like the colt, must learn with the help of others quickly, or he will struggle to survive. It is a need to subsist and provide that propels Browning toward becoming a better hunter, but along the way, he continually contextualizes himself as imbedded within an animal world that also relies on him from time to time. He often addresses animals that he crosses paths with or hunts as "fellow," and in one case, attempts to rationalize to a bear that he must shoot it in order to save his hogs. He admits to deliberately acting as animals occasionally, including one episode where he avoids detection by galloping on his hands and feet. But these playful instances occur when Browning is comfortable and has enough food. His attitude changes when he or his family is hungry, and especially when animals prey upon on his crops. In the latter scenarios, he writes, "I always, to a certainty, took my own out of them" if they threatened his family's crops (135). In order to ensure having enough food, Browning routinely switches from travelling hunter to farm protector, and both function to teach him how to find a balance between taking from and providing for the wilderness around him.

Browning's narrative also predicts the interpretive challenges of the animal world that humans face as their numbers increase and predates a greater public investment in conservation and preservation. For partial subsistence hunters, an increase in family size often meant a greater reliance on farm labor close to home and less time spent hunting in the woods. As Browning's family increases, he becomes more reliant on trading meat from hunting for farm supplies, and eventually, he builds a successful grist mill, and the time he spends farming increases. Browning's need to provide for his family inaugurates what becomes a very successful operation 
at providing for many, but at a cost of lost time in the woods. While he never becomes detached from his prey in the way of market hunters, the transition to becoming a provider to a greater number of people alters how he relates to the world. In a microcosmic way, Browning's life trajectory shows that as human populations boom, there is less time for interacting with animals in ways beyond pets, pests, or as potential food products.

Yet even as his attention strayed and his worries mounted until the mill begins to thrive, Browning still attempted to conserve deer for future hunters through the creation of a deer park in 1836. Here, Browning attempted to designate a space for observation and research rather than the harvest of deer. The venture, which is also the origin of the town of Deer Park, Maryland, would last six years as America's first deer park and it precedes "the 200-acre deer park established in Ottawa, Illinois in 1858 by Judge John Dean Caton (1812-1895) and the more famous 1,000-acre deer park established by the Blooming Grove Park Association in 1871 in Pike County, Pennsylvania" (Wegner, Forty-Four x-xi). During the latter half of his life, Browning expressed hope that future generations would continue to hunt. However, as his material possessions increased, including a home, a mill, and two hundred acres, he realized that responsibilities toward the management of these things separated him from a life that he had once lived. In continuing to reach out and make an effort toward conservation, Browning conveys not only the value of providing for animal life, but the idea that humans benefit from a world balanced to some degree by spaces for animal life to flourish.

During the twentieth century, Americans enacted legislation to curb the hunting excesses that defined a highly damaging nineteenth-century environmental history. If the nineteenth century depicts the bleakest moments of human-animal interaction in America, it also features narratives that convey non-market hunting as important to American identity and that suggest the 
necessity of conserving spaces for animal populations. President Theodore Roosevelt would later become the greatest legislative champion of conservation by establishing many national parks and preserves to honor hunting in American history and ensure its future. Roosevelt and other conservationists realized that without greater protections, market hunting would destroy vast numbers of animals and recreational hunting opportunities. In championing early twentiethcentury accomplishments, Aldo Leopold, writing in favor of game management, a science inaugurated by nineteenth-century excesses and experiments, reminds readers of the necessity of continuing conservation efforts: "We stand guard over works of art, but species representing the works of aeons are stolen from under our noses" (Game Management xxxi). Here, Leopold speaks against the mistakes of the nineteenth century, and he suggests that Americans take more responsibility in assisting the survival of species through recreational management and in fostering sustainability. 


\section{Chapter Four:}

\section{Traversing the Land Together:}

\section{Companion Animals and Family in Twentieth-Century Coming-of-Age Hunting Stories}

Recreational hunting in America peaked in per capita participation during the first half of the twentieth century. By 1945, for example, one of every four American men identified as a sport hunter (Herman 271). Consequently, hunting remained foundational to the childhoods of

many boys and girls who hunted with their family members. Reflecting back on the early part of the twentieth century in 1970, one historian notes, "For millions of American boys, learning to shoot and above all graduating from toy guns and receiving the first real rifle of their own were milestones of life, veritable rites of passage that certified their arrival at manhood" (Hofstadter). By that time, the percentage of Americans who claimed to be hunters had declined, but many of them had experienced hunting as part of their childhoods.

Fictionally, too, hunting appeared as a central coming-of-age activity in what might be described as a renaissance of rural children's fiction after World War II through the 1970s. As American industrialization expanded, masses of people migrated toward cities, prompting the rise of suburbia and the emptying of rural farmlands after new advances in farm technologies. The population of the United States expanded from 76 million to 281 million people during the twentieth century, and "from 1940 onward, suburbs accounted for more population growth than central cities" (Hobbs and Stoops 1;33). Fueled by nostalgia for a changing way of life, many well-known writers with rural backgrounds crafted stories about childhood in rural areas during either the late nineteenth century or the early part of the twentieth century. Their narratives almost always include hunting as a central social activity, something as common as other 
childhood games. Three prominent writers who wrote memorable coming-of-age hunting stories are William Faulkner from northern Mississippi, Fred Gipson from the Texas Hill Country of central Texas, and Wilson Rawls from the foothills of the Ozarks in eastern Oklahoma.

William Faulkner wrote about hunting throughout much of his fiction, but "The Bear" remains his most popular hunting story. From its detailed depiction of the changing landscape of the South to its focus on a boy's growth through annual hunts of a legendary bear, the story offers a social complexity not always found in hunting literature. More importantly, it marks a shift within the hunting story genre toward a greater emphasis on the influence of individual dogs on the formation of children's lives. The result is perhaps the most distinguished hunting story in the American literature canon. Two of Faulkner's two successors, Fred Gipson and Wilson Rawls, wrote more widely read children's hunting stories. Like Faulkner, both drew from personal hunting experiences and sought to depict the relationship between a boy and a canine companion(s). Their novels offer eloquent descriptions of boy-dog relationships, with the idea that canines play a formative role in a boy's childhood growth via shared hunting experiences. In addition to participating in the hunting processes of scenting, chasing, or retrieving, depending on the types of hunts, dogs assisted childhood growth by keeping their companions physically safe and emotionally secure, and they contributed to rearing subsequent generations of younger hunters, who learned not only from their human elders, but also from their experienced canine companions. In the process, many hunting dogs, too, became central to family hunting experiences, and challenged prior notions of human and animal as separate units with the context of family.

Altogether, the unique nature of the boy-dog hunting relationships that William Faulkner, Fred Gipson, and Wilson Rawls portray pushes the twentieth-century hunting story in a new 
direction by granting companion animals greater fictional agency than ever before. All three writers theorize that the process of learning to hunt alongside a companion animal strengthens human-canine emotional bonds and kinship, and offers hunting dogs a way to act upon their evolutionary instincts. Faulkner's presentation of the dog Lion in "The Bear" provides a firmer boy-dog foundation with roots in the relationship between Natty Bumppo and his dogs. Here, Faulkner suggests that like humans, hunting companion animals have personalities that are integral for success during certain hunts. Blurring the line between human and animal, Faulkner posits a greater, non-subservient role for Lion in his quest to bay Old Ben, the story's famous bear, than any of the canines in Cooper's fiction. Expanding Faulkner's vision, Gipson and Rawls both develop new ideas framed within children's stories. In the course of two novels, Hound-Dog Man and Old Yeller, Gipson shows a companion animal as integral to the day-to-day life of a rural child and family. He suggests that hunting within the context of family responsibilities trumps the life of the isolated, wayward hunter, and he portrays the powerful process of mourning the loss of a companion. Rawls also focuses on dogs as family members, but he steps beyond Gipson and Faulkner. In Where the Red Fern Grows and Summer of the Monkeys, Rawls depicts companion animals as teachers or as collaborative learners within family units and shows how hunting with companions helps children better understand prey and their responsibilities toward families comprised of both people and dogs.

\section{Companion Animals: Foundation and Theory}

In developing this chapter, I rely on the literary-historical scholarly work of Jennifer Mason, and within an investigation of humanity, companion animals, family, and mourning, I seek to both build upon and complicate the posthumanist theory of Cary Wolfe, animal studies theory of Alice Kuzniar and Paul Waldau, and research about the lives of dogs by Alexandra 
Horowitz, Cat Warren, and Temple Grandin. Mason's Civilized Creatures: Urban Animals, Sentimental Culture, and American Literature, 1850-1900 describes the importance of companion animals in the development of American culture. Most broadly, Mason asserts that as a byproduct of the urbanization and industrialization of America that picked up in the nineteenth century, increasingly larger percentages of the population spent more time in direct proximity to domesticated animals, which changed how people perceived and treated them and helped enhance a metropolitan appreciation of animals. Routine encounters with animals facilitated the expansion of human sensitivities and an increase in empathy, which over the course of time reshaped modern thought about the lives of certain species, particularly cats and dogs. Contrary to what canonical mid-nineteenth-century literary works such as Melville's Moby Dick (1851) or Thoreau's Walden (1854) convey, encounters with “wild animals were nor the only or even the primary" way that a large percentage of the adult population experienced the natural world during that time (Mason 12). And while nineteenth-century and early twentieth-century American naturalist writers such as Hamlin Garland and Theodore Dreiser likened cities to anthropomorphized beehives because of their compact, nonstop human innovation and activity, these areas also housed domesticated and companion animals that lived in close proximity to people and influenced their lives in more subtle, non-deterministic ways. For example, in the era before refrigeration, humans also interacted with animals such as cows that produced their food, and their household companion animals also helped rear their children. Mason's emphasis on domesticated rather than wild animal encounters encourages scholars to consider additional ways that companion animals influenced children's lives in both the nineteenth and twentieth centuries. Her historical observation that these animals became increasingly central to the construction of urban families prompts one question this chapter explores: what do child-canine 
relationships in literature from rural areas reveal? Here, I expand Mason's discussion by arguing that dogs were central figures in the lives of rural citizens throughout the late nineteenth and twentieth century, and that children's literature reflects the extent and intensity of those relationships.

In writing about coming-of-age hunting stories, I also seek to complicate the theories of Cary Wolfe and Paul Waldau. In his book What is Posthumanism?, Wolfe posits that posthumanist theory enables humans to understand how "accepted modes and protocols of knowledge" effectively "discipline" and provide "form" to understandings of the situating of the self in one's social context (106). In challenging historical assumptions by thinking beyond the human, Wolfe tasks theorists with deconstructing the structures that engulf us and inform ways we organize our lives. One such structure is the idea of what constitutes family, commonly assumed to consist of only humans, and then qualified by value-laden terms such as nuclear, single-parent, and immediate, and in some places, community. Family is integral to the way humans define themselves, and the formation of the self begins with the reinforced, redirected, and rehearsed behaviors of childhood—-behaviors that, as Mason suggests, increasingly became altered by companion animals in America. The examination of human in relation to animal loops back to Wolfe's earlier notion that animals "bear witness" and at times represent the "paradigm of the victim" in a way that allows them to embody or model the struggles of other marginalized groups of people (Animal Rights 61-62). Wolfe, too, sees the blurring of the human-animal line as means of an inquiry that calls us to understand the impossibility of the isolated self. Consequently, more thorough investigations of nonhuman lives provide humans the ability to challenge our "habits of knowledge ... [and our] own prerogatives of power" (Speciesism 103). Wolfe's ideas invite the need to consider companion animals, not quite wild and to varying 
extents co-dependent, as living nonhuman entities that change human understandings of world. His analysis on organizational tropes that shape human lives also invites greater consideration of what may constitute family, as the animals close to humans impact and alter our perspectives on varying day-to-day levels.

As Wolfe nudges inquiry about animals in a new direction, Paul Waldau also assumes that animals also deserve higher status, though he hardens Wolfe's theory into a blanket call for companion animals to serve as political advocates for other wild animals who do not receive preferential treatment from humans because of their wildness. Waldau claims that companion animals, through their affection for humans, have the capacity to suggest that less or unapproachable wild animals also deserve consideration, better treatment, and more forms of legal protection. To a certain extent, Waldau's point is sound. Companion animals occupy a unique space that enables them to elicit sympathy for other animals from humans, who by extension learn to better understand the lives and deaths of nonhuman species. On the other hand, however, the implications of Waldau's point are arguably too ideologically black and white. To presume that the capacities of companion animals should then be used to theorize or attempt to actualize an imagined, harmonious world among humans and animals neglects to consider the fact that like humans, animals often live by consuming other animals before other animals, microorganisms, or bacteria consume them. In short, all lives and deaths are messy, and the bluntness of the contradictions inherent in life and death in hunting stories expose readers to the difficulties of establishing an all-encompassing, animal rights theory that designates humanengineered protections for all species.

Waldau's argument remains most convincing when he claims that companion animals inspire empathy, but the implication of a theorized advocacy campaign featuring companion 
animals as leaders in a movement in favor of all animals would need to deemphasize content (hunting stories, situations, or examples) that might challenge or complicate this ideal scenario. This may be one reason, then, why Waldau and some other animal studies critics neglect to address hunting stories from the likes of Faulkner, Gipson, and Rawls, which show companion dogs as not only complicit in the hunting and tracking of other wild animals, but also hungry and yearning for the possibility. Indeed, hunting stories reveal that dogs are willing and eager participants during the human hunting pursuits of other animals, and that the close human-canine relationship that develops depicts humans and dogs as collaborators within these experiences rather than advocates for justice for all animals. Moreover, the willing participation of dogs suggests that the idea of one unified theory positioning companion animals as advocates for the plights of other wild animals is fraudulent and anthropocentric. However, if not always for the purposes of speaking on behalf of all animals, companion animals do shape hunters' lives, and twentieth-century American writers such as Gipson and Rawls, in becoming more sensible to human interactions with animals and in finding perhaps a more receptive audience within children's literature, push to a deeper psychological depth than other hunting writers by portraying their stories from either the perspectives or memories of children.

The works of various dog specialists and animal studies scholar Alexandra Horowitz help to further contextualize the importance of what Faulkner, Gipson, and Rawls aim to accomplish in their portrayals of hunting dogs-depictions of what it means for a canine to participate in the hunt and close human-animal relationships that invite reflection about the process of human mourning when a companion animal's life ends abruptly. In her book Inside a Dog: What Dogs See, Smell and Know, Alexandra Horowitz notes that among all domesticated animals, dogs were the first and perhaps "most surprising" companion animal, especially when people consider that 
the fact that they evolved from wolves as predators (41). As they became more intertwined with human societies, serving to help pursue and herd animals, dogs thrived in their relationships with humans. Cat Warren identifies the beginning of the early twentieth century as the moment of professionalization of human-canine teams, when the United States police began experimenting with what would become the widespread use of K9 units in New York City and New Jersey, as well as later during the Vietnam War, when Americans began relying much more heavily on the senses of working dogs for military purposes (33). Warren's research reveals just how much dog work descends directly from the hunting and tracking instincts honed throughout prior centuries, and with Horowitz shows that as humans have evolved by cultivating relationships with dogs, dogs too have changed from their prolonged interactions with humans. Indeed, for many dogs, present day "hunts" are perhaps more likely to concern humans rather than wild animals.

As in much of her other work concerning other domesticated animals, Temple Grandin explores how people should treat and understand their canine companions as members of their families. She stresses that healthy dogs must have means to play, explore, and learn — three primary needs that they share with humans and that people must help to provide (Animals Make Us Human 65). Too, Grandin worries and writes extensively about how modern human society's fears of loose dogs and how the sometimes-confined spaces where dogs live may clash with their needs. She describes what she imagines as a negative facet of widespread leash laws: "It's almost as if dogs have become captive animals instead of companion animals, and the house or fenced yard has become like a really fancy zoo enclosure" (Animals Make Us Human 42). Grandin challenges readers to think about how some human societies evolve in ways that may not necessarily be best for canines. Practically, she wants readers to understand their dogs' needs to move, play, explore, and seek; in particular, she pushes people to think about how 
happy dogs conceptualize space and need the freedom to move- a notion central to the joy of the human and canine hunting collaboration

If the writings of Faulkner, Gipson, and Rawls highlight the highs of boy-canine hunting experiences, two novels, Gipson's Old Yeller and Rawls's Where the Red Fern Grows, vividly depict the lows in losing a childhood hunting companion and the consequential sense of mourning, a pivotal idea in Alice A. Kuzniar's Melancholia's Dog: Reflection on Our Animal Kinship. Kuzniar posits that mourning over the loss of a companion animal is a unique human experience that invites reflection and analysis because it encourages people to consider bonds with their lost companions, and she stresses that these moments should not be easily dismissed in art. Indeed, when companion animals pass, the mourning process often reminds humans that we, too, will one day vanish, and these scenarios call our own mortality into question. In Old Yeller and Where the Red Fern Grows, the lives of the three dogs pass, but they remain in the narrators' shared memories. Each story conveys the sharp pain, longing, and reflection that Kuzniar identifies as often ignored or else difficult to render. Within sentimental depictions of boyhood and hunting adventures, these novels posit an elevated and more central role for canines within the hunting story in part by focusing on the devastating loss of a companion animal as part of the harsh reality of rural life.

\section{William Faulkner's "The Bear" (1942)}

As part of Go Down, Moses (1942) Faulkner's “The Bear” is a coming-of-age story that remains the most canonical American hunting story. The story's greatest celebrated significance is its metaphorical linkage of a legendary bear named Old Ben with the decline of a wilderness area in Mississippi, which - like the sometimes cherry-picked, anthologized sections of James Fenimore Cooper's The Pioneers (1823) — tends to overwhelm other considerations. "The Bear" 
revolves around Isaac "Ike" McCaslin, who learns to hunt under the tutelage of Sam Fathers, the son of Indian chief Ikkemotubbe and a quadroon slave. Faulkner structures the story in five sections. The first three sections occur when Ike is between the ages of ten and sixteen, and they depict hunting rituals, the training of a dog named Lion as the only dog who seems to have a chance at baying Old Ben, and a hunt that ends in the deaths of Old Ben, Lion, and Sam Fathers. The much discussed fourth section, which Faulkner later described as integral to the entirety of Go Down, Moses, but best removed from “The Bear" as a stand alone literary work, veers away from hunting into Ike's family history (Gwynn). It involves Ike's reflections about the land and the sins of his ancestors at the age of twenty-one, and ultimately his rejection of his inheritance. The fifth section returns to when Ike is eighteen, and features his reflections about hunting, as well as his return to the now abandoned and rapidly developing area of his childhood hunting camp and the unmarked graves of Old Ben, Lion, and Sam Fathers.

In this story, Faulkner characterizes hunting as a family-centered ritual that solidifies relationships, and he muddies the lines that separate humans, predators, and prey by expressing greater interest in the roles of animals in hunts. Of the relationship between Ike and Sam, Ike's process of learning to hunt, and the pursuit of Old Ben, Faulkner writes, "If Sam Fathers had been his mentor and the backyard rabbits and squirrels his kindergarten, then the wilderness the old bear ran was his college and the old male bear itself, so long unwifed and childless as to have become its own ungendered progenitor, was his alma mater" (Go Down, Moses 160). Here, he collapses the boundaries that separate boy from mentor and boy from prey and that collectively foster his woodcraft education as much as anything else. Cary Wolfe writes that to extend beyond the anthropocentric inquiry may first require reconfiguring "the figure of the human" to think beyond a sense of vision that fosters the necessity of defining, conquering, and gazing 
(Animal Rites 3). In summarizing Ike's education, Faulkner posits that becoming a successful woodsman demands looking beyond the foremost sense of vision and time. From Sam, his early hunts, and Old Ben's footprints, sounds, and smells, Ike ascends from a novice to a respected hunter in the course of six years with a hunting camp of men who reconvene for a couple of weeks each November to hunt and come closer to tracking and killing the bear. In one memorable scene, Ike walks nine hours into the wilderness and deliberately tests his sense of the woods by leaving his compass and watch behind, relying on his sense and the way Sam Fathers repeatedly "coached and drilled" him (158). Ike realizes that he is not quite adept at surviving the entire return trip alone, so he goes back to retrieve them after a few hours and then sees Old Ben. The experience is terrifying, but it is also illuminating because Faulkner suggests that only in the course of spending time tracking Old Ben, of noticing the sounds and smells of the woods, and of listening to a ragtag family of human voices associated with the annual hunt can Ike glean enough knowledge to be a part of a team capable of tracking and killing Old Ben.

In positioning Lion as the foremost hunter in the story, as a force even greater than the maturing Ike, who comes to know every space within a twenty-five mile radius of the camp, Faulkner suggests that the hunt for Old Ben is impossible without Lion's expertise and disposition. In the process, he challenges a history of hunting stories that privilege the hunter, and his or her prowess, weaponry, and love for companion animals by portraying a canine as a leader of the hunt. Wolfe writes that humanists often find the "animal other's knowing us in ways we cannot know and master simply unnerving" (Animal Rites 4). Faulkner heightens the contrast in the story by identifying Lion's closest companion as Boon Hogganbeck, his caretaker who loves and works with an animal by all accounts more talented at hunting than himself. Though he loves trailing the infamous bear, Hogganbeck possesses none of his companion's 
hunting abilities. He is a terrible shot, which Faulkner reminds readers in several different situations, and he depends on Lion to trail and bay Ben. Lion embodies "not only courage and all else that went to make up the will and desire to pursue and kill, but endurance, the will and desire to endure beyond all imaginable limits of flesh in order to overtake and slay" (181). Faulkner shows that Lion's maturing capabilities extend beyond Boon's, and that even though the latter is ostensibly his primary caretaker, it is the dog that triumphantly leads the hunt and knows, with his sense of smell and ability to trail, what humans cannot know alone even as they try to account for his talent. The more proficient Lion becomes, the more the annual hunting party members liken him with humans rather than the pack of dogs he leads. Ike, for example, notices that as he matures, Lion seems to possess an "abject, almost human quality" (181). Like Ben, the dog becomes legendary in a way that triumphs above human ambition and spirit, thereby breaking down assumptions that humans have complete reign over the wilderness and suggesting that there is more to hunting that what appears on the surface as humans pursuing prey.

Even though he inverts the traditional hunting story by positioning two animals as its primary figures, Faulkner's approach to "The Bear" prevents him from fully showing how a hunting dog may be integrated within a family. As the story progresses, "The Bear" exudes both the catastrophic suspense and tragic sense of doom that recalls the intensity of the latter stages of Ahab's hunt for the whale in Herman Melville's Moby-Dick (1851). A similar sense of competition manifests into destructive madness, and it engulfs the core members of the familyLion, Ike, Sam Fathers, Boon Hogganbeck, Major de Spain, and General Compson-in different ways. Faulkner asserts that Lion's "cold and grim indomitable determination ... [and] indomitable and unbroken spirit" are necessary for the hunters to have the slightest change at 
hunting as intelligent an animal as Old Ben $(164 ; 166)$. If he blurs the lines among human, nonhuman, predator, and prey, Faulkner also shows what is at stake when humans seek to control the limits of their environment. He reminds readers that even if Lion has sharper senses and greater abilities than the people around him, their behavior and treatment of him shapes his attitude toward trailing. Hogganbeck, for example, starves Lion for two weeks as part of training him with the goal of nurturing the hungry, ruthless qualities that eventually enable him to bay Old Ben. And just before the final hunt, Ike reflects that it felt like the "beginning of the end of something" (172). Later, when all of his training brings Lion face-to-face with Old Ben, Lion charges the bear, which "caught the dog in both arms, almost loverlike, and they both went down" (183). Faulkner presents this grand image of the dog and bear entangled within the context of the human-conspired meeting that leads to the deaths of both animals plus Sam Fathers, who expresses the spirit of the wilderness more than any other human in the story. He suggests, like Melville, that the human hunger for one specific chase leaves little room beyond the individual interests that culminate into a family's mob mentality led by a dog.

The final section of the story, which features Ike returning to the abandoned hunting camp two years later, signals in Ike - here eighteen and who would hunt for the remainder of his life into his eighties - the benefits of the woodcraft education that taught him to read the woods and hunt with a dog's guidance. If the principal players of the hunt have passed and Major de Spain has sold much of the land to timber companies that now harvest its spoils, Ike retains the knowledge he gained from decentering himself within the wilderness. He finds the unmarked graves of Sam Fathers and Lion simply by eyeing the "bearings on the trees: and did, almost the first thrust the hunting knife finding ... the round tin box ... containing now Old Ben's dried, mutilated paw, resting above Lion's bones" (250). Pausing and paying tribute to their lives 
allows Ike to reflect on the loss of the human and animal bonds that nurtured his love for hunting. Faulkner blurs and merges the human, animal, and family into its most eloquent expression in the chase and tragedy associated with one life-defining hunt. With Ike, who acts conscientiously when disavowing his troubled inheritance and who continues to hunt elsewhere, Faulkner suggests the possibility that young adults can improve and mature from greater sensitivities fostered in part by magisterial encounters with animals. Equally as important, by bringing specific animals into sharper focus at the forefront of the hunting story, he provides a basis for children's authors Fred Gipson and Wilson Rawls.

\section{Fred Gipson and Wilson Rawls}

Basing their works from youthful experiences living and hunting in hills of eastern Oklahoma and the Texas hill country, Fred Gipson and Wilson Rawls extend Faulkner's work in “The Bear." In form, their most famous novels, Old Yeller (1956) and Where the Red Fern Grows (1961), bear the sentimental influence of James Fenimore Cooper, but they lack Faulkner's complex, modernist style. However, like each of these authors, Gipson and Rawls stress the benefits of boys hunting with a companion animal to accompany them. If their ages, responsibilities to their families, and lack of an open western frontier to traverse limit the boys from wandering to a far greater extent than Natty Bumppo, and if they cannot yet fathom the mysteries, tragedies, and reshaping of lands that obsess Ike McCaslin, the nearby woods that contains their small communities provide settings for learning, adventure, and danger.

Where Gipson and Wilson Rawls lived deeply informed their lives and their work. Gipson (1908-1973) was born into a farming family northeast of Mason, Texas, where he farmed, fished, and hunted as a child. He began hunting at the age of seven after hearing his father speak of a man in San Antonio purchasing live rattlesnakes for their venom. Gipson 
scoured the farmland around his house and returned home carrying a live rattlesnake tied to a stick. Horrified, his mother immediately killed the snake, and then upon recovering from shock, she beat her son with a barrel stave (Cox 7-8). Gipson's lifelong interest in the outdoors never subsided because of his literary career. To offer an example of the way he fused his writing career with outdoor advocacy, Gipson used one of his autographing tours as a chance to educate his fans about the importance of grass in Texas, which led one local reporter to entitle an article “Author's Primary Interest is Grass” (Cox 113-14).

As a boy, Wilson Rawls (1913-1984) grew up in eastern Oklahoma on land assigned to his mother because of her Cherokee ancestry. Like Gipson, much of his childhood education evolved from outdoor work and play. As an adult, he tried repeatedly to create a novel based on his boyhood hunting experiences, and it took him multiple attempts to draft Where the Red Fern Grows due to his immense struggle to grasp and convey standard American English in a comprehensible way. Indeed, Rawls burned more than five original drafts of the novel and once noted that his spelling and punctuation mistakes were so embarrassing that he was ashamed to submit the novel for publication (Rawls, "Interview"). After the great success of Where The Red Grows upon its release in 1961, Rawls only wrote one other novel, and devoted much of his life to public speeches about his childhood and outdoor commitments.

\section{Hound-Dog Man (1947)}

Gipson wrote many more novels than Rawls, but his most commercial works are HoundDog Man, the novel that launched his career, and Old Yeller, the novel that made him famous. Both Hound-Dog Man and Old Yeller revolve around what Gipson envisioned as a rural boy's greatest desire: to own and to experience adventure with a hunting dog. In Hound-Dog Man, Gipson addresses whether a busy rural family should allow a companion animal to become a 
family member and child's companion. It is also Gipson's first work to chart the boy-canine theme that he would repeatedly write about throughout his career. The novel's first chapter begins from 12-year old Cotton Kinney's perspective:

I was twelve that Christmas, too old for Santa Claus, but still too young to take a great disappointment with any grace. All that fall, I'd saved my cotton-picking money to buy presents for my folks. I bought Papa a brass-studded dog collar and a lead chain. I got Mama an enameled cake-mixing pan that was just the size to feed a dog out of. And after spending that much money on them, I still didn't get the hound-dog pup I'd been pestering them for. (1-2)

Here, Gipson introduces one of the novel's two central conflicts—a boy's pressing desire for a companion animal versus his parents' objections. Like many children's novels, Hound-Dog Man, although narrated from a child's perspective, reveals that Cotton's parents are concerned about his education. They debate the potential virtues of hunting and companion animals. In her study, Jennifer Mason notes that toward the latter half of the nineteenth century, adults began entertaining the idea of "pet keeping as a means of cultivating empathy, self-discipline, and other virtues" that child-rearing authorities propounded at the time (14). This helped to establish the idea of the family pet as a means to nourish childhood emotional growth, and sparked dialogue about pet ownership among families throughout urban areas. To this extent, Hound-Dog Man mirrors adult conversations about the benefits of a companion animal for children. However, the book presents a greater complication or risk to a child's formal education more specific to rural areas: the allure of the surrounding woods and lands in conjunction with the everyday companionship of a hunting dog. 
In sharing Cotton's mother's (Cora's) perspective, Gipson reveals how a companion animal can threaten family formation. Within a strongly gendered sphere, Cora resolutely defines what constitutes family within the household. She upholds the human-animal divide, gravitating to what Jacques Derrida denotes as characteristics "proper to man" and subscribing to a vision of "a humanity that is above all careful to guard, and jealous of, what is proper to it" (383). At a time of endless household tasks and with the desire to ensure her son receives a suitable education, Cora fears the possibility of allowing a dog to enter the family sphere. Dogs appear to represent an unnecessary distraction in areas surrounded by open lands to explore. They also represent what Cora imagines as poor pathway for the long-term social and moral development. Arguing with her husband, she says, "You want our boy to grow up to be nothing but a no-account, fiddle-footed rake? ... With never a thought in his head but to run wild in the woods with a passel of pesky hound-dogs?" (19). And when her husband counters that he benefitted from hunting with dogs, she replies, "but that was because I laid down the law about dogs. Hadn't been for that, you'd still be fooling away your time in the woods, same as always. And we wouldn't have a rag to cover our backs" (19). Cora's voice here reveals the complex necessity of a human-animal divide regarding companion animals in rural areas during this era. When Derrida writes of the selfish human motives that assume supremacy over animals, he theorizes within a world where a companion animal may not be conceived as an impediment to the work necessary to produce food, complete chores, and gain knowledge and skills to support a family. As much as Gipson supports the benefits of a hunting companion for children, he also carefully conveys and legitimizes Cora's perspective. Without her insistence for clear boundaries, she knows that her husband would not have been able to help provide for a family and that a companion animal might threaten her son's maturation. 
Gipson counters Cora's perspective of the human-animal divide by stressing the necessity of compromise in the presentation the novel's second conflict, the fate of Cotton McKinney's hero, Blackie Scantling, a family friend and bachelor who lives in a shabby shack next to a creek and devotes all of his time to hunting or fishing. In Scantling, Gipson recreates almost the exact physical form of what in a different fictional world could be a descendant of Cooper's Natty Bumppo: "Behind them [his dogs] came Blackie, hobbling a long in a pair of bad-fitting shoes. He was long and lean and hungry looking as his hounds" (4). However much Gipson honors Blackie's hunting prowess, he sides with Cora to suggest that this lifestyle is not an ideal model for a young child. At one point, Blackie visits the McKinney household for dinner and offers to take Cotton and his friend Spud on their first raccoon hunt after Cotton's father declines an invitation due to farm responsibilities. In his argument for serving as a guide for Spud and Cotton, Blackie suggests that his parents are depriving the boy of rural childhood joys alongside a dog in favor of formal and agricultural educations. Cora eventually decides to let Cotton hunt with Blackie, but toward the novel's conclusion, Gipson suggests that there must be a revision of Blackie's lifestyle in order to make room for dogs within the family structure. Near the end of the novel, as Cotton returns from the hunt and as his mother finally believes that he is able balance his responsibilities with a companion animal, Blackie, too, settles into Gipson's vision of family via his marriage to a woman named Dony. As Blackie and Dony ride away with their two dogs Rock and Drum, Cotton questions his father about the marriage, and his father says, “Comes a growing-up time, when it's nothing but right for him [a man] to step between the traces and pull his part of the load" (246). For the first time, Cotton and his mentor Blackie have dogs and families, but also the burden of doing well for the sake of others. Here, Gipson suggests that a strict adherence to the human-animal divide in conjunction with family prevents 
the joys and knowledge that lives with companion animals provide, but he also shows that in the worst scenarios, the enticing, realistic limitations of a hunting lifestyle in rural areas can hamper possibilities for children hunters. He dissolves the human-animal divide by insisting that a family that includes companion animals must also balance itself through the greater commitment of humans to one another.

\section{Old Yeller (1956)}

In its emphasis on the potential roles of companion animals within a rural family, HoundDog Man is a more of a children's story written for adults than Gipson's Old Yeller, Gipson's much more successful and popular novel that also features a dog transforming a boy's life. The stakes are different in Old Yeller because the setting is the late 1860s, the main character Travis Coates is a little older and more responsible than Cotton McKinney, and the Coates family relies more heavily on him to hunt, especially since his father remains absent throughout the story while herding a group of steers far north from where they live. Travis's time with Old Yeller is brief, but impactful. Gipson moves beyond debating the possibility of the companion animal's role within an early twentieth-century family unit to depicting a nineteenth-century situation where a family is automatically more dependent on a companion's help.

In the way that Old Yeller depicts a companion animal working within the context of a human family, the novel offers a progressive vision that suggests that dogs stand to benefit from working relationships when they are given important roles. This is a novel extension from Hound-Dog Man, which was far more concerned with the surface level, possible benefits and drawbacks of companion animals on adult behavior and children's development. Even though the novel features many hunts that help Travis and Old Yeller form a close bond, Gipson focuses on how Old Yeller benefits from his inclusion within the family. This observation undoubtedly 
came from Gipson's own experiences, but it demonstrates a point recent animal scientists have made about the evolution of canines. Writing of dogs' emerging needs, Temple Grandin notes, At some point they probably stopped living in dog families and started associating as small groups of unrelated adults. But they weren't a pack, and they didn't have an alpha. They were coworkers, playmates, and probably sometimes traveling companions. Their main attachment was to their human families, not to each other. (Animals Make Us Human 33).

In showing the benefits of accepting a hunting dog as part of a human family in Old Yeller, Gipson forecasts an ideal scenario where a dog has purposes and free reign to move. The relationship evolves in a drastically different direction from Faulkner's "The Bear," where Lion was training for one purpose: to engage his body and spirit to maximize his chances at succeeding at capturing one great human-appointed foe. Grandin implies a greater responsibility on the part of humans to ensure that dogs are cared for, with the idea that humans can better the lives of dogs by acting in parental roles and imagining dogs as part of a family rather than in the commonly widespread power hierarchy that repositions owners in the roles of absent alpha pack leaders. This emphasis, which gains traction in Old Yeller, is pivotal to understanding of how first-world human perspectives about the roles of dogs began to change during the mid-twentieth century and how they extend into the twenty-first century. Grandin's observation lends credit to the idea that in hindsight, Gipson and others who described their companion animals as part of the family actually sensed something that Grandin and other scientists have begun to validate: the greater roles of canines as members of human families. Inhabiting a past setting to speak to the then present, Old Yeller puts forth vision of family dependent on the roles it affords its cherished dog. 
First, Old Yeller acts as a primary guardian for Little Arliss, Travis’s little brother, while Travis completes farm work, and he finds fulfillment in a role that enables a lifetime of play. Before Old Yeller's arrival, Little Arliss shows a propensity for collecting insects, lizards, worms, and even in one case, a small copperhead snake, and sticking them in his pockets. When the frightening snake incident occurs, their mother instructs Travis to teach Little Arliss the importance of killing poisonous snakes. It is Old Yeller, however, who steps between Arliss and potentially dangerous encounters with other animals during play. Gipson stresses how the duo's interaction contributes to both Little Arliss's and Old Yeller's excitement and fulfillment: “Of course, it was Old Yeller that was doing the catching. He'd run the game down and turn it over to Little Arliss. Then Little Arliss could come in and tell Mama a big fib about how he caught it himself" (33). As he runs through the fields alongside Little Arliss, Old Yeller's liveliness and health reveal a marked contrast from his initial thin, emaciated, and haggard appearance when he first wanders onto the farm. Here, Gipson expands what he began in Hound-Dog Man by showing that dogs, too, benefit from the freedom to run, play, and hunt alongside humans. This portrayal validates Temple Grandin's concern that dogs need greater amounts of freedom to exercise rather than being confined into smaller spaces than some of their predecessors experienced. She writes, "There is a huge change in the lives of dogs from just twenty or thirty years ago: dogs aren't free [to run] anymore" (Animals Make Us Human 41). Grandin positions her argument in favor of dog parks or similar outdoor spaces where dogs can congregate and roam free from leash constraints, and the relationship between Little Arliss and Old Yeller that Gipson depicts supports her arguments that play, both hunting-oriented and not, is central to a dog's mental and bodily health. 
As Old Yeller becomes more integrated into the family, he also assumes responsibility by helping Travis with the burdens of managing a working farm and with providing food for the others. Travis learns to accept responsibility for his family, but he is very dependent upon Old Yeller's help to keep the farm sustainable. Their paramount duty is guarding the cornfield, which Travis's father stresses as very important since their family depends on corn to make bread during the winters (3). In this particular task, the stakes are higher because their ability to guard his family's corn from the hunger of other animals directly affects their food supply. In addition to corn, Travis and Old Yeller also help to protect watermelons from skunks during the late summer ripening and harvest time. This means that both spend their evenings sleeping intermittently outside. Coates reflects,

Working there night after night, guarding our precious bread corn from the varmints, I came to see what I would have been up against if I'd had to do it without the help of Old Yeller. By myself, I'd have been run to death and still probably would not have saved the corn. Also, look at all of the fun I would have missed if I'd been alone, and how lonesome I would have been. (54)

Gipson shows here that companion animals in rural areas assisted humans in necessary ways beyond recreational hunting or play, as families depended upon dogs to help protect their livelihoods. In this sense, hunting dogs are also the basis of what we now more commonly refer to as working dogs. Describing these relationships, Cat Warren writes, "The rare perfection of that human and canine partnership in our weird, complex, mechanized world is what keeps working dogs from obsolescence ... Sometimes they are seen as a sentimental and unnecessary indulgence ... [Yet] They can distinguish scent, cover territory, and accomplish tasks that no machine is capable of" (xv). The extent of the working relationship that Travis and Old Yeller 
form is not always at the forefront of a novel that eventually focuses on more treacherous encounters where Old Yeller protects Travis and his family members, but after it begins, it is always readily apparent. For example, when Travis describes a large meal that his mother prepares, which features roast venison and stewed squirrel, Gipson reveals that the family also depends upon Old Yeller's help to hunt more than just animals that act as nuisances in the cornfield or garden areas (54). Given Travis's other farming responsibilities, he likely saves time and gains a larger quantity of meat by hunting with Old Yeller instead of alone. Pat Shipman notes that studies of present day hunting societies throughout the world consistently show that hunts with canines yield both more total meat and more varieties of meats than not. She argues this benefit may have been one of the top reasons why wolf-dogs, canines' ancestors, became the first domesticated animals (186). In the absence of his father, Travis would otherwise have either hunted by himself or perhaps with his younger brother. He and Old Yeller work together, and this relationship helps Travis realize the necessity and means of helping provide for others.

Gipson also expands the notion of Old Yeller as a family member to a further degree by suggesting that their physical safety in the face of other potentially harmful animals also depends their companion. Here, he suggests that in certain situations, by accident or sometimes on purpose, humans find themselves pitted against dangerous wild animals and must react. Travis loves to hunt, and he becomes more adept at it throughout the novel. Providing for his fellow family members energizes him as much the love of the chase and the desire for an active life, similarly to Cooper's Natty Bumppo. Despite his improvement, though, he is never as a prolific a hunter as Bumppo because of his age, and since he supports others and depends more on an agricultural-based lifestyle. Here, Gipson, writing more than a century removed from Cooper and 
American backwoodsmen such as Daniel Boone and Davy Crockett, revises the idea of the lone hunter, opting instead to show a human depending upon a canine for safety in a more explicit manner than his predecessors. He details a series of events when Old Yeller rescues others in Travis's family — Little Arliss from a bear, their mother and sister from a wolf, and Travis from wild hogs. When threat of harm or death arises from these surprise conflicts, Gipson depicts the rare occasions where a family depends upon a companion animal for safety. He insinuates in each of these instances that rural human-animal conflicts includes struggle and death, and by placing a dog in the position of protector, Gipson grants greater agency to companion animals within the family unit and chips away at the human-animal divide. He also foreshadows the coming, but abrupt hardship when Old Yeller's devotion to the family costs him his life when he contracts rabies from a wolf.

Old Yeller's death invites greater consideration of the function of companion mourning in the hunting stories. Travis narrates the dog's coming and passing in the second paragraph of the book, "I remember like yesterday how he strayed in out of nowhere to our log cabin on Birdsong Creek. He made me so mad at first that I wanted to kill him. Then, later, when I had to kill him, it was like having to shoot some of my own folks" (1). This opening scene may seem jarring and perhaps even peculiarly blunt or cruel within a modern context, where veterinarians or their supporting technicians are more likely to end the lives of suffering companion animals, but Gipson also reminds readers that killing companion animals was sometimes a reality within lives of many rural children. And too, from the first page, he notes the painful severity of these occurrences when Travis equates Old Yeller with "my own folks" (1). Gipson might have delayed mention of Old Yeller's death until the end of the novel, but by referring to it at the beginning, he instead invites audiences to prepare to consider the process of mourning the loss of 
a beloved companion animal, which underscores how much of an impact Old Yeller makes within the Coates family. The elongated, but ongoing bit of knowledge is a marked contrast from earlier rural novels that depict people killing their companion animals abruptly or indifferently for other reasons - e.g. Thomas Hardy's Far from the Madding Crowd (1874), when shepherd Gabriel Oak shoots his dog (George's son) without any remorse for running his herd sheep over a cliff (33-34). One modern interpretative challenge the narrative choice presents, then, is to reconcile how a child could love a companion animal so much, only to later have to kill it himself. By mentioning Old Yeller's death early and abruptly from Travis’s first-person perspective, Gipson attempts to temper a tragic rural situation by revealing the entire narrative to be in honor of one dog's life.

Since Gipson makes clear that Travis suffers from Old Yeller's death both at the beginning and end of the novel, the story is as much a tale of mourning as a tale of adventure because of the lost bond forged between the two companions. Focusing on human mourning after the loss of animals, Alice A. Kuzniar notes that while these companions are alive, humans routinely fail to consider the depth and intensity of shared experiences because of the perception of an assumed impenetrable species barrier (138). She encourages artists to create works that enlighten humans about the complex process of mourning. Writing far in advance of Kuzniar's proposal, Gipson rejects the barrier between boy and dog, and his focus on Travis's emotions highlights the arduousness of facing and attempting to overcome a companion's absence. In the weeks after Old Yeller’s death, Coates notes, “I couldn't eat. I couldn’t cry. I was all empty inside, but hurting. Hurting worse that I'd ever hurt in my life. Hurting with a sickness there didn't seem to be any cure for. Thinking every minute of my big yeller dog, how we'd worked together and romped together” (114). Unlike Faulkner's “The Bear,” which largely leaves 
readers to ponder Ike's feelings about the death Lion outside of the text, Gipson tackles a child's pain directly. Beneath the veneer of what seems on the surface like a much more sentimental childhood story, Gipson introduces Old Yeller's death at the beginning and addresses Kuzniar's later call for texts that elucidate the opening of emotions in face of loss. Kuzniar writes that artists seeking to "breach the gap between species" and to dissolve the human-animal binary within animal stories make "guilt inescapable vis-à-vis the animal dependent on human care ...[and encourage] empathetic shame, [and] the sharing of vulnerability" (6). The situation brings the family closer together as Travis's father returns and talks to his son about moving ahead. The boy realizes that he must mature and that there is a new pup to teach how to hunt, a difficult endeavor without the help of the older and experienced Old Yeller. Gipson, though, stops short of suggesting that the new dog can fully replace Travis's memories and learning experiences from his time with Old Yeller. In acknowledging the extent that Old Yeller shapes Travis's present-day life after his absence, Gipson reveals the boy's ongoing vulnerability amidst his budding maturity and commemorates the dog. Older now than when the novel began, Travis accepts more responsibility in training both his younger brother and the new pup how to hunt.

Travis must look ahead and teach what he has learned, but his co-teacher, supporter, and protector is gone. What is left of the novel, then, is his tribute to Old Yeller, which helps him cope with processing the loss. Describing a similar narrative pattern in autobiographical stories that begin and conclude with a dog's death, Kuzniar writes that the "stories that both start and culminate in the dog's death work through the process of mourning by giving voice to the loss. They countervail depressive muteness and avenge against the passivity one feels in the face of death" (144). In narrating the story, Travis shows that the companion-assisted process of growing up is dynamic, as human and animal life spans differ; that in some situations, the 
combination of the desire, ability, and necessity that shape a relationship alongside a canine cannot be replicated once a companion passes. The human sense of loss can be devastating and overwhelming, but the act of expression of grief through narration is a healthier way to experience the process of mourning rather than quietly existing in a melancholy or depressed state. Beyond the thin glimmer of hope that concludes the novel, the story of love and loss is what remains, and it encourages readers to consider not just hunting adventures, but also walks, trips to the park, or other similar memorable life moments made better by present and passed companion animals.

\section{Where the Red Fern Grows (1961)}

In Where the Red Fern Grows, Wilson Rawls frames the story through eyes of an older adult named Billy Coleman who recounts what he envisions as the ideal childhood. This narrative choice presents an alternative perspective from both Faulkner, who focuses on impactful hunts, moments, and specific years within Ike's life, and Gipson, who writes from young boy's point of view. Reflecting as an adult, Billy places more emphasis on the lessons that companion animals helped him learn while hunting. Billy appears closer to his redbone coonhound dogs Old Dan and Little Ann than schoolmates or family members. Although hunting is primarily a means for protecting and providing for his family for Travis Coates in Old Yeller, this is not the case in Where the Red Fern Grows. Billy's family does not depend on him for food, and so he considers hunting as long recreational nights spent chasing raccoons together with his hounds. During these hunts, they help teach Billy lessons he embraces as an adult. In structuring their story around four major hunts that comprise the most exciting parts of the novel, Billy details how hunting with Old Dan and Little Ann teaches him responsibility, reverence and restraint within the family, and mourning, death, and regeneration. 
During the first hunt, Old Dan and Little Ann impart to Billy the importance of taking responsibility for one's promises to family members, including his dogs. Billy communicates to the pair that if they help tree a raccoon, he will ensure that it comes down from the tree. When the dogs follow through with his request, the sycamore unfortunately happens to be one of the larger trees in the forest. Initially, Billy attempts to walk away from the situation, but the dogs help change his mind. Here, Rawls suggests that the dogs are capable of conveying disappointment at what appears like it might be an unfulfilled promise: "With a whipped-dog look on her face and with her tail between her legs, Little Ann came over. She wouldn't even look at me. Old Dan walked slowly around the tree and hid himself” (78). Billy changes his mind instantly, as he feels angry with himself for telling the Old Dan and Little Ann one thing and then abandoning his commitment. He reverses course and begins chopping at a tree that will take days to fell, and he relies on family members who recognize the lesson Billy is learning and offer him company, food, and advice. Despite their assistance, though, they remain at the periphery of Coleman's obligation. The tree finally falls with the help of the wind, the hounds catch the raccoon, and this test helps Old Dan and Little Ann understand that Billy is dependable. Rawls implies that the boy-canine relationship depends on the softening of a divide between owner and companion. Billy's courageous response solidifies bonds with Old Dan and Little Ann throughout the remainder of the novel.

During the second major hunt, while tracking the "ghost coon," a legendarily elusive raccoon similar to Old Ben, Billy learns reverence and restraint. Here, Rawls suggests that hunting does not always have to end with the death an animal, a theme that he would explore to a greater extent in Summer of the Monkeys. During the interlude between cutting the tree and trailing the "ghost coon," Billy, Old Dan, and Little Ann become revered for their collective 
hunting prowess. As a result, Billy makes a bet with rivals Rubin and Rainie Pritchard that he and the dogs can track the "ghost coon." After a long chase, Little Ann discovers the raccoon's secret whereabouts, to everyone's surprise. When the dogs successfully tree the raccoon, Billy ascends it in an attempt to force the animal down, but the raccoon's cries and its heralded reputation are enough to make him change his mind: "He had lived here a long time, and more than one hunter had listened to the voices of his hounds bawling on its trail" (142). Face-to-face with the "ghost coon," Billy acknowledges its skill and realizes that hunting may not necessarily have to include killing in such memorable situations. Then, he decides to take a stand different than that of Faulkner's hunters chasing Old Ben, though this decision also leads to tragedy. Billy descends the tree and argues with the two brothers when they demand that he force the raccoon to come down. In the midst of the argument, there is a dogfight between Billy's dogs and the Pritchards' dog Old Blue, and Rubin dies in an accident with an ax trying to harm Old Dan and Little Ann. The fight, which pitted two dogs against one, is a mirror image of Billy's position while facing the two larger and more aggressive brothers. Rawls shows Billy learning restraint while in the tree and seeking to avoid a violent conflict with other boys, but he also shows the excesses of a pack mentality. Grandin notes dogs are more likely to be aggressive toward other dogs if they are isolated with a small group and not socialized within a wider community of dogs (Animals in Translation, 159). Even though Old Blue and the Pritchard brothers' refusal to prevent the fight spark the conflict, the consequences deeply impact Billy's perspective about hunting and he stops for an unspecified amount of time. Eventually he recovers, returns to hunting, and improves his spirit with the help of Old Dan, Little Ann, his grandfather, and his father during the most exciting hunt of the novel, a championship raccoon hunting competition in the Ozarks. 
In the novel's third hunt, Rawls not only envisions hunting as a social activity that unites hunters, companion canines, and family members together to meet an extraordinary challenge, but he also suggests - through this episode's appearance just after a significant hunting accident - that canines can assist hunters recovering from mourning the loss of other humans. One of Jennifer Mason's most prominent ideas is that over the course of time Americans began to honor people who displayed compassion toward companion and domesticated animals. As companion animals increasingly integrated themselves into human lives, people began thinking about their responsibilities to them in different ways, and this changed how some people understood each other in the context of companions. Mason notes that human efforts to sympathize or take care of companion animals started to convey to others that they were also more likely to be sensitive toward other social relationships with people (158). This observation could also extend toward the ways that companion animals respond to people. If we discern and acknowledge humans treating companion animals well, we should also consider instances when companion animals demonstrate love and sympathy toward humans experiencing trauma. Although Billy's grandfather pitches the idea of the raccoon hunting contest as way of helping his grandson move on following Rubin Pritchard's death, Old Dan's and Little Ann's efforts make the hunt possible, and they inspire him to keep trying during the contest's tougher moments and amidst horrible weather conditions. Describing their extraordinary effort toward the end of the multiday hunt, the contest judge says, "This beats anything I have ever seen. Why, those dogs can read that boy's mind. ... I can't understand some of the things they have done tonight" (207). These comments remind readers, who know far more of Billy's background than the judge, that companion animals have the capacity to forge deeper and more influential connections with their owners than seems reproducible in art. The contest helps Billy to heal and 
regain his confidence through hunting with the support of his grandfather and father, but it is the extraordinary efforts of Old Dan and Little Ann that play a pivotal part in motivating him to stay resilient during a troubling time.

In the aftermath of the fourth and final hunt of the novel, which features a fatal encounter between Billy, Old Dan, Little Ann, and a mountain lion, Rawls also focuses on mourning the loss of companion animals similarly to Fred Gipson's conclusion in Old Yeller, but he posits a regenerative and ceremonial form of remembrance rather than a family replacement. The dogs pursue what Coleman imagines to be a bobcat before he realizes too late that it is actually a mountain lion. After the cornered mountain lion attacks both dogs and Billy, they finally overcome it, but not before Old Dan is mortally wounded. When Old Dan passes, Billy's father attempts to console Billy by telling him that time will help heal his pain, but his advice does not help much as his son experiences moments of intense grief that neither his father or mother nor his sister can understand. He runs through cornfields and spends the night next to a river near where he hunted with the dogs. The situation worsens a few days later, when Little Ann begins to starve herself in grief at the loss of her companion; when she passes, Billy feels even more sorrow.

Yet, Rawls also finds a way for Billy to work through his anguish and to celebrate their lives through their burial process and what follows. After Little Ann dies, Billy builds a coffin before deciding to bury her next to Old Dan: "I knew that was where she wanted to be. [In the process,] I also buried a part of my life with that dog" (242). Here, Rawls emphasizes the irreplaceable sense of loss that Billy feels. His response to the passing of Old Dan and Little Ann offers an example of what Kuzniar posits as a means to counteract the human belief that "the expressive grief over a mere dog is improper" (139). She writes, "There are consequently few 
public rituals or customs to commemorate the loss.... The absence of official mourning, the social foreclosure of grief, then exacerbates the melancholic" (139). As Kuzniar implies, part of this absence of such a ritual is societal custom, but it may also be a relative lack of access to proper burial spaces. Although pet cemeteries do exist, they are rare, and so in this sense, this largely uninhabited rural area enables Billy Coleman an uninhibited sense of creativity in seeking to honor the lives of his dogs. Later, Rawls conveys that the memories of Old Dan and Little Ann carry on after their deaths through the process of earthly regeneration. He implies that each dog's passing becomes part of a natural process that helps beget new life in the literal and symbolic growth a sacred red fern "in all its wild beauty, a wavering red banner in a carpet of green," that later appears above the ground where the dogs are buried just as Billy and his family move away from area (248). Later, as an adult, Billy acknowledges that his dogs' deaths altered his life by signaling an end to his childhood. With the final few paragraphs of the novel, when he returns to the present as a much older man, Billy expresses a desire to revisit the burial place, adding hopefully, "I'm sure the red fern has grown and has completely covered the two little mounds. I know that it is still there, hiding its secret beneath those long, red leaves, but it wouldn't be hidden from me, for a part of my life is buried there, too" (249). For a second time, Billy emphasizes the idea of losing part of himself in the passing of Old Dan and Little Ann, but he is far more hopeful in reflection, as the process of mourning and his decisions in honoring in his dogs inexplicably foster a direct, meaningful, and regenerative environmental imprint that marks an extraordinary phase of his life.

\section{Summer of the Monkeys (1976)}

In Where the Red Fern Grows, Rawls aligns particular hunts with what two dogs help protagonist Billy Coleman learn; in its far more comic successor Summer of the Monkeys, Rawls 
challenges the notion that companion animals can represent wild animals, attempts to humanize prey, and characterizes hunting as a means to strengthen families that include companion animals. The author depicts a boy named Jay Berry Lee and his dog Rowdy attempting to hunt down and re-capture nearly thirty monkeys from a travelling circus following a railroad accident that set them free. Notably, the novel offers a counter to Paul Waldau's theory about the roles of companion animals as advocates for wild animals. He writes, "In one sense, then, companion animals can also be seen as ambassadors for the nonhuman beings who do not fit into this constructed, overtly human-centered category ... Companion animals, then, create opportunities" (28-29). His claim that companion animals can represent wild animals leaves little room for a discussion about what occurs during hunting. Summer of the Monkeys challenges Waldau's theory by suggesting that companion animals might be complicit in this human-imposed representative role, as hunting involves an instinctual psychological enjoyment of the chase for some animals that remains separate from bodily nourishment.

Summer of Monkeys entertains a hunting scenario that explores the negotiation of mental and physical desires between a boy and a dog. As they begin their search, Jay Berry trains Rowdy how to hunt the monkeys. He notes, "Even though I tried my best to explain to Rowdy that I didn't want him to catch anything, I don't think he understood why. It is hard to explain things like that to a rabbit hunting-hound" (49). And when they locate the monkeys, Jay Berry notices that Rowdy's disposition changes: "Growling and showing his teeth, he started getting to his feet. He was getting ready to tie into those monkeys and I knew it. I laid my hand on his back and I could feel his rock-hard muscles knotting and quivering" (52). Here, Rowdy's instinct is to pursue and capture rather than represent other animals, which shows that while it is an ambitious idea to designate companion animals as advocates for wild animals, it is also faulty because it 
requires people to humanize the instincts of companion animals —or, to define what they represent more for our own desires or the biosphere's needs than their natural and circumstantial impulses. This is not to say that human-led action is unmerited, as Rawls points out that Jay Berry must work to temper Rowdy's instinct to save the monkeys from harm. However, instead of angling one species to stand in for another, Rawls channels a close boy-dog relationship to posit that change may be more situational, localized, or evolved from a family relationship; that knowledge emerging from negotiations resulting from the undoing of human-animal boundary should also factor into politicized positions.

If all of the works discussed in this chapter hinge on dramatic plots, then Summer of the Monkeys is the most outlandish of them all, in part because with the minor exceptions of Old Ben in "The Bear" and the "ghost coon" in Where the Red Fern Grows, it asks readers to consider and empathize with the perspectives of the pursued animal. Guided by Jimbo, the monkeys continually outsmart Jay Berry and Rowdy. Throughout the story, the monkeys elicit empathy from readers. As the most human-like of all animals, they appear more as mischievous playmates rather than prey. Rawls makes clear that they are not a natural fit in the Ozark Mountains of Oklahoma, and so they must be caught and returned to the circus. In temporarily placing monkeys in this role, Rawls humanizes prey by calling attention to the degree of similarity among the monkeys, Jay Berry, and Rowdy as they attempt to outwit or capture each other. The oddness of the situation, with Jay Berry and Rowdy engaging in an unconventional hunt and with monkeys loose in the Ozarks, asks readers to consider what separates a family of hunters from families of groups of prey. Rawls suggests that neither of the parties can stand in for one another and that they all have separate desires and roles in the hunt, but he also notices that it is sometimes more difficult for humans, but not necessarily other animals, to hunt animals that we 
easily identify with in circumstances where all human needs are met. In depicting a similar sensibility among humans and monkeys, Rawls does not decry hunting, but instead asserts that human hunters have a responsibility to consider other species-related factors when hunting that companion animals may not be able to intuit or realize.

In the novel's final act, Rawls also expands the nature of the hunting story by incorporating a plot twist that further humanizes prey animals and transforms the adventure into a rescue mission. He does this by emphasizing how the health and kinship among animal families and communities mirrors the relationships within Jay Berry's and Rowdy's own family. Following a storm, the monkeys are collectively in poor condition. As Jay Berry and Rowdy set out for one last chance to locate them, they stumble upon a mother duck watching over her young ducklings, teaching them how to hunt for food and guiding them toward safety. In the midst of an otherwise extraneous and sentimental scene, Rawls notes a large and dangerous catfish lurking nearby. When it splashes in the water, Rawls writes, "Instantly the mother duck quacked her alarm and herded her babies into the shallows. She knew all too well that a baby duck would make a good meal for a big old catfish" (220-21). Rawls suggests that predator-prey relationship appears throughout the natural world even within what might be understood by humans as touching or sentimental situations, and that family-oriented social structures sometimes work as a means to thwart the danger. This scene with the ducks thematically transitions readers to a situation where Jay Berry works with Jimbo, the lead monkey, to help rescue the other monkeys. Soon after he and Rowdy locate the monkeys, Jay Berry realizes that they are not faring well outside of captivity and their natural environs. In reaching out and showing compassion toward one of the smaller monkeys, Jay Berry is finally able to convince Jimbo to lead them back toward his family's house. 
Rawls stops short of inviting deeper criticism about the lives of animals within circuses, which is largely outside of the scope of setting and story, but he does stress how the elongated hunting adventure with Rowdy enables Jay Berry to help both his family and a group of monkeys. Much of the money that Jay Berry earns goes toward financing reconstructive leg surgery for his sister Daisy. In the novel's final scene, Daisy returns home and is able to run with Jay Berry and Rowdy: "Hand in hand, Daisy and I ran through the clover, the alfalfa, and the timothy ... I had never seen my little sister so happy. It made me feel good all over" (282). Here, Rawls again emphasizes the dominant theme that links both of his novels - hunting as a family-oriented affair that often depends upon the knowledge and participation of multiple generations of humans and their companions. In lieu of the killing of a trophy animal or an extraordinary hunting tale, Summer of the Monkeys concludes with the simpler ending showing a brother, sister, and dog running happily near their house and the prey presumably alive and thriving in better conditions.

William Faulkner's “The Bear” and the novels of Fred Gipson and Wilson Rawls reaffirm that for multiple generations of Americans throughout the late nineteenth and twentieth centuries, canine companions helped to define the hunting experience and educate hunters about how the process of hunting consisted of environmental and psychological, human-animal interactions far more entangled and complex than simply the idea of one human with a weapon killing animals alone. All three writers stress more pivotal roles for companion animals and broaden the scope of the American hunting story beyond that shown in James Fenimore Cooper's The Leather-stocking Series. They reconsider the concept of family to include canines that hunt alongside boys, and they focus more in depth on the process of mourning the loss of a cherished companion animal and on what relationships with companions teaches young hunters. 
In these works, Faulkner, Gipson, and Rawls also eschew worldwide hunting expeditions for a focus on their local environs: the Mississippi wilderness, the desolate hill country of Texas, and the Ozarks of eastern Oklahoma. In repositioning hunting an a family affair in surroundings close to home, these authors sought a popular audience that either believed or once knew that hunting was a recreational sport that could foster the physical and emotional development of children within their communities. 


\title{
Chapter Five:
}

\section{Trailblazers and Travellers: Women's Hunting Narratives in the $20^{\text {th }}$ and $21^{\text {st }}$ Centuries}

\begin{abstract}
Although American hunting stories from the nineteenth and twentieth centuries offer a broad panorama of different types of hunting lifestyles and probe at the various ways that humans interact with animals, the genre faces limitations stemming from exclusive white masculinit y. As a result, one primary threat to the genre's stability is the degree to which sexism and racism date and condemn its writers, and cast a dark shadow over hunting stories. Like much of the other genre fiction during the past couple of centuries, these narratives display the harmful ugliness and vulgarity that characterizes the worst white American male attitudes toward women and people of color, as well as environmentally hazardous attitudes toward animals. The degree of past offense is often so extreme that it renders many hunting narratives obsolete in the twentyfirst century, marking them as products of a bygone era as America and other first-world nations strive to become more multiculturally inclusive and environmentally proactive. Concomitantly, a bigoted historical legacy also helps to date hunting as a recreational sport by discrediting some of its major proponents, who undercut their authority by expressing intolerable racial, sexist, or classist attitudes, and who invite and solidify the idea that hunting is a pastime for imperialists, racists, and sexists more than anyone else.
\end{abstract}

As a means of moving forward from a history of prior wrongs and proclaiming the need for change in regards to voice and perspective, the following chapter is partly a recovery effort that demands that women's contributions to hunting literature be included within the subfield. It explores the hunting accounts of four women during the twentieth and twenty-first centuries. Pauline Brandreth and Courtney Borden (in the 1930s) and Lily Raff McCaulou and Georgia 
Pellegrini (within the last decade) each faced the challenge of participating and finding their own spaces within a sport overwhelmingly seen as a masculine escape from femininity and its domestic trappings and responsibilities; with great determination, each writer earned respect within the hunting community despite great odds.

Even in the present, hunting remains primarily a male-dominated recreational sport although there is reason to believe that cultural attitudes are evolving as demographics slowly begin to change. In the early 2000s in America, ninety-five percent of hunters were men. Ninetyone percent of them were white, they tended to be less formally educated and inhabited smaller towns, and their per capita representation had been decreasing for decades (Dizard 43). By 1960, the percentage of hunters nationwide had dropped to eleven percent from a twenty-five percent in 1945; now, it currently stands at five percent with participation rates varying by state (Bronner 32). For example, on the higher end in states such as Montana, North Dakota, South Dakota, Arkansas, West Virginia, and Maine, where hunting remains popular, fourteen to nineteen percent of residents identify as hunters; in California, Connecticut, and Massachusetts, where hunting is least popular, fewer than one percent of residents describe themselves as hunters (Bronner 27). Between 2006 and 2011, however, and in contrast to continuing declines in the overall percentages of people who identify as hunters, the number of women participating in the recreational sport increased twenty-five percent, and in total, women now comprise eleven percent of all American hunters (Schmitt). Women have more access to hunting and greater representation than ever before, which has contributed to an increased interest in teaching girls how to hunt and providing more opportunities for them to hunt. This twenty-first century development prompts a greater exploration of women's contributions to hunting literature and thought. 
Two of the more memorable hunting books by women, Paulina Brandreth's Trails of Enchantment (1930) and Courtney Borden's Adventures in a Man's World: The Initiation of a Sportsman's Wife (1933), offer insight into women hunting's lives in the early part of the twentieth century, and two of the more recent works, Georgia Pellegrini's Girl Hunter (2011) and Lily Raff McCaulou's Call of the Mild: Learning to Hunt My Own Dinner (2012), inaugurate a new era of women's hunting writing in the twenty-first century. Based on similarities in narrative structures and areas of emphasis, McCaulou's localized memoir continues in the tradition of Pauline Brandreth, while Pellegrini's travelling account expands upon Courtney Borden's work. As a result, both sets of texts portray how hunting has changed following the increase in conservation-oriented regulation that expanded at the beginning of the twentieth century, as well as the feminist movement, the advent of Earth Day, and greater environmental interest that began in the United States in the 1960s and 1970s.

The first half of the chapter focuses on Pauline Brandreth and Lily Raff McCaulou. Each of these writers highlights one particular area of the country and focuses on the nature of the hunting trophy. Brandreth writes within an aristocratic-oriented hunting tradition, and she privileges the trophy as not only an emblem conveying hunter's effort, experience, skill, and luck, but also as a reminder of a greater, ritualistic experience. Offering an opposing perspective, McCaulou decries the trophy as a now dated form of material worship by criticizing a long-established system that privileges trophy size, and she offers alternative celebratory measures for future forms of hunting. In imagining the hunted animal as a co-actor in the creation of one human's life experience, McCaulou positions the hunting and eating experience as the apex of hunting rather than trophy collecting, which she envisions as a detrimental in a 
more modern era where hunting stories are increasingly captured and shared via digital photography or recordings.

The second part shows how Courtney Borden and Georgia Pellegrini re-envision the insular man's world of hunting by focusing on the impact of hunting on the human body in regards to physical exertion and the preparation and consumption of animals. While Borden's account reveals the frustrations and pleasures that accompany travelling alongside her husband on various hunts throughout a one-year period, Pellegrini refocuses the travelling hunter's account by using it as a mechanism for personal expression through food creation and gourmet cooking of the animal afterwards. By writing about what transpires after the hunt, when humans process a dead animal into food and it becomes a part of the human body, Pellegrini attempts to appeal to a foodie generation by championing hunting a means of celebrating food and making more conscious eating choices within a highly industrialized food system.

\section{Women's Hunting Narratives, Ecofeminism, and Posthumanism}

Women's hunting narratives remain underexplored in part because they present a conundrum to some traditional ecofeminist perspectives. Central to this tradition is Annette Kolodny's foundational work The Lay of the Land (1973), where the author argues that colonists, settlers, and writers feminized the American landscape through metaphor as they migrated here, prompting subsequent generations to imagine the landscape as a feminine provider and protector in the midst of engaging in environmentally-damaging actions. Kolodny notes that the country's fast developmental pace from primitive woodlands to becoming an industrial power enabled native writers to look closely at the ways that the alteration of the landscape contradicted the wishful utopian visions that accompanied its feminization. She writes, "Only in America has the entire process remained within historical memory, giving Americans the unique ability to see 
themselves as willful exploiters of the very land that once had promised an escape from such necessities" (8). Colonists settled the land and pushed Native Americans further and further toward undesirable territories and reservations through subsequent generations, which culminated in the closing of frontier and further moves toward a highly industrialized America. In its emphasis on the use of feminine language in conjunction with environmental degradation enacted primarily by men, Kolodny's study contributed to the development of early ecofeminism, which aligned femininity with the care of the environment and masculinity with its despoliation. Mary Daly’s Gyn/Ecology (1978) expanded Kolodny’s work and ecofeminist study in more overtly political terms. Daly identifies patriarchy as centrally responsible for damages toward women and the Earth's flora and fauna. Of the consequential societal damage, she writes, "males and males only are its originators, planners, controllers, and legitimators of Patriarchy" (39). Daly’s analysis feeds directly into discourse against hunting, not only for its associated violence but also for its high rates of male participation. Although she does not directly address hunting, Daly would likely find many of its modern practitioners who embrace a conservationist approach to wildlife problematic in the way that they seek to exert control over natural environments and animal populations through management. Her study suggests that the sort of behaviors hunters practice are too closely similar to their ancestors' prior actions which had led to major environmental damages. Greta Gaard, in Ecofeminism: Women, Animals, and Nature (1993), also links the irresponsible disregard of the Earth with masculinity, and she explicitly calls for ecofeminists to continue "to expose ... dualisms and the ways that feminizing nature and naturalizing and animalizing women has served as justification for the domination of women, animals, and the earth" (5). Delineating gendered spheres, she pits "women, emotion, animals, nature, [and the] body" against "men, reason, humans, culture, and the mind" (5). At 
the crest of the mid-1990s, Gaard called for further research explicating the male-centric damages. Within a couple of years, scholar Mary Zeiss Stange responded, but she altered the course of ecofeminism by complicating some of its pivotal assumptions.

In 1997, Stange published Woman the Hunter, in which she rejected ecofeminism in its then current iteration because it simplified women's relationships with the environment and seemed to imply that it was possible to live a non-consumptive lifestyle. Stange writes, “...American ecofeminism often unwittingly, but nonetheless deliberately, accepts and perpetuates traditional gender stereotypes about femaleness and femininity, and about women's identity with nature - their 'innate' passivity and nonviolence_-against men's inborn aggressiveness and alienation from the nonhuman world" (Woman 2). She sought to disprove assumptions too often taken for granted as foundational principles and to ultimately improve the development of ecofeminism by positing that hunting could be a legitimate part of both women's and feminists' experiences. In bringing consumption to the forefront, she also paved the way for later intersections between ecofeminism and ecomaterialist or posthumanist theories. When writing about consumption's absence within ecofeminist discourse, Stange notes, "No matter how lightly one treads the earth, one leaves one's mark in myriad ways, not all of them intended or immediately evident" (Woman 8). Because of this gaping theoretical hole, Stange claims that gendered symbolism assumptions taken too literally are faulty because they inevitably umbrella large swaths of women who live in different and sometimes contrary ways. Stange's study does not focus specifically on the history of women's hunting narratives, but it grounds the possibility that all women's stories, no matter whether they adhere to a dominant metaphorical narrative or not, are potentially useful in creating a fuller picture of how women interact with their environments. 
If Stange points to the potential for recovering women's hunting writing, a model work of scholarship for this endeavor is Karen Kilcup's Fallen Forests: Emotion, Embodiment, and Ethics in American Women's Environmental Writing, 1781-1924 (2013). Like Stange, Kilcup stresses the complexities of women's experiences within a vast span of time, which culminate in literary art that emerges from real life impressions of the natural world. She, too, implicitly steers clear of overarching nature metaphors, arguing instead for the need for some environmental critics to "reground textual study in physical reality, even while realizing the widely varying meanings of materiality" (15). For many of the writers Kilcup researched, "writing equaled activism," a means to embody and capture their experiences to convey their concern around the use of natural resources and as an attempt to ignite change (16). Though the book's title suggests that her research ceases after the first quarter of the twentieth century, Kilcup's afterword includes analysis that links the women writers of her study to modern authors and activists such as Barbara Kingsolver, Jamaica Kincaid, Annie Dillard, and Winona LaDuke. She emphasizes how prior renderings of environmental embodiment reappear in the different modes or forms of expressions of these writers nearly a century later. Following in the tradition of Kilcup, I contend that women's hunting narratives — which are missing from Kilcup's studyalso add something to the history of women's writing. Because of the unique perspective they provide, women's hunting stories invite analysis about how hunting has changed for women during the course of the past century. In this sense, my goal for this chapter is both to recover women's hunting stories and to uncover what they add to discussions of posthumanist relationships and ecomateriality.

The posthumanist writings of Matthew Taylor, Karen Barad, and Stacy Alaimo form the basis of my analysis of the consumption of animals in regards to hunting. Taylor differentiates 
posthumanism from humanism by viewpoint: humanists see themselves as separate via reason and other human qualities from posthumanists, who consider themselves inextricably grounded within a world of many living things beyond humans and their actions, and sometimes even chemical compositions or reactions (8). Taylor cautions that no matter one's view, participants within both traditions are to a certain extent locked into behavior patterns that rely on the nonhuman world to satisfy "our all-too-human agendas" (8). This, however, does not mean that posthumanism is a moot theoretical field; instead, if it cannot fully empower humans to control their desires or needs, it can make them more aware of just how intertwined we are in living worlds outside of our skin that become parts of our bodies and experiences. A more attuned audience would theoretically create more awareness and concern for the environments that physically become a part of us through the air we breathe, food and water we drink, and the material emblems that we use to define and shape our existences. Posthumanist readings of hunting stories enable greater emphases on hunting trophies (long considered the emblems of the sport), the actual experience's influence on the body, and food.

Karen Barad's agential intra-action and Stacy Alaimo’s trans-corporeality help to situate human-animal relationships in regards to hunting. Barad describes agential intra-actions as "specific causal material re-enactments that may or may not involve "humans"” and that, as they occur, constitute the creation of phenomena (817). As all matter is in the process of creation, growth, or dissolution, no one thing is static; instead, what we conceive of as differences among matter or properties occurs as a result of human perception of phenomena. Stacy Alaimo's concept of trans-corporeality helps to clarify this proposition. Writing in response to twentieth century theories that isolated or fragmented humans from their natural worlds, and that focused on language-oriented signs or systems that theorized what it meant to be human, Alaimo notes 
that trans-corporeality returns the human body to a "world of biological creatures, ecosystems, xenobiotics, humanly made substances" (Bodily Natures 15). For Alaimo, the "material interconnections of human corporeality within the more-than-human world" helps scholars move past constructions of race, gender, class, and sexuality into studies that focus less on social hierarchies and racial human composition and more on "interchanges and interconnections between various bodily natures" (Bodily Natures 2). From a purely corporeal perspective, Barad's and Alaimo's theories point to newer critical directions with the notion of analyzing evolving states within a rapidly changing and endangered world. Together with Kilcup and Taylor, Barad and Alaimo help conceptualize how women's hunting writing reveals that "morethan-human" environments become a part of women's lives and how they imagine and share their relationships with the natural world. In debating the purpose of the hunting trophy or its potential replacements, and in documenting how the physical nature of hunting and the resulting nourishment positively impacted the human body, Paulina Brandreth, Lily Raff McCaulou, Courtney Bordin, and Georgia Pellegrini alter the course of hunting discussions by positing that during and after the hunt, humans change as the experience of pursuing prey animals becomes part of the human during the hunt as well as afterwards during through consumption and memory. Championing the underrated influence of the hunting experience on the human body, these authors encourage hunters to consider their responsibilities to the lands and animals that literally become a part of them as hunters.

\section{Trailblazers: Paulina Brandreth and Lily Raff McCaulou}

At first glance, Paulina Brandreth (1885-1946) and Lily Raff McCaulou (1980-) appear markedly different because of generational differences, social class, and their homes on two separate coasts. Brandreth, who published her work under the pseudonym Paul Brandreth, wrote 
about the Adirondack region in New York, where she lived and hunted among family members and friends on a 24,000-acre tract of land that her father owned (Wegner vii). Largely enabled by her family's wealth and social connections to upper class hunting society, Brandreth spent much of her life in the woods, which culminated in her book Trails of Enchantment in 1930. Conversely, Lily Raff McCaulou accidentally stumbled upon hunting, which became her passion after she accepted a job as a journalist in Bend, Oregon. Having lived all of her prior life in the Washington, D.C. and the New York City areas before moving to Oregon, McCaulou had no experience hunting and pursued it as a way to better understand and participate within her local community. Like Trails of Enchantment, her book Call of the Mild is an account of hunting within one region of the United States. Both authors write with a hopeful perspective while also seeking to understand the complexities and conundrums of the environment. In this manner, they embody what environmental scholar Aaron Sachs characterizes as an "Arcadian” mode. Writing about Henry David Thoreau as a means of explanation, Sachs notes that while the famous naturalist was at times critical and cantankerous, there was also a side of him that remained hopeful and resilient as a naturalist observing one particular area (87). If Thoreau often claims more attention for his persona as a social critic, his Arcadian spirit appears throughout his writings and conveys another layer of his personality. Like Thoreau and generations of other nature and hunting writers who pursued similar courses of action by concentrating their principal works in one region, both Brandreth and McCaulou optimistically write about hunting in a specific area in a way that is both celebratory and insightful as it seeks to engage in modern hunting culture.

One central question that twentieth century hunting writers grapple with is the representational meaning of the hunting trophy. Some writers characterize the hunting trophy as 
an example of human mastery and dominion over the animal world. John Madson, for example, writes that the trophy "may represent a hunter's effort not only to possess beauty, but also to keep something important to him from slipping away and being forgotten. And if the trophy testifies that here is a strong and skillful hunter_well, what's the use of denying it?" (131). For Madson, a trophy may be emblematic of a story, but it is also a hierarchical means of organizing hunters based on their proficiency. Underlying this viewpoint, still common among some present-day hunters, is a form of mastery and control that Annette Kolodny characterizes as a part of a historical masculine impulse. Kolodny identifies works of American literature that wrestle with the concept of the pastoral in the midst of waves of modernization, and she argues that they continually position the feminized landscape as "both vulnerable and victimized" (143). In response to fictional hunters and male characters who seek to reshape the environment for human use in the works of James Fenimore Cooper and William Faulkner, Kolodny identifies a "continuing fascination with the lone male in the wilderness, and our literary heritage of essentially adolescent, presexual heroes [that] suggest that we have yet to come up with a satisfying model for mature masculinity on this continent" (147). Following Kolodny's logic as it relates to hunting, the question then arises as to whether the American hunting trophy can be conceived as anything more than an emblem of primitive masculinity within posthumanist understandings of the American landscape. In part, what distinguishes Pauline Brandreth's and Lily Raff McCaulou's writing from other women's hunting narratives is their focus on the concept of the hunting trophy in looking critically at a common aspect of hunting. Writing in 1930, Brandreth positions the hunting trophy as a distinct post-hunt material emblem that serves as a reminder of one particular hunt within a hunter's life, and thereby becomes inextricably enmeshed with the evolution of one human life, whereas McCaulou suggests that both new video 
technologies and prior decades of overemphasis on size and measurements date the hunting trophy, and that too often it becomes reductive of the complexities of hunting. Because their divergent views are both interrelated with the development or becomings of human hunters, they can both be contextualized within posthumanist theories that stress the elemental instances or materials that hasten growth. If both hunters seem to emphasize a can-do sense of individualism that may seem contradictory to the deconstruction of the idea that all material things belong to humans, they demonstrate how individual lives can be altered by how humans conceive and respond to hunting trophies.

During Pauline Brandreth's lifetime, the popularity of trophy hunting in America was in its earliest formal stage because of the relative newness of the Boone and Crockett Club, an organization established in 1887 by Theodore Roosevelt and other conservationists. Founded five years before the Sierra Club, the Boone and Crockett Club was the first private organization to champion conservation at the national level, and it served as a model for later hunting-oriented environmental groups such as Ducks Unlimited, the National Wild Turkey Federation, Pheasants Forever, and Whitetails Unlimited (Reiger 23; McIntyre 178). Members of the Boone and Crockett Club helped to spearhead what became the Lacey Act of 1900, which prohibited the transfer of game animals or products for sale from state to state, and thereby criminalizing the market hunting that drastically reduced game populations during the nineteenth century. In addition to its conservationist efforts, the organization remains known for starting a point system based on size measurements of trophies for different species. This ongoing program emerged from a period of time between 1906-1922, when the future of some large game populations remained in peril and when Boone and Crockett member William T. Hornaday founded the National Collection of Heads and Horns at the Bronx Zoo in New York City as part of an effort 
to educate the public about the importance of conservationism ("History"). A combination of the rise in conservationism, the closing of the frontier, the Lacey Act, President Theodore Roosevelt's efforts to create national parks, and the exhibit Hornaday opened encouraged American hunters to focus on quality rather than quantity, or to pursue elaborately planned hunting expeditions that focused on trophy hunting, and, by extension, to create environmental conditions via conservation measures that would allow trophy hunting to continue.

Among the experienced hunters that Brandreth often accompanied, the central goal was to "get their trophy ... with a clean shot" (78). Hunting within the bounds of large land parcels with conservationism in mind and without a great need for either money or food, these hunters placed utmost value on their conceptions of "fair chase" in pursuit of whitetail deer trophies. Brandreth explains some of the trophy's mystique:

One of the chief charms about hunting the whitetail rests in the fact that practically every trophy taken bears a stamp and individuality entirely its own. It is rare to find two heads exactly alike. The shape, spread, symmetry and number of points display an almost endless variety. The color of the horns is also subject to differences, some being brown or yellowish, while others look bleached, and are of a much lighter tint. (41).

The hunter's “painstaking” process of pursuing an animal and securing a distinct trophy distinguished hunting from other recreational activities (316). Moreover, the trophy hunting experience linked modern hunters to prior generations, even if it originated with a greater focus on attaining a trophy. An emphasis on trophy hunting could redefine hunting in a way that would align with conservationist efforts while encouraging competition and sportsmanship. 
Brandreth's writing about trophy hunting also diverges from women's environmental writing that focuses on the exploitation of nature at the hands of men. Karen Kilcup notes that one unfortunate and unjust side effect of women's writing about this type of environmental abuse is the vulnerability "to charges of feminine sentimentalism and nostalgia, unenlightened childishness, and anti-progressiveness" in the context of a male-dominated "liberal democracy [that] privilege[s] individual achievement" to the detriment of environmental concern (13). As Kilcup suggests, some women, writing about environmental issues in the face of some of these stereotypes, approached risky rhetorical situations courageously while writing in opposition to masculine values. Others writing in more male-dominated fields, as in the case of Brandreth, sought to publish their thoughts by pretending that they were men. Brandreth sought to bridge the gap between hunting trophies and the complex hunting experiences that accompanied the pursuit of a trophy. If attaining a trophy was the goal, the process of the hunt connected humans to the predator-prey processes of the natural world, and it also increased the amount of time they spent in wilderness areas. Brandreth believed that the distinctness of one deer's life, embodied in the form of the trophy, mirrored the stamp of the individual hunter's life that developed from extended time spent in woods: "The wilderness has ever been a molder of unique personalities. Like the sea and the desert it has set its stamp on the individuality of men" (99). In Brandreth's ideal world, both nature and human thinking work in tandem to enrich the human mind, spirit, and comprehensive understanding of the natural world. She continues, "In spite of civilization, in spite of luxury and money and modern conveniences and mechanical progress, we are products of nature, and to nature we turn for the realization of things that are often infinitely more satisfying and stimulating than the creations of our brains and hands" (312). In a mechanized world of assembly lines that produced identical mass-produced products, the hunting 
trophy represented something humans could neither fully control nor shape, and could only pursue with diligence through elongated hunting experiences. The trophy personified the individualized experience that required hunters to slow the pace of their lives to participate in a ritual that Brandreth believed had the capacity to shape their lives regardless of gender.

In this sense, the trophy serves as a frozen-in-time representational token of preserving one person's hunting experience. In contrast to the way that market hunting from the prior century flourished under the assumption that wild animals were living commodities, Brandreth wrote in favor of trophy hunting as a means of repositioning the recreational sport as something greater than mass slaughter. Preserving the experience of pursuing a trophy for greater numbers of individual hunters would require more human-led conservation in the face of an expanding industrial society that reduced wilderness areas and depended upon an increasing population of humans. Posthumanist theory helps contextualize Brandreth's emphasis on the value of individual's experience as personified through the trophy. In explicating her concept of intraactions, Karen Barad reconceives agency as a performance within a certain snapshot of time rather than a personal attribute. She writes of agency as an "ongoing reconfiguring of the world" and as a means to suggest that environments are constantly in the process of change or becoming (818). If this conceptually enables humans to realize the lack of control that they have in an everyday sense by breaking down their understandings of things previously assumed as within their control, it also calls for foresight and premeditated action in an attempt to maintain a more livable world. Brandreth's celebration of an individual's experience among other hunters, then, may provide humans a means of realizing that the trophy may reflect one environmental encounter within a constantly evolving and living material world that necessitates consideration about human influence. 
Facilitating the moment of killing an animal for the purpose of securing a trophy, as Brandreth shows, requires humans to engage in the environment in a systematic, beneficial, and novel way in contrast to the errors of the prior century. In short, under the greater umbrella of the concept of fair chase, twentieth century hunting would require greater intra-actions on the part of humans to transform deer hunting into a sustainable activity and to encourage the pursuit of trophies. Brandreth credits the outlawing of summer hunting, night hunting, and trailing deer with hounds for increasing deer populations, but she goes further to suggest that the dates of the month-long fall hunting season be scaled back by two weeks to account for weather conditions that enabled too great a number of deer to be harvested $(6 ; 55)$. These suggestions are particular to hunting in her region and exhibit the foresight gleaned from extended wilderness observations. Brandreth also aligns improved trophy hunting with forestry and preservation, writing at length about managing forests through clear-cutting and burning, and securing and maintaining public and private lands from the potential "despoliation by a commercialistic age" (10). The possibility for hunters to have a chance at an experience where they could obtain a trophy became the motivational factor to galvanize animal population management and environmental change. Brandreth theorized that expanded opportunities for hunters to enrich their lives through the pursuit of a trophy would inspire them to be more environmentally-cognizant, and to take positive actions in while also pursuing an individual goal. Aligned with the aims of a prior generation of conservationists, her writing helped to facilitate the subsequent creation of conservationist and hunting clubs that sought to preserve hunting by reshaping environments to benefit animal populations.

Writing a little more than eighty years after Brandreth, Lily Raff McCaulou also focuses on trophy hunting and writing as a means to document and theorize hunting experiences. Unlike 
Brandreth, McCaulou was an outsider who learned to hunt after moving to Oregon. Whereas nearly everyone in Brandreth's family and social circles were involved in hunting, none of the people in McCaulou's family hunted, and so with the help of a few others and through extensive reading, she trained herself to hunt as a means to explore a passion of many of the members of her new community. Because of her role as a newcomer to the general hunting world, McCaulou's Call of the Mild offers a fresh take on hunting, unencumbered by traditions that sometime threaten to undermine its future.

Notably in contrast to Brandreth, McCaulou argues for the limitations of pursuing trophies while pointing toward perhaps a new era of hunting. From her perspective, the twentyfirst century problem with privileging trophy hunting is the power of the camera - particularly in the way that photography and video recordings portray trophy hunting to non-hunting audiences. In direct opposition to the Boone and Crockett Club, she characterizes the points-based record keeping system as "nefarious" with potentially negative consequences that include hunters overemphasizing the result of killing large game animals rather than the entire hunting process (184). To this extent, she counters Brandreth by suggesting that the trophy hunting tradition has become so entrenched, documented, and recorded that it has undermined prior intentions. Throughout her book, McCaulou explores how to embody her role as one living, breathing, and inspiring woman hunter in the face of technologies that misconstrue the process of hunting instead of demystifying it. Karen Kilcup notes that modern women writers who address environmental issues must grapple with how material or technological progress aligns and serves capitalist interests that culminate in colonialism, imperialism, and exploitation of the natural world. She writes that in the face of such challenges, women environmental writers "writ[e] about home in distinctive ways ... [contemplating the differences among labels such as] 
domestic and wild, native and immigrant, civilized and savage" as a means of conveying socially responsible and environmentally-sensitive roles (331). Kilcup's study does not directly address modern hunting writers, but she identifies the predominant issue that guides McCaulou: how to facilitate an individualized hunting experience that benefits both the hunter and environment within a market- and data-driven economy. Whereas Brandreth envisions the trophy as a distinct fingerprint of a particular hunt, McCaulou argues that the subsequent technological trends of ubiquitous photography and video recording of trophy hunts introduced methods of presentation that threaten to undermine the experience for both hunters and outsiders. Decrying hunting television shows, she criticizes "around-the-clock channels ... [that] display little if any footage of the actual pursuit, instead focusing solely on the kill" and that tell stories of the elongated hunting process in a five-minute time span (183). She continues, "The bulk of the footage is a rapid sequence of spotting an animal, setting up a shot and taking it. The hunter and guide spend a few seconds admiring the animal and remarking on its gargantuan size. Then the show switches to a new hunt" (184). Because of the limitations of the medium and a cultural premium placed on trophy hunting, hunting shows stress the moments of the hunt that leave the strongest impression rather than the sometimes elaborate process. Although veteran hunters who better understand what occurs behind the scenes may experience the rhetorical effect in a different manner, McCaulou argues that the risks of misrepresenting the recreational sport to people such as her former self, during the years she considered the sport either barbaric or outdated, outweigh the benefits.

McCaulou's coinciding concern regarding the evolution of documenting and broadcasting the decontextualized trophy experience is an overemphasis on animal size or measurements, and so she articulates an alternative vision. Like Brandreth, she comes to 
understand hunting as a means to encourage individual participation in evolving environments and seeks to convey its additional benefits. One way she reconsiders hunting is by casting light on the entire hunted animal rather than what makes it a prized trophy. Karen Barad writes that the "reconceptualization of materiality" through an understanding of agential intra-actions "makes it possible to take the empirical world seriously again, but this time with the understanding that the objective referent is phenomena, not the seeming 'immediately givenness' of the world" (823). As applied to hunting, Barad's view of materiality might ask modern trophy hunters to think like subsistence hunters who value all of the parts of the hunted animal. Within a modern context and from her newcomer perspective, McCaulou attempts to approximate this vision. She writes about how hunting adds a more complex layer of meaning to her consumption of meat: "One of the thing I appreciate most about hunting is that it highlights the uniqueness of each animal, each meat, each meal. Instead of 'thighs' or 'breasts,' a meal is composed of something specific, such as 'the American widgeon from that slough in Montana on a cold, cloudy day last fall'" (129). In contrast to identifying one animal part for consumption, this perspective emphasizes multiple materialities - a specific bird, a particular landscape feature, the geographic location, and the season - that may influence one human meal. Later, she writes, "That fatal shot created between us a bond that will last longer than an animal's earthly life. Its flesh nourishes me, and the new life growing inside me. In return, I bear a responsibility to the species this meat belonged to, and to that land that nurtured it" (298-99). By emphasizing a convergence of factors that enables success for herself as a hunter and eater of animals, McCaulou calls attention to a variety of pre- and post-hunt elements that play a part in the entirety of an experience, or as Barad would articulate it, the phenomena of a hunting performance. 
In prizing the breadth of the experience rather than one item, McCaulou also considers actions that preserve hunting traditions and offer new ones in a changing America. "At its best," McCaulou writes, "hunting balances short-term use with long-term preservation" and along with fishing, it "teach[es] us to understand the earth in way that more passive activities such as hiking and nature-watching do not” (296). To ensure its continuation, she suggests making careful environmental conservation measures the pinnacle goal for hunting rather than the trophy. Enabling hunting opportunities for those who want to learn to how to hunt means rethinking land use and development. In the western states, much of the impetus rests with the United States Government, which owns huge parcels of land; in the eastern part of the country, state governments and individual landowners bear more responsibility. Of landowning hunters, McCaulou writes, “A family’s favorite hunting spot, year after year, should become an irreplaceable heirloom that they fight to protect" (297). Conserving landscapes and increasing opportunities for newcomers also remains important in order for the sport to thrive. Without action from governments and individuals, hunting in America is at risk of becoming a "pastime of only the very rich," or a relic of bygone American culture (295). Altogether, McCaulou conveys that each of these experiential aspects of hunting - an increase in opportunities, whether real or imagined, for all Americans and the conservation of hunting spaces and game populations — should be more central to hunters' goals of preserving the recreational sport for future generations. Instead of focusing on relentless pursuits of larger game and more impressive trophies, increasing possibilities for hunters and creating and monitoring hunting spaces present opportunities for complex intra-actions with nonhuman life for a larger number of Americans.

\section{Travellers: Courtney Borden and Georgia Pellegrini}


Courtney Louise (Letts) Borden's (1899-1995) Adventures in a Man's World (1933) and Georgia Pellegrini's (1981-) Girl Hunter (2011) are travel memoirs about each woman’s experiences as hunters in the twentieth and twenty-first centuries. Far more than either Brandreth or McCaulou, both of whom look outward in placing a greater emphasis on hunting in one place, Borden and Pellegrini reflect on the internal intricacies of hunting as travellers in search of meaning and often in the company of men. Each of their works offers advice for women who either hunt with others or hunt alone while far from the familiarity of home. They present examples of a hunting tourism-oriented sub-genre known for "point[ing] to the complex cultural codes at play on the game trail" in regards to gender dynamics (Jones 152). Both authors initially approach hunting as outsiders, and they explore human-animal relationships within an inseparable context of gender that impacts their unique perspectives. Borden structures her book seasonally to account for different types of hunts. Pellegrini, on the other hand, travels alone and hunts with friends, acquaintances, and people she meets. She organizes Girl Hunter based a variety of hunts throughout the United States and England and concludes each chapter with recipes for each of the animals she pursues.

Borden and Pellegrini also focus on the potential impact of hunting on shaping the human body. A well-known urban socialite before she began hunting, Borden reveals how hunting may require strenuous activity that pushes the human body in ways that a comfortable urban life does not. Pellegrini, on the other hand, emphasizes what transpires after the hunt and argues that hunting one's own food fosters a greater appreciation of the environment that enabled the production of the culinary delight. By stressing that what we eat comes from places that we directly or indirectly influence, she suggests that to hunt is to become better aware of what comprises food and of humanity's ties to the land and nonhuman animals. 
As a member of a wealthy Chicago family, Courtney Borden appeared throughout the local media from an early age after becoming a teenage celebrity in 1914, when she and three of her friends declared themselves "The Big Four," or the most beautiful debutantes in Chicago (West 8). While two of the four (Genevra King and Edith Cummings) would later ascend to literary fame as the inspirations for Daisy Buchanan and Jordan Baker in F. Scott Fitzgerald's The Great Gatsby (1925), Borden would compose two travel autobiographies about hunting alongside her second husband, Borden Dairy heir and amateur naturalist John Borden, after the pair married in 1924. In the first book, The Cruise of the Northern Light (1928), she writes about an adventuring and hunting trip to Alaska as Mrs. John Borden to attain walrus and polar bear specimens for Chicago's Field Museum (Stange, Heart Shots 369). In Adventures in a Man's World, she more confidently asserts herself as a hunter separate from her husband. Borden published the account in February 1933, a little less than five months before she and Borden divorced. Within three weeks of their separation, both of them remarried - she with Argentine ambassador Felipe de Espil — and she spent much of the rest of her life travelling to and from South America, which also inspired an additional travel account (“Mrs. Borden,” 17).

At the beginning of Adventures in a Man's World, Borden writes about the changing relationship of Americans to hunting by the early 1930s as she announces her main purpose for her account. When her husband asks if she would like to go on an extended hunting trip, Borden agrees because in joining him, she would be able to provide “insight into a man's world and why many husbands spend autumn week-ends away from home" (3). Indeed, Borden sought to capture a common experience for wives of hunters who lived in urban America. As cities flourished, hunters began living closer to their urban workspaces, and they had to travel farther distances from home to hunt. With more forms of entertainment and civic responsibilities in the 
city, many hunters also began to hunt less frequently, opting to go during vacations or long weekends. They often left women and children behind with the hope of returning reinvigorated after hunting. In positioning herself as making a similar journey, she frames the adventure as a means to both test her endurance away from nearby conveniences and understand the mindset of a generation of men like her husband.

What emerges is a meditation about how the absence of urban materiality forces humans to reexamine their relationship to the natural world while hunting as they are forced into more immediate contact with spaces cluttered with living, evolving flora and fauna rather than inert devices or settings that facilitate human comfort and consumption. Mary Zeiss Stange notes that as humans transitioned away from hunter-gatherer lifestyles, they accumulated property and possessions that refashioned the rhythms of their lives (Woman 47). Borden makes plain the physical struggles of hunting and the ways that it provides both anguish and a sense of relief from the comforts of the city. This theme begins in her prior book The Cruise of the Northern Light, when she describes the lifestyle of an Alaskan hunting guide as he leads their hunting party during a bear hunt. In contrast to the way she comprehends wealth, Borden writes about their guide Olson's belief that, "a man's strength and endurance is [sic] his fortune" (54). In Adventures, she describes exhausting partridge and rabbit hunts where her hunting party spends the greater part of two afternoons moving in strenuous pursuit with limited success. During the second afternoon, she notes, “...I'm usually much too tired to hurry, as well as breathless ... My legs won't propel me one step farther and my feet weigh a ton" (61). Having spent much of her life in a location where food is plentiful and requires minimal effort to obtain, the physical exertion of hunting is immensely challenging. 
To this extent, Borden seeks to lessen the distance between her highly organized home society that requires scant physical exertion and her more primitive experiences with the hunting party that demand so much effort; in doing so, she seeks to detail the potential for nonhuman worlds to reshape the self. Matthew Taylor, while writing of a major shared aim between counter-Enlightenment and posthumanist thought, notes that "the effort to exceed the human self's limitations eventuates not in the self's abandonment but in its self-gratifying transformation; in both, we not only survive our integration into the larger world, we are, at last, realized by it" (10). While her husband and fellow hunting companions move forward as part of the hunts, Borden often slows down and periodically records her reflections, documenting thoughts that reveal her transformations. She examines the way hunting changes her perceptions when, for example, she unexpectedly falls in the mud, or when the elusive nature of some game animals initiates deep feelings of frustration followed by improved patience. She unravels herself from bodily comforts she has taken for granted in order to show how difficult hunts with obstacles such as unpredictable weather and rough terrain strip away the romanticism of the outdoors. Well aware of her privileged social position in Chicago, Borden shows how its trappings shield and sterilize women from coming into contact with the elements of the natural world. A Chicago Tribune article concerning Borden shows the social and cultural gap between how the city viewed Borden's adventures and what she aimed to accomplish. Offhandedly and amusedly, an unnamed writer reports that Borden hunted many times with her former husband, and that they "went far into untrodden paths, as far as their yacht would take them, and then found other transportation ("Mrs. Borden"). That form of transportation, as Adventures but not the article reveals, often consisted of simply their feet and a sense of persistence to enduring the outdoor challenge. In Borden's vision of hunting, exertion not only characterizes the hunt itself, 
but satisfies a human urge to extend one's physical capabilities in a way that does not necessarily involve imagining ownership or dominion over one's world. Put another way, the self becomes a part of that world only through physical engagement with it. Borden speculates that the exercise involved in some forms of hunting enables humans to improve their long-term physical health, to sharpen their senses, and to enrich their imaginations at the cost of temporary discomfort.

Ironically, too, Borden came to view the arduous journeying and unfamiliarity of sustained, day-after-day engagement in the fields, woods, and streams as a means to soothe the excesses of the familiar patterns of work life in the city, as well as to better understand people she would not normally encounter. She writes, "The more tired we were, or worried, and when things seemed piled too high, we sneaked off to the sanctuary of the woods for a week-end that we knew, no matter how brief, would send us back to the battlefield invigorated in body, and our thoughts in order" (187). Although she frames the beginning of her memoir as an investigation into why men like her husband long for hunting or fishing trips as their primary means of leisure, Borden comes to the conclusion that she, too, finds meaning in the wilderness and that the experience entails comprehending one's place in the natural world; it was more than a mere form of societal escape. She comes to think that the "greatest luxuries" are the "refreshing peace of the woods and the waters," she recognizes that hunting and fishing had "become a recognized part of my own life" $(186 ; 205)$. She finds, too, that the expeditions put her and her husband in contact with others outside of their social class, including hunting guides and families who are out of work and living partial subsistence lifestyles from fields and streams. These realizations reaffirm the necessity of conservation and ensuring hunting and fishing access for future generations. To conclude the book, Borden writes, "Rich man, poor man, begger [sic] man, thief, what different in the trout stream or shooting field? None. Only the comparison in 
technique and fair play ... with fish in our streams and birds in our fields - yes - civilization must be safe" (240). In distancing herself from the artifice of the city and placing herself amidst foreign, outdoor elements, Borden makes the case that hunting and fishing helps men and women come to know how physical and mental nourishment.

If Courtney Borden stresses how hunting shapes the mind through required persistence and the body through movement, her successor Georgia Pellegrini focuses on how hunting can revise one's understanding of the human palate. To some extent, Pellegrini's social milieu mirrors Borden's although eighty years separate them. Educated in prep schools and private colleges, she later became an investment banker for Lehman Brothers before realizing that she found her job unfulfilling. She writes, “The seams of my home life began to unravel as I got older. I moved farther and farther away from manure and raspberry jam on the quest for prestigious degrees and prestigious jobs. ... They took over ... and I took the path of least resistance into corporate life. It was a life that nourished my bank account but never my soul" (8). Similarly to Lily Raff McCaulou, Pellegrini cultivates a passion for hunting during a career change, after she decides to pursue a dream of working as a professional chef. In the transition, she becomes interested in hunting because of the appeal of preparing local and wild foods. During the course of four years, Pellegrini participates in a variety of hunts to learn about what hunting means to people living in different areas of the United States and, in one instance, England. Since her point of reference from before she began hunting is cuisine, Girl Hunter differs from many travelling hunter memoirs that focus on trophy hunting by prizing culinary art as the pinnacle goal of hunting.

Pellegrini relies on food as a means to entice people toward hunting or at least to consider hunting as a more legitimate recreational activity. This is a novel addition to hunting literature, 
which often stresses technique, storytelling, or the social aspects of hunting. Though prior hunting accounts and stories often feature references to meals following or in between hunts, these instances typically occur either as interludes or during moments of respite. Consequently, the process of rendering animal bodies into meals remains vastly undervalued and underemphasized within the context of the genre, as hunting stories and game recipe books traditionally appear in separate publications. This division is a pivotal example of why gender matters in the context of hunting. For multiple generations, much hunting literature has separated hunting from one of its more appealing aspects: eating. The stereotypical parceling of labor, man as hunter and woman as cook, is part of what Pellegrini seeks to challenge by concluding each of her hunts with recipes. The recipes do not comprise the bulk of each chapter, but they serve as multi-page conclusions that reaffirm each hunt as a quest for food and that educate hunters about ways to prepare game.

Pellegrini's memoir structure also benefits from an audience more attuned to food since the advent of foodie culture. The twenty-first century "Foodie Revolution," which has sparked public interest in the art of cuisine, places greater value on the origins and handling of food ingredients. Primarily rooted in urban culture, the movement demands more transparency in regards to food creation as well as the production of raw ingredients, and it aims to create more transparent links between chefs, farmers, and consumers. A renewed cultural interest in food enables Pellegrini to reflect on the modern trans-corporeal relationships within the context of hunting. Explaining trans-corporeality, Stacy Alaimo describes food as the "most palpable example" because humans must eat to survive; she explains that while eating for the majority of people living in first world cultures appears as simple as a quick trip to a grocery store, posthumanist materialist research helps consumers consider the "agencies [that] reveal 
themselves during the route from dirt to mouth" ("Trans-Corporeal," 253). In engaging with the idea of trans-corporeality, Pellegrini also reaches out toward people who choose not to hunt or to eat meat, in part to show that all humans share a link with the food system. In a conversation with a hunter, for example, she reveals that her father is vegan (33). However, she challenges omnivores not only to consider where their food comes from, but also to consider taking action to become a part of its production:

We were meant to participate in nature rather than keep it at arm's length. I see evidence everywhere that we have become so self-conscious in nature that we now designate areas where those 'wild' traits are allowed to be expressed, to the point that wilderness has become the last great zoo. And it turns our natural human instincts into an abstract condition, rather than a natural human state. (11).

The devaluing or deskilling of activities associated with the outdoors, whether that be hunting or backyard gardening, creates mindsets that Pellegrini theorizes as so distant from natural processes of food production to the point to where many Americans blindly consume food products whose origins and required labor they cannot imagine. It is this disconnect between body and earth that both Pellegrini and Alaimo seek to disrupt.

If Alaimo calls attention to particular agencies within nonhuman lives that pass into and influence the growth and nourishment of the body, as well as the human-created chemicals or toxins that facilitate the growth and consumption of those living things, Pellegrini claims that actions such as hunting and preparing one's food can be a first step toward knowing what we eat, and how we physically become what we become. Asserting the necessity of considering the agencies of the various layers of the material world that envelop humans, Alaimo argues that "trans-corporeality denies the human subject the sovereign, central position. Instead, ethical 
considerations and practices must emerge from a more uncomfortable and perplexing place where the 'human' is already part of an active, often unpredictable, material world" (Bodily, 1617). Here, Alaimo asserts that the human is no longer the predominant earthly figure that can exert any form of imagined complete control. Instead, she concedes that miniscule or unseen, wild, and non-wild materials expend forces or influences that shape our beings. Accepting the inevitability of being shaped beyond our control enables productive possibilities of examining and seeking to understand the ways these forces shape human lives. In a post-industrial world, this admittedly cannot account for toxins that humans cannot see, but it does place us in positions that encourage more active interactions with the natural world, that potentially improve general knowledge about food origins, and that generate interest in addressing the toxins that threaten our food supply and our lives. A trans-corporeal perspective revises prior, taken-for-granted assumptions and encourages readers to look more closely at what they consume and where it comes from before it becomes a part of them.

In writing a woman's story about learning to see plant and animal life from a hunter's perspective, Pellegrini uses humor and unexpected ironies to reimagine a world routinely stereotyped and to promote new ways of understanding hunting. During the morning of her first turkey hunt, she sees a few wild hogs cross a road and thinks, "those small hogs didn't look like hairy four-legged creatures to me; rather, like running sausages" (123). On the one hand, this may sound reductive, as Pellegrini positions the wild hogs as little more than food on the run, but read another way, the image of food on the run coarsely conveys the idea that what all readers eat has roots in outdoor spaces, and it allows the possibility for people to consider how our actions affect the environments that sustain the food that ultimately nourishes us. For humans to thrive, formerly wild fields or woodlands must be plowed and planted to alleviate hunger and 
foster growth. As Mary Zeiss Stange notes, life, death, and regeneration occur during each planting and harvest. Zeiss writes, "Discomfiting as it may be to contemplate, we-as individuals and as a species-live because others die.... One ... may abhor meat-eating on the grounds of cruelty. But in a single, sunny afternoon, a farmer plowing a field wreaks more carnage, in the form of outright killing and the destruction of nests and mating areas ... than the average hunter does in a lifetime" (Woman 119-120). In documenting her hunting experiences, Pellegrini calls attention to the way modern American society separates from and evades issues such as killing in hunting and agriculture. If the cultural tendency to conceal, or at the very least look way from, the means of food production as an ugly affair, it is also one that denies many people the possibility of knowing what it means to be a living, killing, and consuming human, and one upheld by ironies and corporate abuses that result from too many people averting their eyes. Coming to understand the cultural and geographical realities of where much food comes from, she writes, "The remote places that have fewer food choices tend to be the same places that create choice for the rest of the country" (39). In short, the rural hells that many metropolitans deride impact the body via food production. Until recently, the distance from where the majority of our food originates and the elaborate cuisine that the foodie movement celebrates has never been greater, Pellegrini suggests, because our eyes have been focused elsewhere to the detriment of our health. Hunters overly focused on trophy hunting, too, are not immune; and Pellegrini seeks to alter their viewpoints by suggesting that various recipes, food preparation, consumption offer as much of an adventure as the hunts. She asserts that when the hunt ends, more work awaits. Unlike trophy hunting, where there is one principal focus that privileges large game animals, food preparation appeals to a wider swath of people, all of whom eat and many of whom prefer different types of food. Using herself as an example, Pellegrini notes that despite 
all of her various travels and hunts for varieties of different game animals, nothing tastes better than squirrel, or what many big game hunters consider as "tree rat" (192). Although food cultivation and visiting local farmer's markets remain more popular options overall, Pellegrini suggests that hunting, too, is part of a greater process of becoming more engaged with food origins and preparation.

Posthumanist readings of Brandreth, McCaulou, Borden, and Pellegrini reveal that much more happens during the hunting process than what was previously deemed the destructive masculine tendency to simply shoot, kill, and dominate. By interrogating the function of hunters' most prized emblems and stressing the impact of hunting on the improvement of the human body and sharpening of the human mind, these women authors adhere to the ecofeminist plight of calling attention to destructive practices that damage the natural world and put both animal populations and hunters' reputations among the broader non-hunting public at risk. Put another way, by focusing on the evolution of the entangled human, they seek to improve both the art of hunting and conservation measures that enable it to continue. They also implore hunters to know that what they hunt and eat is tied deeply and inseparably to the land, and they thereby imply the need for greater environmental measures and awareness that extends beyond gender toward conserving the natural world. 


\section{Conclusion:}

\section{Hunting's Futures}

Cultural debates continue as people grapple with issues that appear throughout the history of American hunting stories. As the breadth of Washington Irving's writings foreshadow, some conflicts stem from representations of what it means to be a hunter within a rapidly developing country. Overall, there are greater numbers of hunters who live and work in metropolitan areas than ever before, who shop at box stores such as Cabela's and Bass Pro Shops, and who hunt recreationally during their time off. Yet, if they comprise a more visible class of hunters, there are also adherents of more minor forms of hunting that attract controversy or little fanfare. For example, although it is still practiced throughout the United States, hunting with traps has been continually under fire, as industrialization has rendered it mostly obsolete for the Americans not living subsistence lifestyles and as many people view it as inhumane. Yet, on the other end of the spectrum, people who live in Oklahoma may join the Oklahoma Falconry Association, which teaches hunters how to become hawkers, or people who hunt with hawks, as part of a form of hunting which garners less attention. The vast spaces and lifestyle differences throughout the United States sometimes collapse online, leading to healthy debates or discussions, as well as misinterpretation, incorrect assumptions, and cultural clashes. By the time Washington Irving had stopped writing about hunting, he had experienced its evolution from what comprised his local, boyhood hunting adventures in New York to the rise of extractive hunting in the west. Today, in a much more settled country with greater concentrations of people in certain areas, great variations of hunters still exist, although unlike during Irving's time, hunters carry greater 
responsibility in accounting for what they do and why they hunt to a larger public more distanced from the recreational sport than during prior centuries.

As James Fenimore Cooper's The Leather-stocking Series reveals, hunters have been close to both companion and prey animals throughout the history of hunting, an idea that recently has become more relevant. With the decline of hunters and increase in wildlife in some suburban areas, some people in twenty-first century America may be closer to wild animals than they imagine as certain species appear in their yards, gardens, and or just outside their windows consuming vegetation or food meant for outdoor companion animals. In some suburban pockets throughout the country, deer have become so numerous and, from gardeners' and small-scale farmers' perspectives, so destructive that cities and towns have initiated urban deer hunts. On the one hand, these hunts generate more interest in archery, ostensibly a safer method of hunting amidst high human population densities, but they also prompt others to posit ways to manage urban wild animal populations without resorting to hunting. In writing about Natty Bumppo's relationship with his canines, Cooper describes how hunting experiences with companion and prey animals become part of what defines a human life. Instead of having to traverse farther to the west to hunt, as Cooper and a host of his literary successors suggested until the closing of the frontier, some hunters can now hunt in their local neighborhoods. Consequently, for some communities, urban hunting appears at the forefront of civic discussions each fall and rekindles debates among preservationists and conservationists about the role of hunting in shaping the landscapes and wild animal populations in urban communities.

Newer hunting technologies and changing traditions contribute to the evolution of hunting as hunters continue to grapple with the idea of fair chase, which has roots in the devastation of animal populations during the market hunting era in the nineteenth century, as 
well as maintaining subsistence hunting rights for a minority of the country's population. The devastation detailed in accounts by Francis Parkman, as well as the great lengths that the whaling enterprise demanded of Americans, shows that many species can easily become endangered or potentially extinct, as in the case of the passenger pigeon, due to overhunting. Proactive efforts that began expanding at the turn of the twentieth century by naturalists, conservationists, wildlife biologists, regulatory agencies and the Federal Government now help to monitor hunters through the establishment of formal hunting seasons, the numbers of animals allowed to be killed, and lottery systems that limit participation. Although these efforts remain far from perfect, as in the case of occasional clashes between federal or local agencies and indigenous people's hunting rights, they seek to allow hunting traditions to continue and evolve. And while for the majority of the Americans grocery stores eliminate the need to hunt for food, subsistence hunting in the vein of Meshach Browning and Philip Tome still occurs sparsely in the most isolated parts of the country and throughout rural Alaska. Newer tracking technologies and game cameras allow Americans to better monitor wildlife populations, but for some they also make hunting seem too efficient and weaken the idea of fair chase. Regarding the development of all technologies, both past and present, hunters continue to debate the impact of their hunting experiences. Some experienced hunters, to offer an example, elect to use primitive weapons such as bows and arrows or muzzleloaders, while others opt for high-powered rifles or shotguns with scopes.

Technological developments, in addition to modern lifestyle changes, also influence the ways that parents now rear their children, which impacts perceptions about hunting as a part of childhood. Whereas hunting was more common for children and particularly boys during the first few decades of the twentieth century, it is less popular now, and shooting more often occurs on video game screens than in real life. If certain urban or suburban parts of the country exist 
outside of these trends by supporting shooting as a high school sport, they are among a small minority. Too, the increased reach of televised media, the expansion of twenty-four hour news, and the heightened value of living online and in the moment has also impacted public perceptions about weapons and gun culture in relation to children. In the twenty-first century, no longer is carrying a pocketknife a rite of passage for many boys, and amplified fears of gun violence from a seemingly nonstop stream of school and public shootings promise to redefine the relationship among a sizable majority of American children and real guns. If online environments occupy more of children's time than the outdoors, children still benefit from relationshi ps with companion animals such as dogs and cats. These relationships are far closer in spirit to what Fred Gipson and Wilson Rawls reveal in Old Yeller and Where the Red Fern Grows than what William Faulkner portrays in The Bear, and so companion animals continue to nurture and support children's lives within the home, if not as much while hunting in the fields or woods.

Perhaps the most sensational stories involving children as hunters point to one of the hunting's more problematic conundrums now: how to make the recreational activity fully intelligible to audiences with short attention spans. In an era of live streaming, Tweeting, and click bait, where online commerce and popularity is measured and driven by what quickly catches and retains the gaze of the human eye, hunting struggles. For many people who do not hunt or have never attempted to hunt, the foreign appears compressed into nibble-sized clips often cloaked in sensationalism not unlike the penny dreadfuls of Victorian Era in England. Among the more shocking and eye-catching, and for many repulsive, tropes that currently represent hunting online are stories that feature photographs and accounts of pre-adolescents hunched next to large game animals, typically in Africa. The underlying motives of these clips 
often seem to be monstrous parenting - primarily for the environmental injustice and wantonness of killing large animals in foreign countries, but also for the aberrant idea of allowing and celebrating young children trophy hunting. These stories and images may show the limitations of a continued emphasis on trophies among hunters. Lily Raff McCaulou and Georgia Pellegrini offer new takes on hunting by suggesting that it become more inclusive of others and by asserting greater emphases on the process, time commitments, and sacrifices one must make in an effort to improve at hunting, by proclaiming that a renewed emphasis on the culinary arts that hunting enables in an era of industrialized food production may be a better means to communicate the benefits of hunting to a wider audience.

Each of these present day concerns recalls the notion that with the exceptions of extractive and subsistence hunting, hunting has long been considered an escape away from the realities of an everyday and increasingly modernizing life in America. From Rip Van Winkle ignoring the agricultural mores of his community and continually absconding from his chores to Natty Bumppo and his dogs finding personal solace and freedom through hunting to Courtney Borden escaping high society to test her physical strength and resolve to Ike McCaslin avoiding school during two-week hunting camps during the fall, hunting has remained interwoven within the greater atmosphere of American culture and environment even as sometimes wellintentioned, progressive societal mores, visual representations, and changing lifestyles have threatened and lessened its popularity. For many, twenty-first century hunting may consist of virtual reality or online play, and for others it may mean a reduced emphasis on killing with a greater goal of wildlife photography, and still others, to supplement their diets or continue family traditions. In the face of new encounters with evolving landscapes in both real and virtual 
environments, hunting stories and writings continue to help Americans comes to terms with what hunting means in the twenty-first century. 
Works Cited

Adams, Carol. "What Came Before The Sexual Politics of Meat: The Activist Roots of a Critical Theory." Species Matters: Humane Advocacy and Cultural Theory. ed. Marianne DeKoven and Michael Lunsbad. New York: Columbia U P, 2012: 103-138.

Alaimo, Stacy. Bodily Natures: Science, the Environment, and the Material Self. Bloomington, IN: Indiana U P, 2010.

. "Trans-Corporeal Feminisms and the Ethical Space of Nature.” Material Feminisms. ed. Stacy Alaimo. Bloomington, IN: Indiana University P, 2008: 237-264.

Andrews, William L. "Introduction.” The Life of John Thompson, a Fugitive Slave. ed. William L. Andrews: New York: Penguin, 2011: xvii-xxx.

Anthony, David. “ 'Gone Distracted': 'Sleepy Hollow,' Gothic Masculinity, and the Panic of 1819." Early American Literature 40.1 (November 2005): 111-144.

Barad, Karen. "Posthumanist Performativity: Toward an Understanding of How Matter Comes to Matter.” Signs: Journal of Women and Culture in Society. 28.3 (2003): 801-831. Print.

Barker, Martin and Roger Saban. The Lasting of the Mohicans: History of an American Myth. Oxford: U of Mississippi P, 1996.

Bergman, Charles. Orion's Legacy: A Cultural History of Man as a Hunter. New York: Plume, 1997.

Berger, Jason. Antebellum at Sea: Maritime Fantasies in Nineteenth-Century America. Minneapolis: U of Minnesota P, 2012.

Borden, Courtney. Adventures in a Man's World. Mechanicsburg, PA: Stackpole, 2005. Borden, Mrs. John. The Cruise of the Northern Light. Mechanicsburg, PA: Stackpole, 2004. Browning, Meshach. Forty-Four Years of the Life of a Hunter. Mechanicsburg, PA: Stackpole, 
2005.

Brandt, Anthony. "Introduction." The Adventures of Captain Bonneville. Washington, D.C.: National Geographic Press, 2003: ii-xviii.

Burnstein, Andrew. The Original Knickerbocker: The Life of Washington Irving. New York: Perseus, 2007.

Brandreth, Pauline. Trails of Enchantment. Mechanicsburg, PA: Stackpole, 2003.

Bronner, Simon J. Hunting Tradition: Inside Hunting and Animal Rights Controversies. Lexington: U P of Kentucky, 2008.

Buell, Lawrence. The Future of Environmental Criticism: Environmental Crisis and Literary Imagination. Malden, MA: Blackwell P, 2005.

Carmine, James. "Off the Grid: Rights, Religion, and the Rise of the Eco-Gentry." Hunting: In Search of the Wild Life." ed. Nathan Kowalsky. Malden, MA: Wiley-Blackwell, 2010: 239-251.

Catalano, Susan. "Henpecked to Heroism: Placing Rip Van Winkle and Francis Macomber in the American Renegade Tradition.” The Hemingway Review 17.2 (spring 1998): 111-117.

Chase, Owen. The Loss of the Ship Essex, Sunk by a Whale. ed. Thomas and Nathaniel Philbrick. New York: Penguin, 2000: 13-74.

Coetzee, J.M. The Lives of Animals. Princeton, N.J.: Princeton U P, 1999.

Cooper, James Fenimore. Chronicles of Cooperstown. Cooperstown, NY: H \& E. Phinney, 1838. . The Deerslayer. New York: Library of America, 1985.

. The Last of the Mohicans. New York: Library of America, 1985.

. The Pathfinder. New York: Library of America, 1985.

. The Pioneers. New York: Library of America, 1985. 
. The Prairie. New York: Library of America, 1985.

Cracroft, Richard A. Washington Irving: The Western Works. Boise, ID: Boise S U P, 1974.

Cronon, William. "The Trouble with Wilderness; or, Getting Back to the Wrong Nature." Uncommon Ground: Rethinking the Human Place in Nature. New York: W.W. Norton \& Co., 1995: 69-90.

De Tocqueville, Alexis. Democracy in America. New York: Penguin, 2003.

Daly, Mary Gyn/Ecology. Toronto, ON: The Women's Press. 1979.

Derr, Mark. A Dog's History of America: How Our Best Friend Explored, Conquered, and Settled a Continent. New York: North Point Press, 2004.

Derrida, Jacques. "The Animal That Therefore I Am (More to Follow).” Critical Inquiry 28.2 (2002): 369-418.

. The Beast and the Sovereign. vol. 1. ed. Michel Lisse, Marie-Louise Mallet, and Ginette Michaud. trans. Geoffrey Bennington. Chicago: U of Chicago P, 2009.

Dekker, George. The American Historical Romance. New York: Cambridge U P, 1987.

Dizard, Jan E. Mortal Stakes: Hunters and Hunting in Contemporary America. Amherst, MA: U of Mass P, 2003.

Dolin, Eric Jay. Fur, Fortune, and Empire: The Epic History of the Fur Trade in America. New York: W. W. Norton \& Co., 2010.

Dolin, Eric Jay. Leviathan: The History of Whaling in America. New York: Norton, 2007.

Dorsky-Rubin, Jeffrey. Adrift in the Old World: The Psychological Pilgrimage of Washington Irving. Chicago: U of Chicago P, 1988.

Douglass, Frederick. My Bondage and My Freedom. New York: Penguin, 2003.

Evans, J. Claude. With Respect for Nature: Living as Part of the Natural World. Albany, New 
York: State of N.Y. Press, 2005.

Faulkner, William. Go Down, Moses. New York: Penguin, 1960.

. The Reivers. New York: Library of America, 1999.

Ferguson, Robert A. "Rip Van Winkle and the Generational Divide in American Culture. Early American Literature 40.3 (November 2005): 529-544.

Fiedler, Leslie. Love and Death in the American Novel. New York: Criterion, 1960.

Flores, Dan. "Bison Ecology and Bison Diplomacy: The Southern Plains from 1800 to 1850." Journal of America History 78.2 (September 1991): 465-485.

Franklin, Wayne. James Fenimore Cooper: The Early Years. New Haven: Yale U P, 2007. . The New World of James Fenimore Cooper. Chicago: U of Chicago P, 1982.

Gaard, Greta. “ Living Interconnections with Animals and Nature.” Ecofeminism: Women, Animals, and Nature. ed. Greta Gaard. Philadelphia, PA: Temple U P, 1993: 1-12.

Gatta, John. Making Nature Sacred: Literature, Religion, and Environment in America from the Puritans to the Present. New York: Oxford U P, 2004.

Giltner, Scott. Hunting and Fishing in the New South: Black Labor and White Leisure after the Civil War. Baltimore: Johns Hopkins U P, 2008.

Gipson, Fred. Hound-Dog Man. New York: Harper \& Row, 1949. . Old Yeller. New York: Scholastic, 1995.

Glave, Dianne. Rooted in the Earth. Chicago: Lawrence Hill, 2010.

Glotfelty, Cheryll. "Introduction: Literary Studies in an Age of Environmental Crisis." The Ecocriticism Reader: Landmarks in Literary Ecology. Athens, GA: U of Georgia P, 1996: XV-Xxxvii.

Grandin, Temple. Animals in Translation: Using the Mysteries of Autism to Decode Animal 
Behavior. New York: Scribner, 2005.

. Animals Make Us Human. New York: Mariner, 2009.

Gwynn, Frederick. Interview with William Faulkner. 15 February 1957. accessed 10 June 2016. < http://faulkner.lib.virginia.edu/display/wfaudio01_1\#wfaudio01_1.24 >

Hardy, Thomas. Far from the Madding Crowd. New York: Norton, 1986.

Haraway, Donna. The Companion Species Manifesto: Dogs, People, and Significant Otherness. Chicago: Prickly Paradigm Press, 2003.

. "A Cyborg Manifesto: Science, Technology, and Socialist-Feminism

In the Late Twentieth Century." Simians, Cyborgs and Women. New York: Routledge, 1991: 149-181.

. "Awash in Urine: DES and Premarin ${ }^{\circledR}$ in Multispecies Response-ability.” WSQ:

Women's Studies Quarterly. 40.1 (spring / summer 2012): 301-316.

. When Species Meet. Minneapolis: U of Minnesota P, 2008.

Herman, Daniel Justin. Hunting and the American Imagination. Washington: Smithsonian Press, 2001.

"History of the Records Program." The Boone and Crockett Club. 2014. accessed February 2, 2016. < http://www.boone-crockett.org/bgRecords/records history.asp?area=bgRecords $>$

Hobbs, Frank and Nicole Stoops. "Demographic Trends in the 20th Century." U.S. Census Bureau. November 2002. Accessed 29 October 2015. http://www.census.gov/prod/2002pubs/censr-4.pdf.

Hofstadter, Richard. “America as a Gun Culture.” American Heritage. 21.6 (1970). Accessed 10 November 2015. http://www.americanheritage.com/content/america-gun-culture Horowitz, Alexandra. Inside of a Dog: What Dogs See, Smell, and Know. New York: Scribner, 
2009.

Hubbard, Tasha. "Buffalo Genocide in Nineteenth-Century North America: Kill, Skin, and Sell." Durham: Duke U Press, 2014: 292-305.

Hyde, Anne F. Empires, Nations, and Families: A New History of the North American West, 1800-1860. New York: Ecco, 2012.

Irving, Washington. The Adventures of Captain Bonneville. New York: Library of America, 2004.

. Astoria. New York: Library of America, 2004.

."The Art of Book Making." The Sketchbook of Geoffrey Crayon, Gent. New York:

Library of America, 1983.

. Bracebridge Hall. New York: Library of America, 1991.

. Journals and Notebooks Volume 1: 1803-1806. Madison: U of Wisconsin P, 1969.

. "The Legend of Sleepy Hollow.” The Sketchbook of Geoffrey Crayon, Gent. New York:

Library of America, 1983.

. "Rip Van Winkle.” The Sketchbook of Geoffrey Crayon, Gent. New York: Library of America, 1983.

. A Tour on the Prairies. New York: Library of America, 2004.

Jones, Brian Jay. Washington Irving: An American Original. New York: Arcade, 2008.

Jones, Karen R. Epiphany in the West: Hunting, Nature, and Performance in the Nineteenth-

Century American West. Boulder, CO: University of Colorado P, 2015.

Kelly, Richard. "Introduction.” A Christmas Carol. ed. Richard Kelly. Peterborough, Ontario:

Broadview, 2003: 9-30.

Kelly, William. “Introduction.” Selected Writings of Washington Irving. ed. William Kelly. New 
York: Modern Library, 1982: i-xlv.

Kilcup, Karen. Fallen Forests: Emotion, Embodiment, and Ethic in American Women's Environmental Writing, 1781-1924. Athens: U of Georgia P, 2013.

Knight, Richard. "Leopold and the 'Still Unlovely Mind"”. The Essential Aldo Leopold: Quotations and Commentaries. ed. Curt Meine \& Richard L. Knight. Madison, WI: U of Wisconsin P, 1999: 32-44.

Kolodny, Annette. The Lay of the Land: Metaphor and Experience as History in American Life and Letters. Chapel Hill: U of North Carolina P, 1975.

Krech, Shepherd, III. The Ecological Indian. New York: Norton, 1999.

Kuzniar, Alice A. Melancholia's Dog: Reflection on Our Animal Kinship. Chicago: U of Chicago P, 2006.

Lawrence, D.H. Studies in Classic American Literature. New York: Viking, 1961.

Leopold, Aldo. Game Management. Madison, WI: University of Wisconsin P, 1986. . Round River: From the Journals of Aldo Leopold. New York: Oxford U P, 1993. . A Sand County Almanac. New York: Ballantine, 1970. . "Wildlife in American Culture." Journal of Wildlife Management 7.1 (January 1943): 16.

Long, Robert Emmet. James Fenimore Cooper. New York: Continuum, 1990.

Lorbiecki, Marybeth. Aldo Leopold: A Fierce Green Fire. New York: Oxford U P, 1996.

Maddox, Lucy. Removals: Nineteenth-Century American Literature and the Politics of Indian Affairs. New York: Oxford U P, 1991.

Madson, John. "Why Men Hunt.” A Hunter’s Heart: Honest Essays on Blood Sport. ed. David Petersen. New York: Henry Holt and Company, 1996: 130-35. 
Marks, Stuart A. Southern Hunting in Black and White: Nature, History, and Ritual Within a Carolina Community. Princeton U P, 1992.

Mason, Jennifer. Civilized Creatures: Urban Animals, Sentimental Culture, and American Literature, 1850-1900. Baltimore: Johns Hopkins P, 2005.

McCaulou, Lily Raff. Call of the Mild: Learning to Hunt My Own Dinner. New York: Grand Central Publishing, 2012.

McDermott, John Francis. "Introduction to A Tour on the Prairies." Washington Irving: The Critical Reaction. ed. James W. Tuttleton. New York: AMS Press, 1993: 164-174.

McHugh, Tom. The Time of the Buffalo. Lincoln, NE: U of Nebraska P, 1979.

McIntyre, Thomas. "What the Hunter Knows” A Hunter's Heart: Honest Essays on Blood Sport. ed. David Petersen. New York: Henry Holt and Company, 1996: 174-181.

McKibben, Bill. Interview by Rich Kelly. Library of America. Library of America April 2008. Web. 15 February 2013.

__. "Introduction." My First Summer in the Sierra. by John Muir. New York: Library of America, 2011: xi-xviii.

Mitchell, Domhnall Martin. "Introduction.” The Prairie. Cambridge: Harvard U P, 2014: ix-xix. “Mrs. Borden is Bride of Ambassador." Chicago Tribune. 28 July 1933:17. Print.

Muir, John. The Story of My Boyhood and Youth. New York: Library of America, 1997.

Nash, Roderick. Wilderness and the American Mind. $4^{\text {th }}$ ed. New Haven, CT: Yale U P, 2001.

Nelson, Richard K. “Introduction: Finding Common Ground.” A Hunter's Heart: Honest Essays on Blood Sport. ed. David Petersen. New York: Henry Holt, 1996: 1-10.

Nickerson, Thomas. “The Boy's Story.” The Loss of the Ship Essex, Sunk by a Whale. ed. Thomas and Nathaniel Philbrick. New York: Penguin, 2000: 81-184. 
Northup, Solomon. 12 Years a Slave. New York: Penguin, 2012.

Parkman, Francis. The Oregon Trail. New York: Penguin, 1988.

Peck, Daniel. A World by Itself: The Pastoral Moment in Cooper's Fiction. New Haven, CT: Yale U P, 1977.

Pellegrini, Georgia. Girl Hunter. Boston: Da Capo Press, 2011.

Person, Leland S. "The Historical Paradoxes of Manhood in Cooper's The Deerslayer. NOVEL 32.1 (Autumn 1998): 76-98.

Philbrick, Nathaniel. In the Heart of the Sea: The Tragedy of the Whaleship Essex. New York:

Pollan, Michael. The Omnivore’s Dilemma: A Natural History of Four Meals. Penguin: New York, 2006.

Powell, Christopher. "What Do Genocides Kill? A Relational Conception of Genocide.” Journal of Genocide Research. 9.4 (2007): 527-547.

Rawls, Wilson. “Interview” Idaho Falls Post Register. 17 March 1974. Accessed 22 October 2015. <http://www.ifpl.org/index.asp?p=rawls/life . Summer of the Monkeys. New York: Bantam, 1992. . Where the Red Fern Grows. New York: Bantam, 1989.

Reiger, John F. American Sportsmen and the Origin of Conservation. $2^{\text {nd }}$ ed. Norman, OK: University of Oklahoma P, 1986.

Ringe, Donald. James Fenimore Cooper. Boston: Twayne, 1988.

Ronda, James P. “Washington Irving’s West.” The Historian 66.3 (September 2004): 546-551.

Rust, Richard. "Irving Rediscovers the Frontier." Washington Irving: The Critical Reaction. ed. James W. Tuttleton. New York: AMS Press, 1993: 156-163.

Sachs, Aaron. Arcadian America: The Death and Life of an Environmental Tradition. New 
Haven, CT: Yale U P, 2013.

Schmitt, Kristen A. "More Women Give Hunting a Shot.” National Geographic Online. 4 November 2013. accessed 25 January 2016.

$<\quad$ http://news.nationalgeographic.com/news/2013/11/131103-women-hunters-local-meatfood-outdoor-sports/>.

Samuels, Shirley. "Generation through Violence: Cooper and the Making of Americans." New Essays on The Last of the Mohicans. ed. H. Daniel Peck. New York: Cambridge U P, 1992: 87-114.

Sandilands, Catalina. "Violent Affinities: Sex, Gender, and Species in Cereus Blooms at Night" The Cambridge Companion to Literature and the Environment. ed. Louise Westling. New York: Cambridge U P, 2014: 90-103.

Schell, Jennifer. "A Bold and Hardy Race of Men": The Lives and Literature of American Whalemen. Amherst: U of Massachusetts P, 2013.

Shipman, Pat. The Animal Connection. New York: W.W. Norton \& Company, 2011. . The Invaders: How Humans and their Dogs Drove Neanderthals to Extinction. Harvard U P: Cambridge, 2015.

Smith, Greg. "Supernatural Ambiguity and Possibility in Irving's 'The Legend of Sleepy Hollow."” The Midwest Quarterly 42.2 (Winter 2001): 174-182.

Smith, Herbert. "Introduction.” Bracebridge Hall. Boston: Twayne, 1977: xiii-xxxiii.

Stange, Mary Zeiss. Heart Shots: Women Write about Hunting. Mechanicsburg, PA: Stackpole, 2003. . Woman the Hunter. Boston, MA: Beacon, 1997.

Sterba, Jim. Nature Wars. New York: Crown, 2012. 
Taylor, Matthew. Universes Without Us: Postmodern Cosmologies in American Literature. Minneapolis: University of Minnesota P, 2013.

Terrell, John Upton. Furs by Astor. New York: Morrow, 1963.

Thoreau, Henry David. Walden. New York: Dover, 1995.

Tomc, Sandra. “ 'Clothes Among Sticks': James Fenimore Cooper and the Flat Frontier.” Texas Studies in Literature and Language. v. 51 n. 2 (summer 2009): 142-178.

Tome, Philip. Pioneer Life; or Thirty Years a Hunter. Mechanicsburg, PA: Stackpole, 2006.

Traister, Bryce. “The Wandering Bachelor: Irving, Masculinity, and Authorship.” American Literature 74.1 (March 2002): 111-137.'

Vallely, Anne. “Animal Matters: Human/Animal and the Contemporary West." Animals and the Human Imagination: A Companion to Animal Studies. ed. Aaron Gross and Anne Vallely. New York: Columbia U P, 2012: 113-120.

Van Doren, Mark. "Introduction.” The Oregon Trail. New York: Junior Literary Guild, 1931: ivii-xiii.

Waldau, Paul. Animal Studies. New York: Oxford U P, 2013.

Warren, Cat. What the Dogs Knows: The Science and Wonder of Working Dogs. New York: Simon \& Schuster, 2013.

Warner, Michael. “Irving's Posterity.” ELH 67.3 (fall 2000): 773-799.

Wegner, Robert. "Foreword." Forty-Four Years of the Life of a Hunter. by Meshach Browning. Mechanicsburg, PA: Stackpole P, 2006: v-xiv.

_ . "Foreword." Trails of Enchantment. by Paul Brandreth. Mechanicsburg, PA: Stackpole, 2003: v-Xvii. . Legendary Deerslayers. New York: Krause, 2004. 
Weil, Kari. Thinking Animals: Why Animal Studies Now? New York: Columbia University P, 2012.

West, James L. W., III. The Perfect Hour: The Romance of F. Scott Fitzgerald and Genevra King. New York: Random House, 2005.

White, Craig. Student Companion to James Fenimore Cooper. Santa Barbara, CA: Greenwood, P, 2006.

Williams, Jericho. “Trigger Warning: Thoreau, 'Chesuncook,' and the Complications of Hunting.” Thoreau Society Bulletin 286 (summer 2014): 1-2.

Williams, Raymond. The Country and the City. Oxford: Oxford U P, 1975.

Wolfe, Cary. Animal Rites: American Culture, the Discourse of Species, and Posthumanist Theory. Chicago: U of Chicago P, 2003. .'Speciesism, Identity Politics, and Ecocriticism: A Conversation with Humanists and Posthumanists." The Eighteenth Century 52.1 (2011): 87-106. . What is Posthumanism? Minneapolis, MN: U of Minnesota P, 2010.

“World Population History.” World Population History. June 2016. Accessed 15 June 2016. <http://worldpopulationhistory.org>

Wright, Nathalia. “General Introduction to Journals.” Journals and Notebooks Volume 1: 1803-1806. by Washington Irving. Madison: U of Wisconsin P, 1969: xv-xxvi.

Wyman, Sarah. “Washington Irving's Rip Van Winkle: A Dangerous Critique of a New Nation." ANQ 23.4: 216-222. 